\title{
A BOTTOM GRAVITY SURVEY OF THE CONTINENTAL SHELF BETWEEN POINT LOBOS AND POINT SUR, CALIFORNIA
}

Walter Browne Woodson 
Library

Naval Postgraduate Scnool

Monterey, California 93940 


\section{WNWA POSTGRADUATE SGHOOL Ronterey, California}

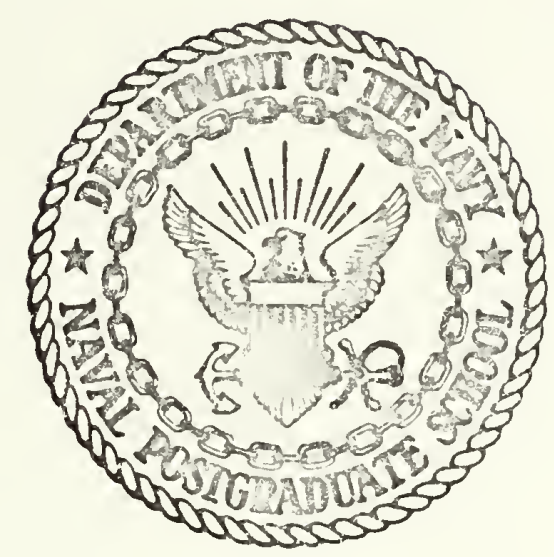

\section{THESIS}

A BOTTOM GRAVITY SURVEY OF THE CONTINENTAL SHELF BETWEEN POINT LOBOS AND POINT SUR, CALIFORNIA.

by

Walter Browne Woodson, III

R. S. Andrews

Thesis Advisor:

J. J. von Schwind

September 1973

Approved for public release; distribution unlimited. 

A Bottom Gravity Survey of the

Continental Shelf Between Point Lobos and Point Sur, California

by

Walter Browne Woodson, III

Lieutenant, United States Navy

B.A., University of Mississippi, 1966

Submitted in partial fulfillment of the requirements for the degree of

MASTER OF SCIENCE IN OCEANOGRAPHY

from the

NAVAL POSTGRADUATE SCHOOL

September 1973 



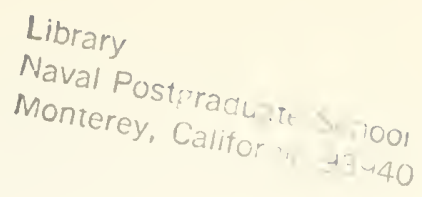

ABSTRACT

From an occupation of 68 ocean bottom and 38 land gravity stations between Pt. Lobos and Pt. Sur, California, a complete Bouguer anomaly map was produced and analyzed. The steps in data reduction leading to the complete Bouguer anomaly field is presented, unique features of which are associated with bottom gravimetry.

The geological interpretation of the gravity data shows excellent correlation with earlier seismic records of the proposed offshore extension of the Serra Hill fault, a structure long associated with the Sur-Nacimiento fault zone. Two dimensional models of gravity anomaly profiles were constructed across this fault and a nother fault located several kilometers to the northwest and extanding into the western tributary of the Carmel Canyon. The results indicate a minimum vertical displacement of the basement of approximately $2 \mathrm{~km}$ on the southwest sides. It was concluded that these two faults are one in the same. Evidence is presented which indicates that the Palo Colorado fault zone, located approximately $2 \mathrm{~km}$ to the east, parallels the Serra Hill fault and subsequently leads into the eastern tributary of the Carmel Canyon. 

I. INTRODUCTION $\ldots \ldots \ldots$

A. OBJECTIVES _............

B. LOCA TION AND TOPOGRAPHY .................. 10

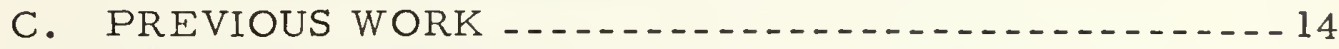

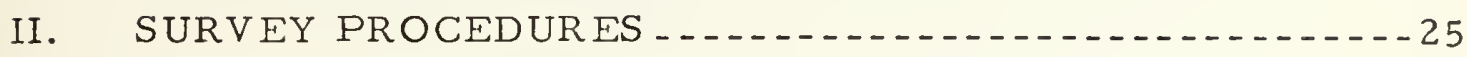

A. UNDERWA TER GRAVIMETRY _......................

1. Equipment $\ldots \ldots \ldots \ldots$

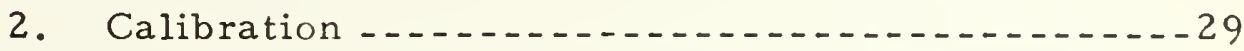

B. STATION SELECTION AND LOCATION _........... 33

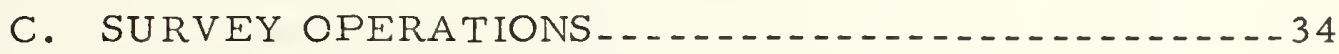

1. Measurement Procedures _.............. 34

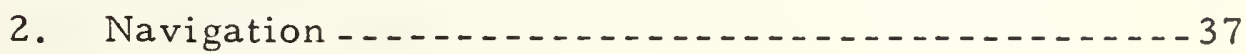

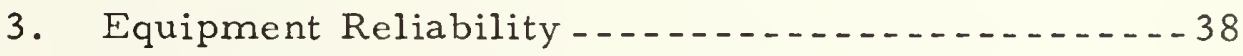

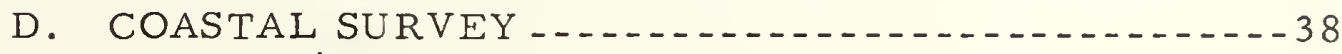

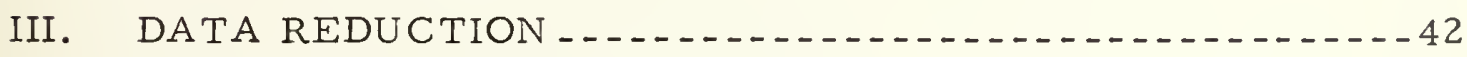

A. OBSERVED GRAVITY $\ldots \ldots \ldots \ldots \ldots \ldots$

1. Instrument Drift Correction ................ 44

2. Earth Tide Correction -.................. 45

3. Curvature Correction _................. 45

B. THEORETICAL GRAVITY ....................... 46 

C. TOTAL UNDERWA TER REDUCTION _............... 46

1. Corrections

a. Initial Bouguer Correction _...

b. Free-Air Correction -........ 48

c. Secondary Bouguer Correction ........... 49

d. Terrain Correction - .

2. Gravity Anomalies... 56

a. Free-Air Anomaly -

b. Simple Bouguer Anomaly .......... 57

c. Complete Bouguer Anomaly -............ 57

D. PARTIAL UNDERWATER REDUCTION TO COMPARE WITH SEA SURFACE GRAVIMETRY............. 58

1. Elevation Correction..................... 58

2. Mass Adjusted Free-Air Anomaly _.......... 59

E. LAND REDUCTION _......... 59

1. Corrections........... 59

a. Bouguer Correction -

b. Free-Air Correction -..... 60

c. Terrain Correction -....... 60

2. Gravity Anomalies ........... 62

IV. DATA PRESENTATION AND ANALYSIS .............. 63

A. GENERAL DISCUSSION ...

B. CBA ANALYSIS $\ldots \ldots \ldots 656$

C. TWO_DIMENSIONAL PROFILES _........... 71

D. CONCLUSIONS _... 

APPENDIX A: DATA REDUCTION CORRECTION VALUES FOR INDIVIDUAL STATIONS _............... 93

APPENDIX B: VARIOUS GRAVITY ANOMALIES AND LOCATIONS FOR INDIVIDUAL STATIONS _..... 98

APPENDIX C: COMPUTER PROGRAM..................... 103 REFERENCES CITED .................................. 106 INITIAL DISTRIBUTION LIST _... FORM DD $1473 \ldots \ldots \ldots \ldots p$ 



\section{LIST OF TABLES}

Table Page

I Explanation of Geologic Abbreviations 21

II Possible Errors in Complete Bouguer Anomaly Calculation (values in milligals) 



\section{LIST OF FIGURES}

Figure

1 Bathymetry of the Survey Area $1 . . . . . . . . .11$

2 Survey Area Limits and Location............... 13

3 Geological Boundaries of the Salinian Block

(after Greene et a1., 1973) _.................. 16

4 Regional Fault Map (after Greene et a1. , 1973)....... 19

5 Regional Geology and Fault Location

(after Dohrewend, 1971) (geologic abbreviations

listed in Table I)

6 Simplified Diagram of the LaCoste and Romberg

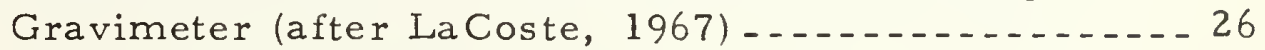

7 Model HG6 Gravimeter Ready for Us e _........... 27

8 Internal View of the Model HG6 Gravimeter

9 Schematic Diagram of the Auxiliary Equipment - . - . 30

10 Auxiliary Equipment Installed Aboard the

R/V ACANIA_.......................................... 31

11 Naval Postgraduate School's Oceanographic

Research Vessel R/V ACANIA _................ 32

12 Ocean Bottom and Land Station Density and

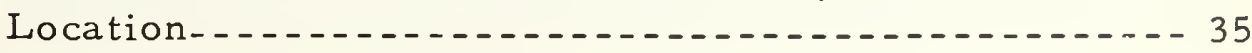

13 La Coste and Romberg Model G-08 Geodetic

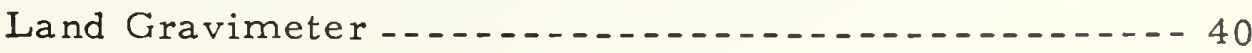

14 Schematic Representation of the Steps

Necessary to Compute the Elevation Correction

$(\boldsymbol{\sigma}=$ density in grams per cubic centimeters) $\ldots . .-.-51$

15 Schematic Diagram Showing Areas Involved in

Terrain Corrections for Ocean Bottom Stations -..-.- 54 

16 CBA Distribution for the Continental Shelf and Adjacent Coastline Between Pt. Lobos and Pt. Sur (values in milligals, contour interval 2 mgal)

17 PDR Profile Locations and Fault Scarp

Position from a Bathymetric Study -...........-72

18 PDR Profile A.A'

19, PDR Profile B-B'

20 PDR Profile D-D'

21 PDR Profile E-E' $E^{\prime} \ldots \ldots$

22 PDR Profile F-F $F^{\prime} \ldots \ldots \ldots$

23 PDR Profile $\mathrm{H}_{-} \mathrm{H}^{\prime} \ldots \ldots \ldots \ldots$

24 Location of Two-Dimensional Modeling Profiles _-_._-79

25 Depth to Basement of Profile Model A_A'

26 Calculated and Observed Gravity for Profile A_A'_._. 83

27 Depth to Basement of Profile Model B_B'

28 Calculated and Observed Gravity for Profile B-B'_-_._ 85

29 Depth to Basement of Profile Model C_C'

30 Calculated and Observed Gravity for Profile C_C'_._._ 87

31 Summary Fault Map Indicating Proposed Locations_-.. 90 



\section{A CKNOW LEDGEMENTS}

The author wishes to express his appreciation for the professional guidance and cheerful support provided by his thesis advisors, Dr. Robert S. Andrews and Dr. J. J. von Schwind of the Naval Postgraduate School (NPS) Department of Oceanography. To Capt. "Woody" Reynolds and the crew of the R/V ACANIA go a heartfelt thanks for their timely assistance in all aspects of the gravity survey operations and for their never-ending good sense of humor. Dr. Howard Oliver, Dr. S. L. Robbins, and Mr. Richard Farwell of the U. S. Geological Survey (USGS) provided the land gravimeter, computer programs, and much helpful information needed to conduct the survey. Mr. H. Gary Greene, USGS marine geologist, made available much unpublished material pertaining to the local geology of the survey area. Acknowledgements are also made to Mr. 'Yogi' Parks and Mr. Joe Bighorse of LaCoste and Romberg for their patience and guidance in the maintenance of the underwater gravimeter. STl Rick Desgrange and Mr. Dana Mayberry of the NPS Ocea nography Department were essential in maintaining the underwater gravimeter in working order. The NPS Public Works Department and Mr. Pete Wisler provided necessary assistance on a number of occasions. Finally, this work would not have been possible without the assistance of Lt. Henry Spikes, co-worker and good friend.

Partial funding for this project was provided by NPS Research Foundation from Office of Naval Research Resources. 



\section{INTRODUCTION}

\section{A. OBJECTIVES}

The continental shelf between Point Lobos and Point Sur, California (Fig. 1), is an area in which the geology has only been superficially examined. In contrast, the coastal region of this part of the California coast has been studied extensively in the past, and continues to be in the present, due to increased public awareness of probable future earthquakes and proposed residential and commercial construction.

Seismically active fault zones exist along the continental shelf of Central California. The area between Pt. Lobos and Pt. Sur must be included as one of these zones. Although no major earthquakes have occurred in this region throughout the period of record (since 1926), there is a good probability for future seismicity based on the recent mapping of offshore structures by Greene et al. [1973].

The present gravity survey was undertaken to add to the sparse geological data that presently exists and in hopes that the composite will, in the future, produce a detailed and complete understanding of the structure of the continental shelf and surrounding area.

\section{B. LOCATION AND TOPOGRAPHY}

The area of study encompassed in this research is that of the continental shelf, from the coastline west to the 100 fathom (183 m) contour and from Pt. Sur north to Pt. Lobos, California. This area 



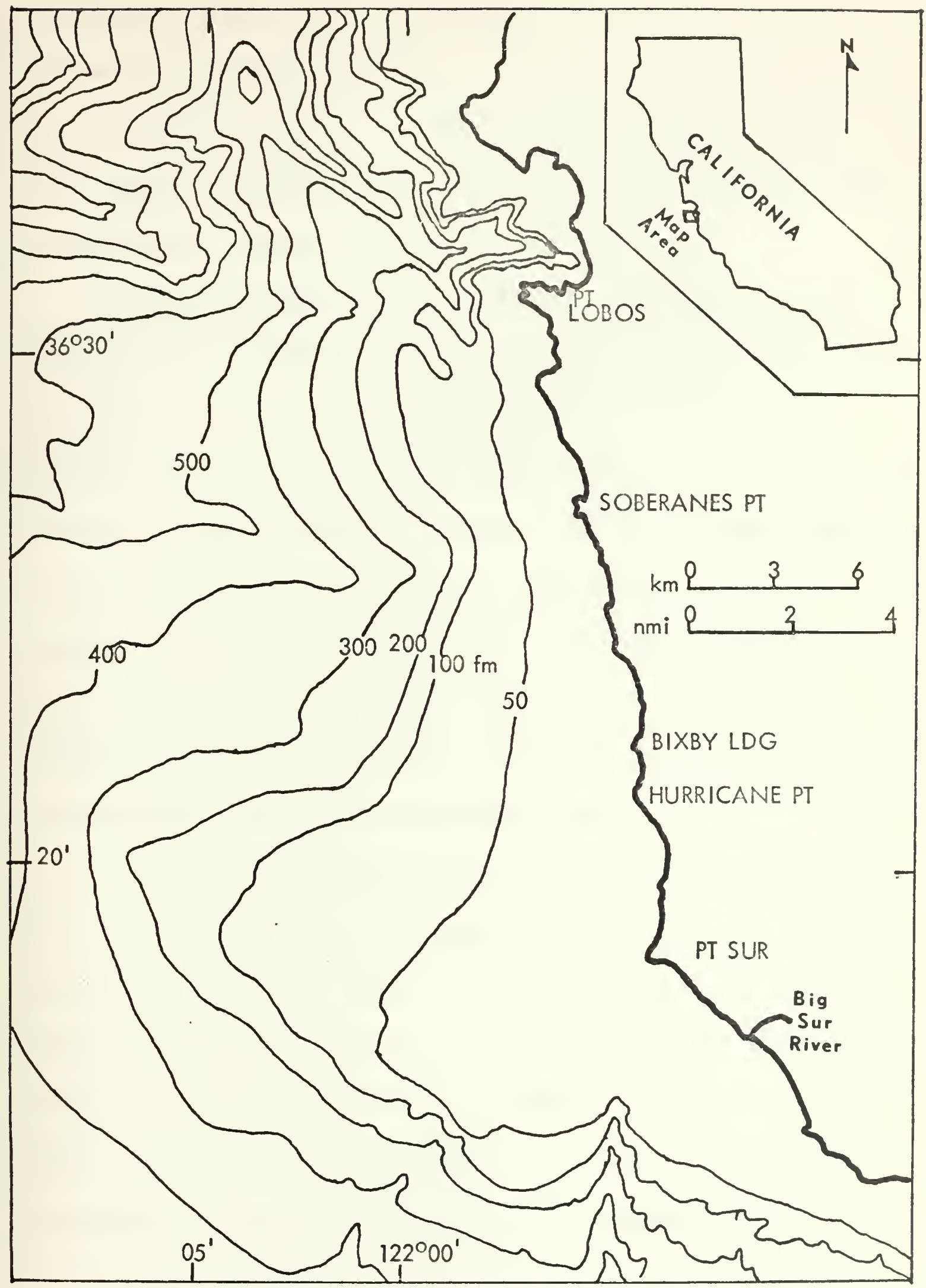

Figure 1. Bathymetry of the Survey Area (depth contours in fathoms) 

is bounded by latitude $36^{\circ} 18.5^{\prime} \mathrm{N}$ and $36^{\circ} 31.5^{\prime} \mathrm{N}$ and by longitude $121^{\circ} 54^{\prime} \mathrm{W}$ and $122^{\circ} 58.8^{\prime} \mathrm{W}(\mathrm{Fig}$. 2). In this region the shelf break occurs at approximately the 70 fathom $(128 \mathrm{~m})$ contour at an approximate distance of $2 \mathrm{~km}$ from the shoreline in the north to over $11 \mathrm{~km}$ to the south off of the Pt. Sur tombolo.

The shelf is interrupted in the north by two tributaries of the Carmel Canyon located approximately $3.7 \mathrm{~km}$ southwest of Pt. Lobos, by an extension of the Monterey Canyon to the west of the central portion of the area, and by the Sur Canyon almost due south of Pt. Sur. The area generally exhibits flat terrain over the continental shelf with the exception of one or two northwest trending fault scarps of approximately $20 \mathrm{~m}$ relief and numerous rock outcroppings marking the seaward extensions of the many rocky headlands. Dohrewend [1971], from bathymetric and seismic profiling, determined the slope of the shelf to be approximately $1.5^{\circ}$ over $90 \%$ of the area.

Immediately to the east of the area, the Santa Lucia Range rises abruptly attaining frontal heights of over $800 \mathrm{~m}$. This rugged range extends the entire length of the area attaining a maximum separation from the coastline of $16 \mathrm{~km}$ at Pt. Sur. Two major streams, the Big Sur and Little Sur Rivers, are found on the western half of the range. Both have only seasonal flow, and like all streams in the area, are separated from the eastern side of the mountains.

Two well defined marine terraces are evident along the coastline, one averaging 25-30 m above present sea level, and the other, 



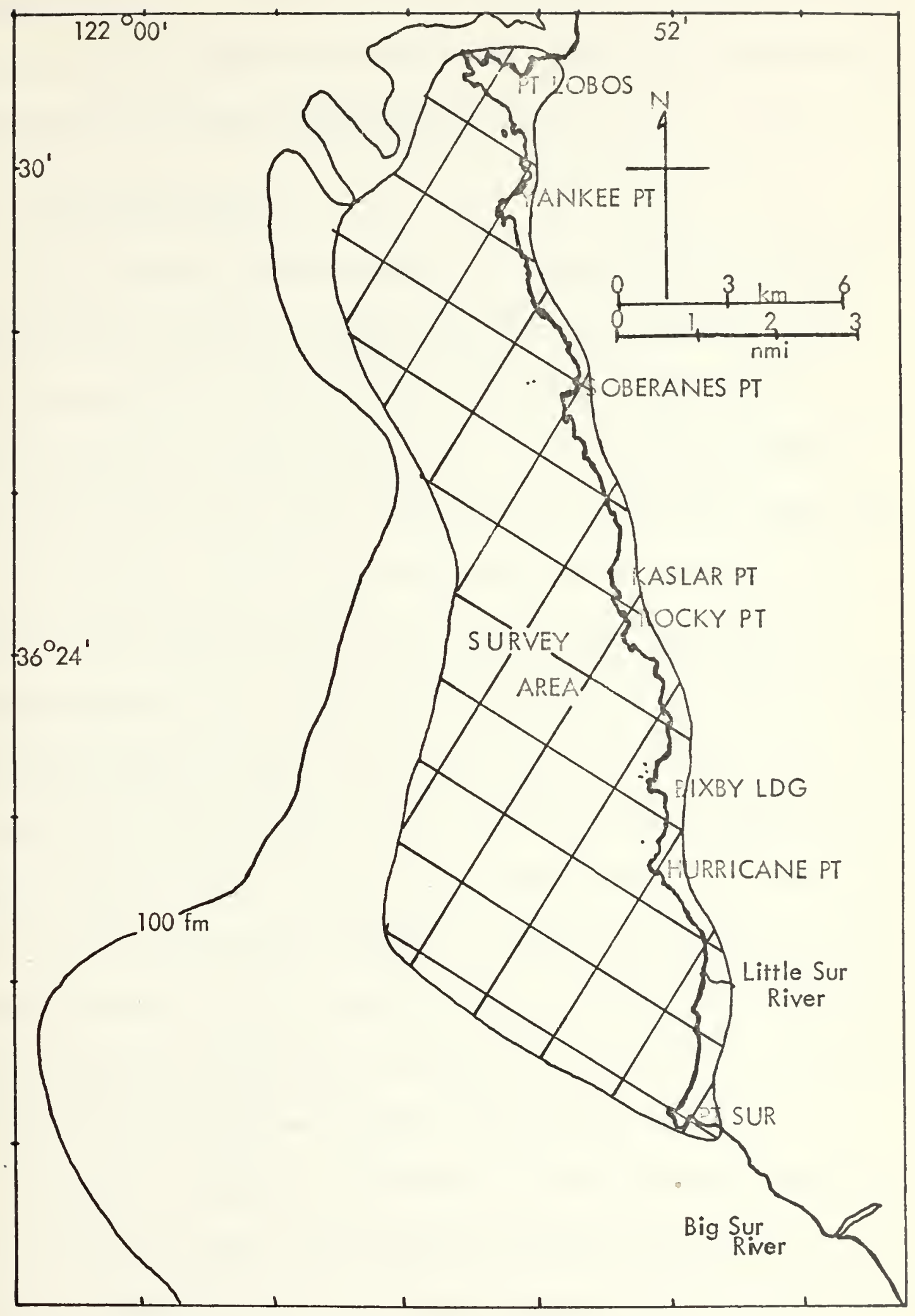

Figure 2. Survey Area Limits and Location

13 

approximately $65 \mathrm{~m}$ [Trask, 1926; Phifer, 1972]. These well defined marine terraces are probable evidence of the recent emergence of the northwest portion of the Santa Lucia Range. This uplift is most likely continuing at the present time [Phifer, 1972].

\section{PREVIOUS WORK}

It has only been within the past 3 or 4 years that any geological work has been carried out within the study area. Dohrewend [1971] and Ellsworth [1971] utilized seismic reflection profile records, precision depth recording (PDR) traces, and core and grab samples to describe the geology of the continental shelf between Pt. Lobos and Pt. Sur. Greene et al. [1973] conducted a study of faults and earthquakes in the Monterey Bay region. Most of their work within the region appears to be a compilation of previous onshore studies, coupled with some offshore seismic reflection profiles and dredge hauls used to approximate offshore extensions of onshore faults. Colomb [1973] made a study of recent sediments on the shelf between Pt. Lobos and Pt. Sur, and in conjunction with this, conducted two bathymetric and seismic profiling cruises through the area. These studies represent, as far as can be ascertained, the extent of the scientific investigation of the continental shelf between Pt. Lobos and Pt. Sur.

Before attempting to understand any of the offshore geology it is first necessary to have a thorough appreciation of the onshore geology of the surrounding area. There exist several geological investigations 

of the adjacent coastal regions as well as some offshore studies to the north.

Trask [1926] mapped and studied the geology of the Pt. Sur Quadrangle. Shepard [1948], Martin [1964], Martin and Emery [1967], and Greene [1970] investigated the geology of Monterey Bay and the Monterey Bay Submarine Canyon. Martin and Emery's work contains a brief description of the continental shelf just to the south of the Carmel Canyon. Page [1970] describes the geology of the area surrounding the Sur-Nacimiento fault zone at the southern edge of the study a rea including a probable time sequence of events in the formation of the present day geology. The following geological summary of the area is based on the above works.

Three major fault zones that exist in the vicinity of the area of study influence the local geology. These include the San Andreas, the Palo Colorado-San Gregario, and the Sur-Nacimiento fault zones. It is generally believed that the boundary of the Salinian Block is the San Andreas fault to the northeast and the Sur-Nacimiento fault to the southwest. The Salinian Block is comprised chiefly of Cretaceous granitic- metamorphic rocks with oceanic crust of Franciscan assemblage to either side (Fig. 3). Overlying the granitic basement rocks of the Salinian Block is a layer of Tertiary strata, primarily sedimenta ry rocks.

The Sur-Nacimiento fault zone extends northwest through the southern and central Coast Ranges of California and presumably extends 



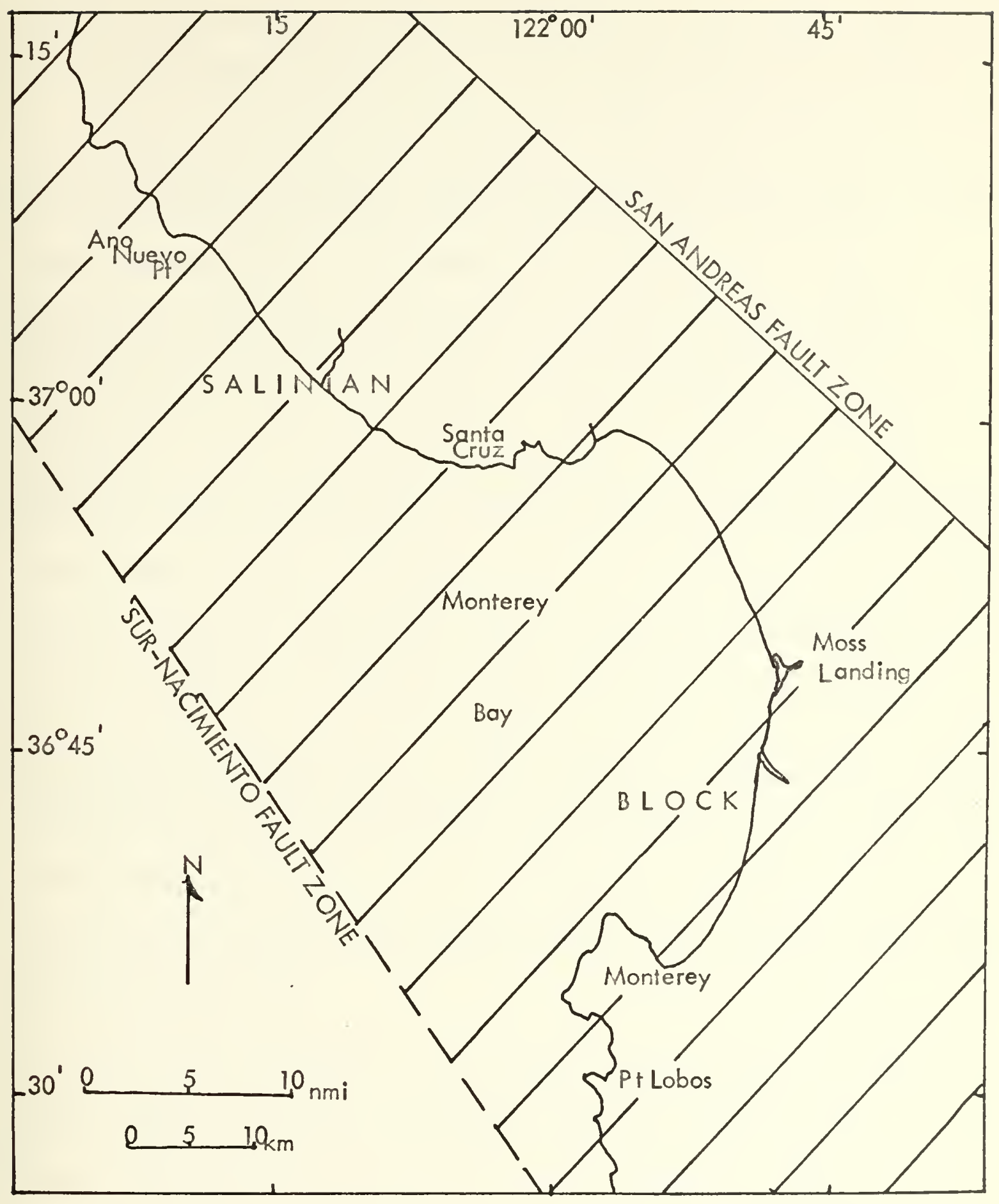

Figure 3. Geological Boundaries of the Salinian Block (after Greene et al., 1973) 

offshore on the continental shelf just north of Pt. Sur [Page, 1970]. The Sur-Nacimiento fault zone consists of the Sur fault zone, which can be traced for $67 \mathrm{~km}$ southeast from Pt. Sur, and the Nacimiento fault, the southern extension of the Sur fault zone which continues down to the southern portion of the Coast Range of California. Page postulates that the Sur fault zone was the result of a tectonic collision between Pacific oceanic crust and the Salinian Block granite along the continental coast. He stated that at least part of the Sur fault zone marks the former margin of the continent; that it is probable that oceanic trench deposits which accumulated out in the Pacific moved into contact with the continent. The oceanic portion moved either nor theasterly or easterly relative to the North American continent as the result of sea floor spreading along the Pacific Rise while the continental portion moved as the result of sea floor spreading from the Atlantic Ridge. Page also wrote that the oceanic portion of the Franciscan assemblage was downthrust under the edge of the continental plate thus creating the northeast dipping Sur fault zone.

Trask [1926] named the metamorphic rocks of the Salinian Block to the northeast of the Sur-Nacimiento fault zone the Sur Series. This series consists of quartzites, schists, gneisses, marbles, and granulites. The Sur Series throughout the Salinian Block is intruded by granitic rocks composed of quartz diorite, granodiorite, and admellite. The granitic rocks are believed to be generally younger 

than the Franciscan rocks which they now border. Page asserts that fault displacements existed to explain the fact that the Franciscan assemblage was generally unaffected by the intrusion of the granites. The Franciscan assemblage, found only on the southwest side of the Sur-Nacimiento fault, consists primarily of graywake, shale, volcanic greenstone, and some interspersed serpentine.

The Palo Colorado fault (Fig. 4) occupies a narrow (approximately $3 \mathrm{~km}$ wide) fault zone connecting in the south with the onland Serra Hill [Sierra Hill of Trask, 1926]-Palo Colorado fault complex near Kaslar and Hurricane Points and in the north with the San Gregario fault and a thrust fault on Ano Nuevo Point [Greene et al., 1973]. Trask [1926], in defining the geological setting of the Pt. Sur Quadrangle, described the macrostructure of the area with a series of northwest-southeast trending fault-bound blocks. Two of these boundaries are the San Andreas fault zone to the northeast and the Sur-Nacimiento fault zone to the southwest.. The third boundary is the Palo Colorado fault zone which subdivides the Salinian Block between the San Andreas and Sur-Nacimiento zones. To the northwest of the Palo Colorado zone, Santa Lucia quartz diorite dominates entirely, and to the southwest, the Sur Series with some quartz diorite and some Cretaceous sedimentary rocks can be found (Fig. 5 and Table I). 



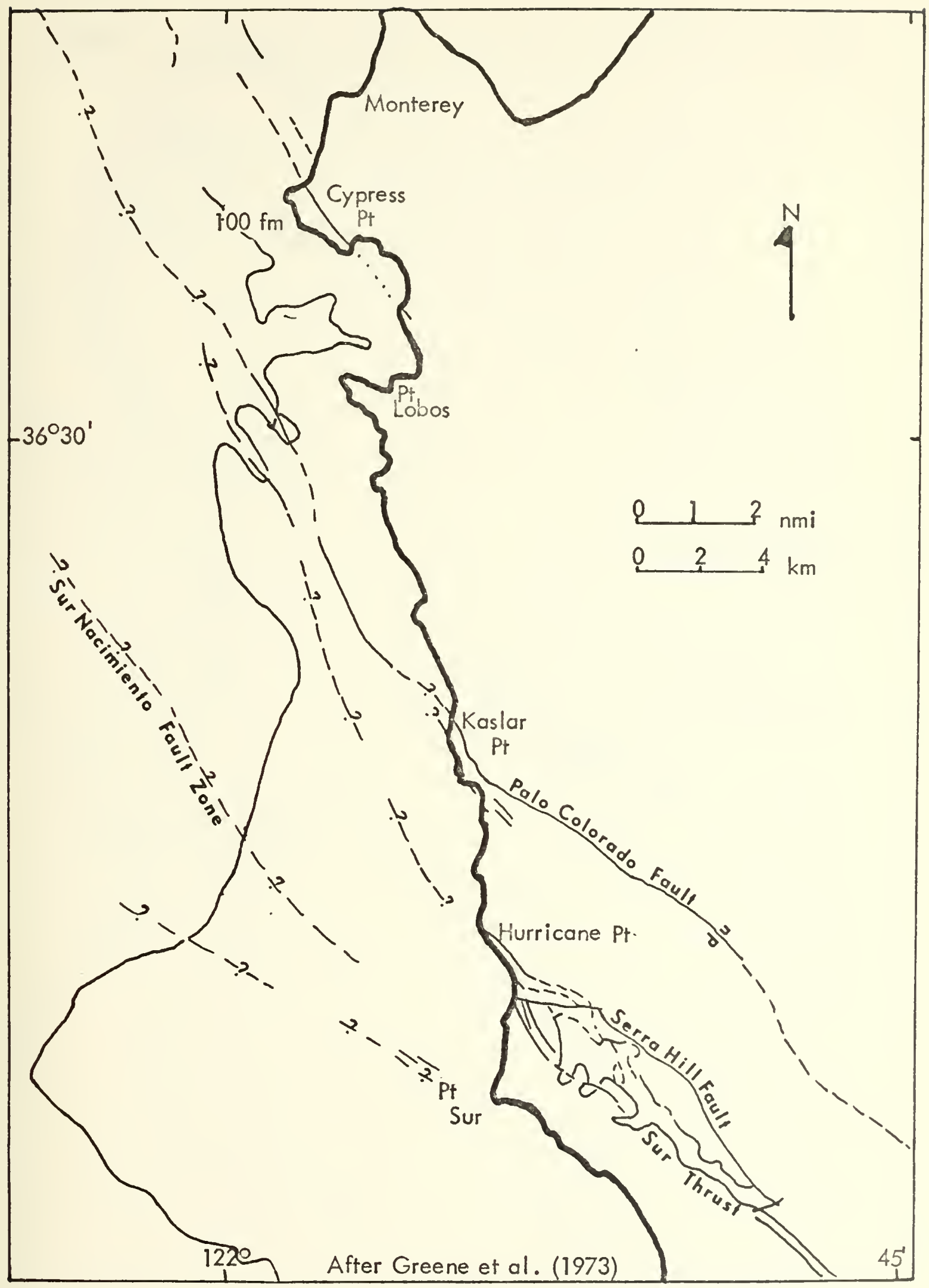

Figure 4. Regional Fault Map

(after Greene et al., 1973) 



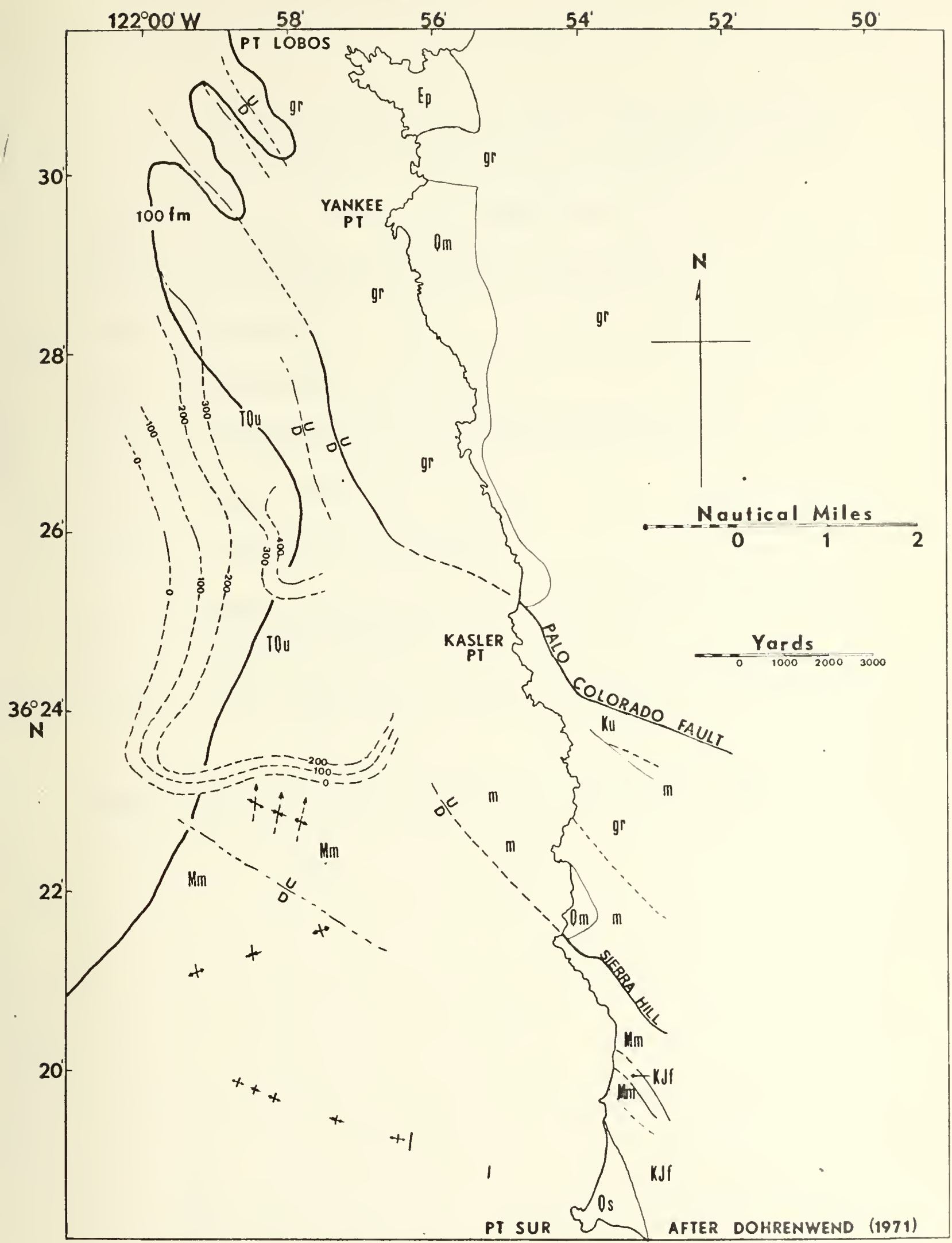

Figure 5. Regional Geology and Fault Location (after Dohrewend, 1971) (geologic abbreviations listed in Table I) 



\section{TABLE I}

\section{EXPLANATION OF GEOLOGIC ABBREVIATIONS}

TQu Tertiary - Quaternary undifferentiated

Mm Miocene marine (Monterey Formation)

Qm Pleistocene marine

Qs Quaternary dune sand

Ep Paleocene marine (Carmelo Formation)

$\mathrm{Ku} \quad$ Upper Cretaceous marine

KJf Franciscan Assemblage

gr Cretaceous granitic rocks (Santa Lucia granodiorite and quartz diorite)

$\mathrm{m}$

Pre-Cretaceous metamorphic rocks (Sur Series)

Sedimenta ry rock isopach contour line (meters)_._.400_._- 

Both Trask [1926] and Page [1970] consider the Serra Hill fault part of the Sur fault zone, while Greene et al. [1973] believe it may be a southern extension of the Palo Colorado-San Gregario fault zone. This fault zone leaves the coast near Hurricane Point and is lost in a zone of seismic incoherency, but becomes well defined in the central and northern regions. The fault dips $50-60^{\circ} \mathrm{NE}$ near Hurricane Pt. with granodiorite northeast of the fault thrust over upper Miocene sandstone to the southwest and with an estimated vertical separation of $300 \mathrm{~m}$ [Gilbert, 1971]. The probable offshore extension exhibits the same characteristics and in the north can be traced to the western tributary of the Carmel Canyon and may have controlled the location of this submarine canyon [Greene et al., 1973].

Northeast of this fault another fault leaves the coast in the vicinity of Kaslar Pt. Greene et al. [1973] believe that this fault may bend eastward and connect with the Palo Colorado fault on land. This idea is supported by Trask's description of the location of the Palo Colorado fault. Dohrewend [1971] and Ellsworth [1971] obtained seismic profiles $(7.5 \mathrm{kHZ})$ of a well-formed west facing scarp in this area giving further support of a seaward extension of the Palo Colorado fault. Dohrewend calculated that Pliocene and Pleistocene sedimentary rocks approximately $200 \mathrm{~m}$ thick on the southwestern side are in fault contact with the quartz diorite on the northeastern side. Greene et al. [1973] state that the Palo Colorado fault zone is well defined 

offshore of Pt. Lobos across the eastern tributary of the Carmel Canyon. This conclusion was based on seismic reflection profiles and dredge hauls across the canyon which indicated at least $120 \mathrm{~m}$ sepa ration with relative upper movement of the east wall. Just $1.5 \mathrm{~km}$ to the southwest, the probable offshore extension of the Serra Hill fault can be traced into the western tributary of the Carmel Canyon. The authors included this fault as part of the Palo Colorado-San Gregorio fault zone. Trask, in describing the onshore Palo Colorado fault zone, states that the fault is a high angle thrust which has been traced $25 \mathrm{~km}$ to the southeast and crosses the coast about $200 \mathrm{~m}$ north of Garrapatas Creek (located just north of Hurricane Pt.). Phifer [1972] states that the Palo Colorado fault crosses $150 \mathrm{~m}$ north of Doud Creek since outcrops of the Santa Lucia quartz diorite on either side of the gap has been severely sheared. He places the crossing of the Palo Colorado fault $600 \mathrm{~m}$ to the north of where Trask originally mapped it. Near the cove just north of Kaslar Pt. there is further evidence of more faulting with a strike N40W in which quartz diorite is thrust over sandstone and conglomerates. Near Rocky Creek there is evidence of a series of thrust faults covering a zone $800 \mathrm{~m}$ wide bordering both sides of the creek mouth. The southern blocks are overthrusted. A fracture on the north side of the zone appears to extend northwest and run into a fault zone crossing Rocky Pt. This latter zone appears to be associated with some part of the Serra Hill fault. 

From the above description one can see that the geology of the region is more complex than the idealized three block macrostructure. Within the area there appear to be seven or eight major faults and numerous minor ones. The interrelationships and the exact seaward extensions of these faults and the types of structure which they border, is in most cases little more than conjecture. The question still arises as to the seaward location of the Sur Fault. Page [1970] believes that it branches out to the west across the continental shelf in order to pass to the west of the Farrallon Islands, which are made up of granites. Both Page and Greene et al. contend that the Sur Fault zone lies to the west of the Palo Colorado-San Gregorio fault zone. But if, as stated before, the seaward extension of the Sur fault zone begins in the vicinity of Hurricane Pt., there is no evidence of it proceeding out to the west in order to parallel the Palo ColoradoSan Gregorio fault zone, although there is evidence of numerous smaller fault zones in the deeper waters of the continental shelf. 



\section{SURVEY PROCEDURES}

A. UNDERWATER GRAVIMETRY

The object of underwater gravimetry is no different from the object of sea surface or land gravimetry; i.e., to measure the spatial variation of the earth's gravitational field. The modern day precision instrumentation used for relative gravimetry measurements, whether on the sea floor, on the sea surface, or on land, all involve the same basic principle of measuring the elongation of a sensitive spring with a known mass or beam attached at one end (Fig. 6). Underwater gravimetry does, however, involve some unique equipment modifications, procedural techniques, and data reduction methods. These will be discussed in the sections which follow.

\section{Equipment}

A La Coste and Romberg Model HG6 underwater gravimeter on loan from the Naval Oceanographic Office was utilized for this ocean bottom survey. Figure 7 shows the gravimeter ready for use, while Fig. 8 is an internal view of the meter with the top hemisphere removed. Under laboratory conditions the manufacturer specifies a reading precision of $\pm 0.02 \mathrm{mgal}$. Experience from past surveys [Brooks, 1973; Cronyn, 1973], as well as the present one, indicates an operational accuracy of $\pm 0.10 \mathrm{mgal}$. The meter is similar in design to the LaCoste and Romberg land gravimeter and has a 



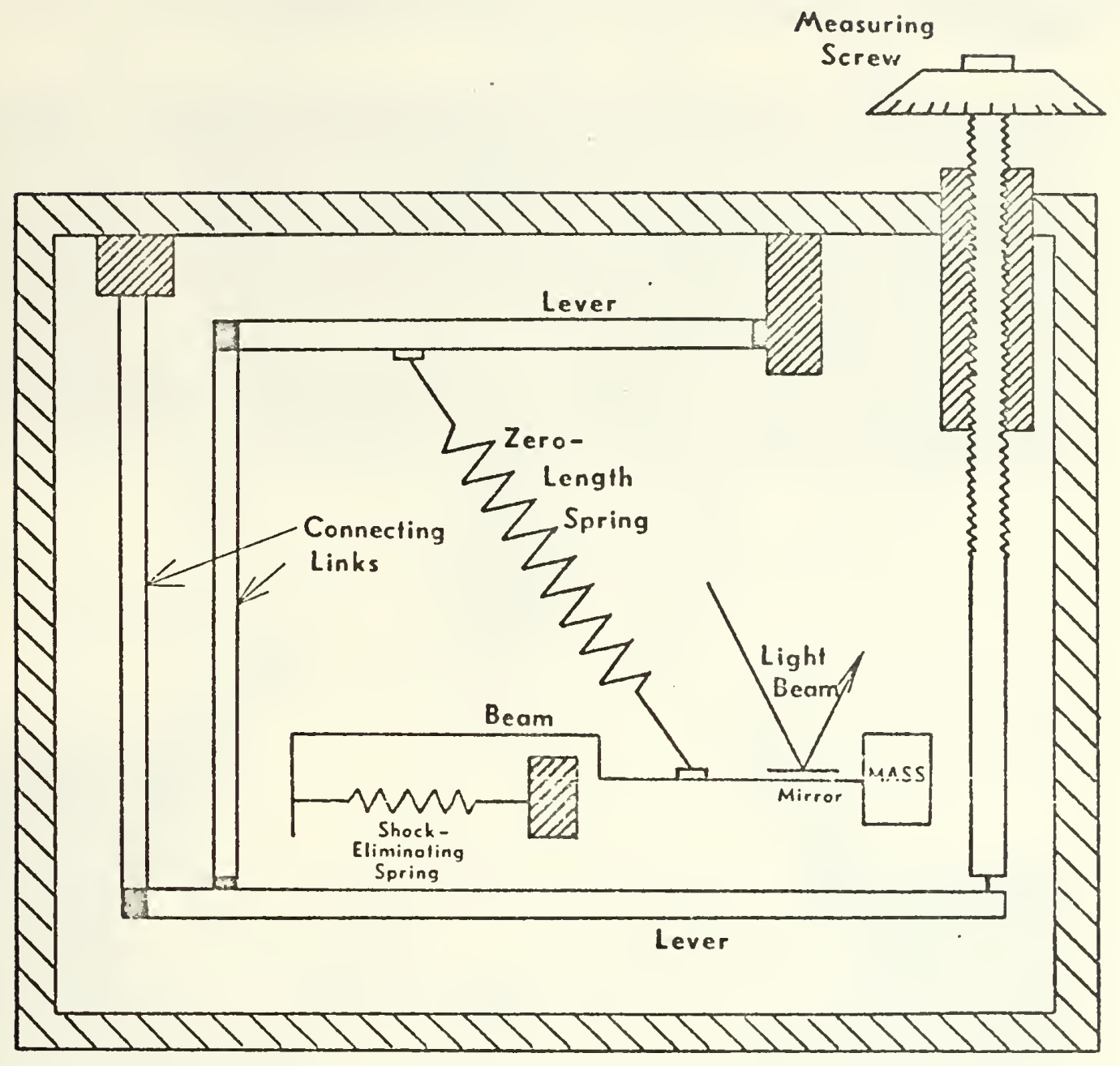

Figure 6. Simplified Diagram of the LaCoste and Romberg Gravimeter (after Lacoste, 1967). 



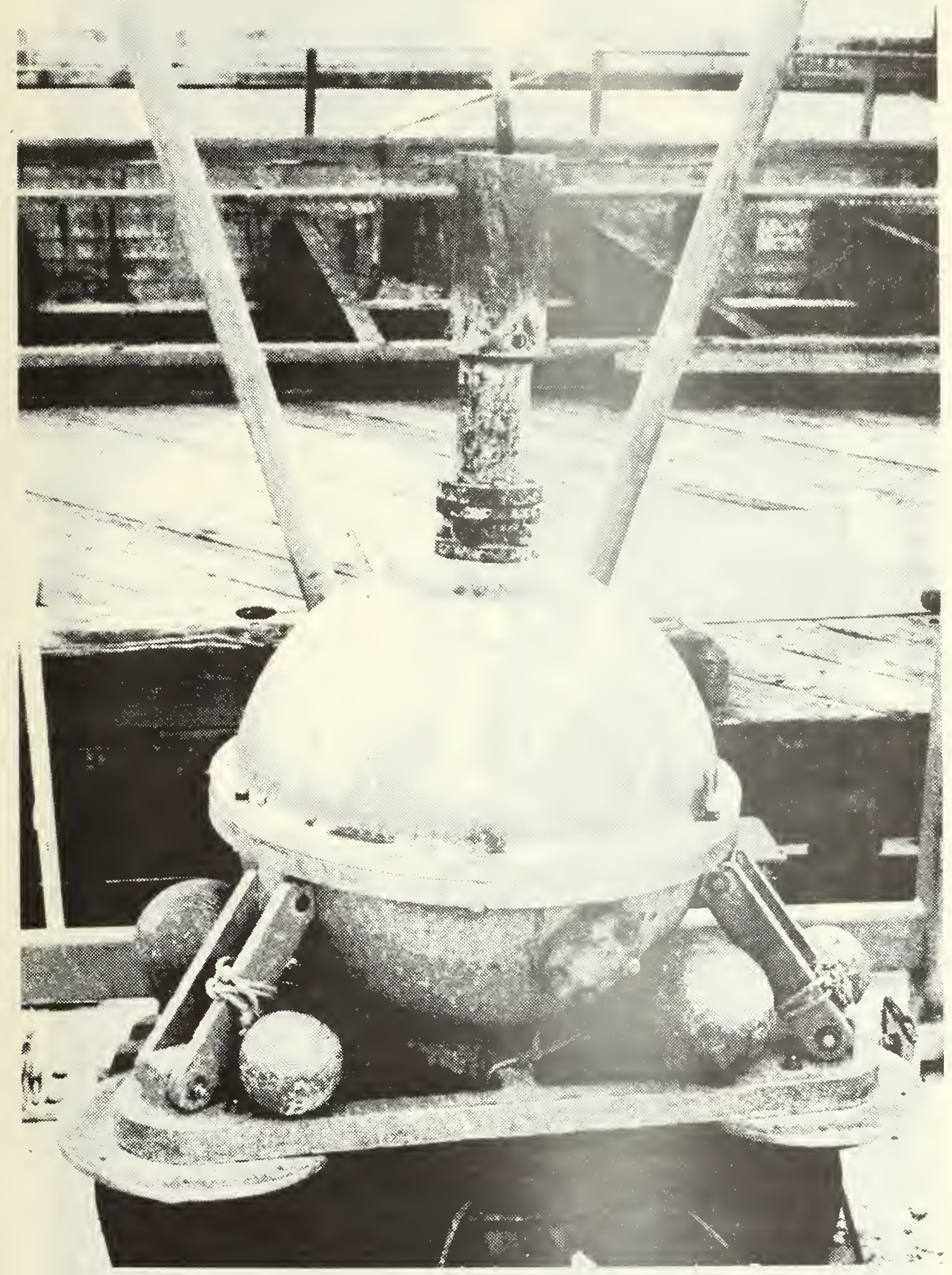

Figure 7. Model HG6 Gravimeter Ready for Use 


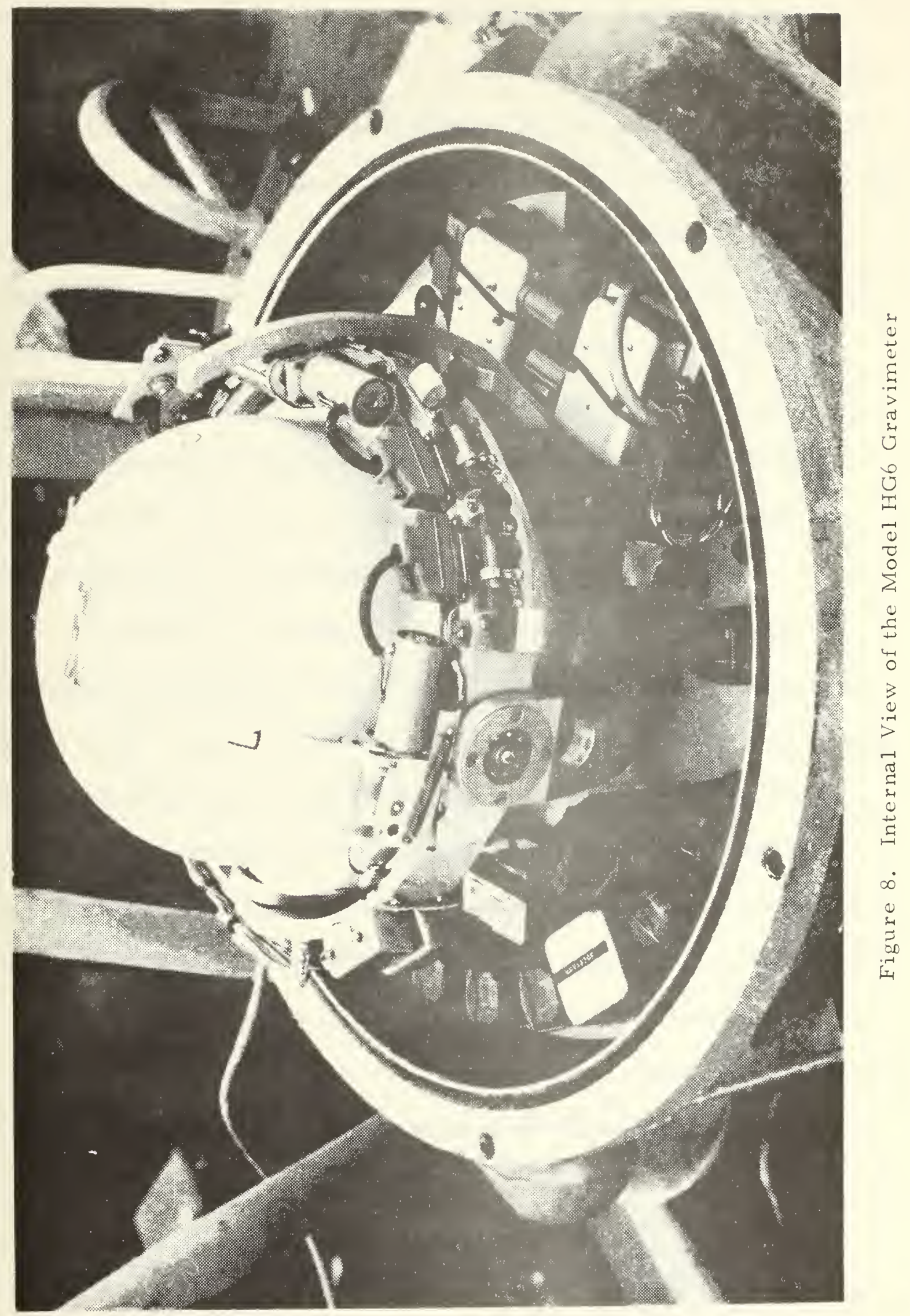



comparable $7000 \mathrm{mgal}$ range. The modification of a land meter to permit underwater measurements includes the mounting of the meter within two thick aluminum hemispheres, the inclusion of an automatic leveling system and depth sensing unit, and an insulated multi-conductor shielded by an armored cable. The cable enables measurements to be taken remotely at a control box. Remote operation through the control box consists of various step functions which include nulling of the pressure sensor depth unit, high and low speed meter leveling, flood and tilt indication, clamping/unclamping of the gravimeter mass, nulling of the mass position, and the gravity counter display giving the measuring screw adjustment to null the mass.

Auxiliary equipment includes a specialized winch with a secondary termination at the bitter end of the armored cable through a set of slip rings. A marine gasoline engine is coupled to a hydraulic pump which is used to position an A-frame and to run the hydraulic winch. Power to the meter itself is supplied by the ship's 115 vac system through a rectifier and an isolation transformer to the control box and the meter. Figure 9 is a schematic diagram of the auxiliary equipment while Fig. 10 illustrates the equipment as installed on NPS R/V ACANIA (Fig. 11). The engine, winch, and A-frame assembly were mounted to the after upper deck of the ACANIA.

\section{Calibration}

The meter itself was calibrated by utilizing two standardization bases located in the immediate area. The first base, WA-84, 



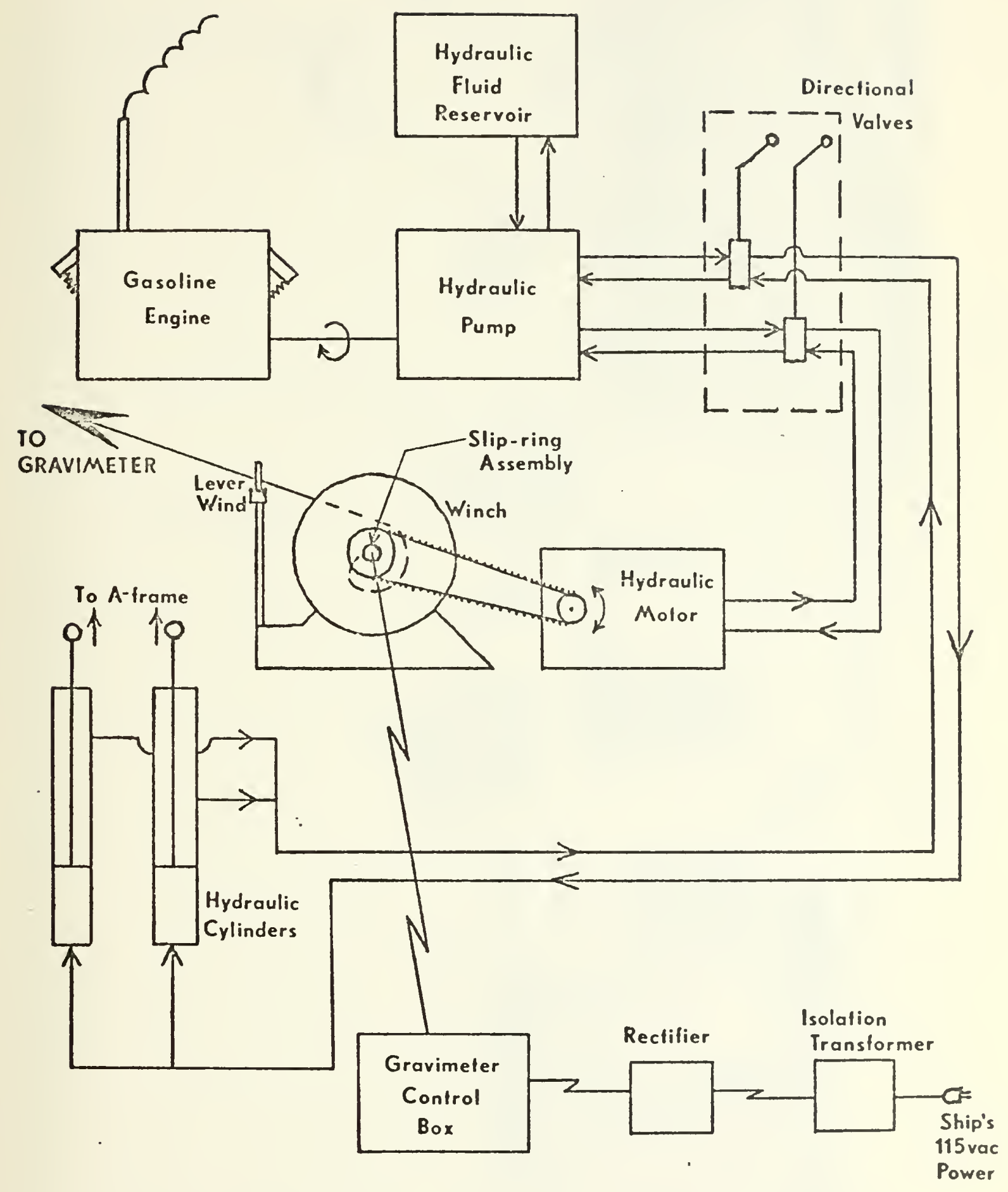

Figure 9. Schematic Diagram of the Auxiliary Equipment. 



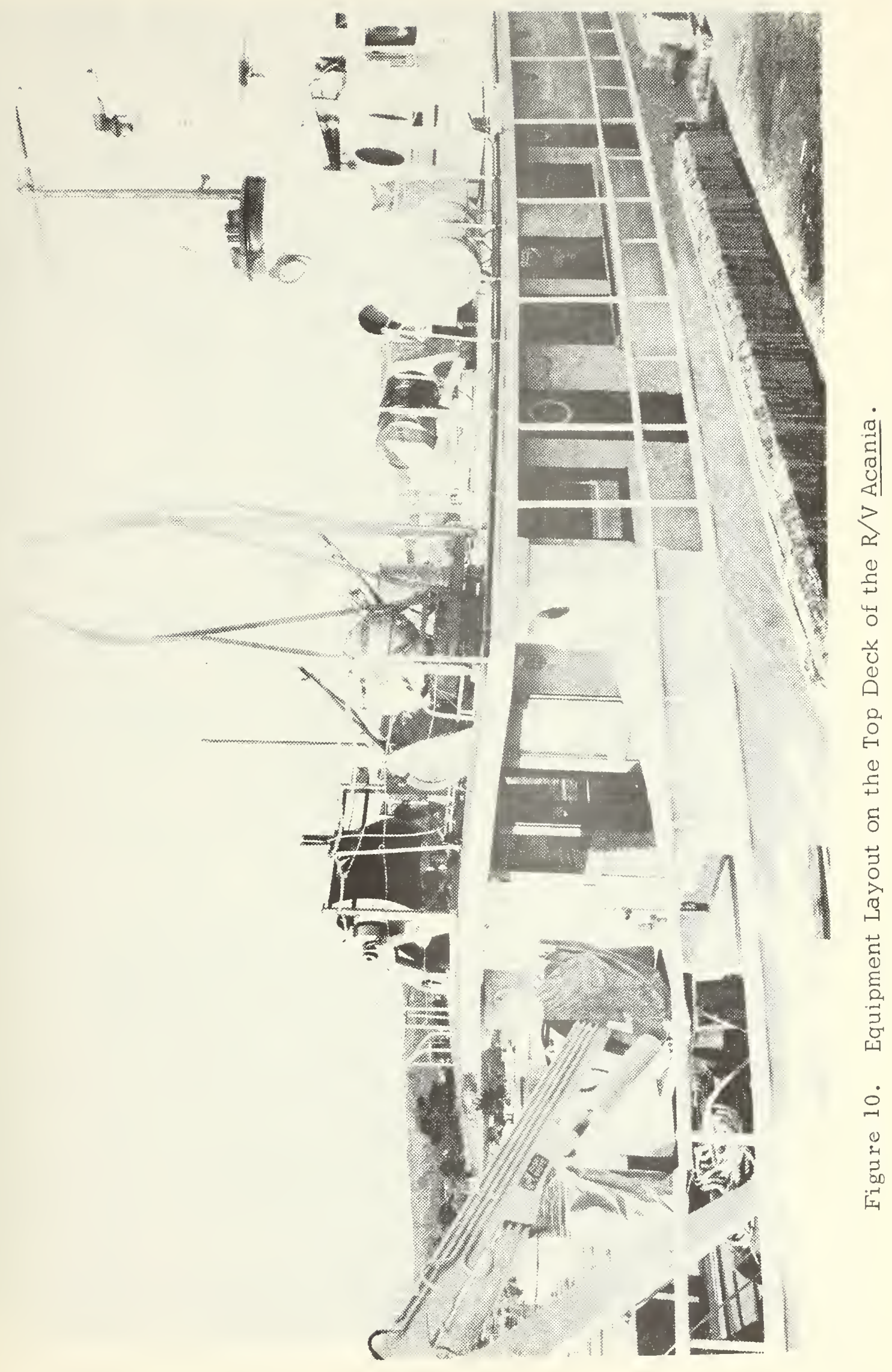




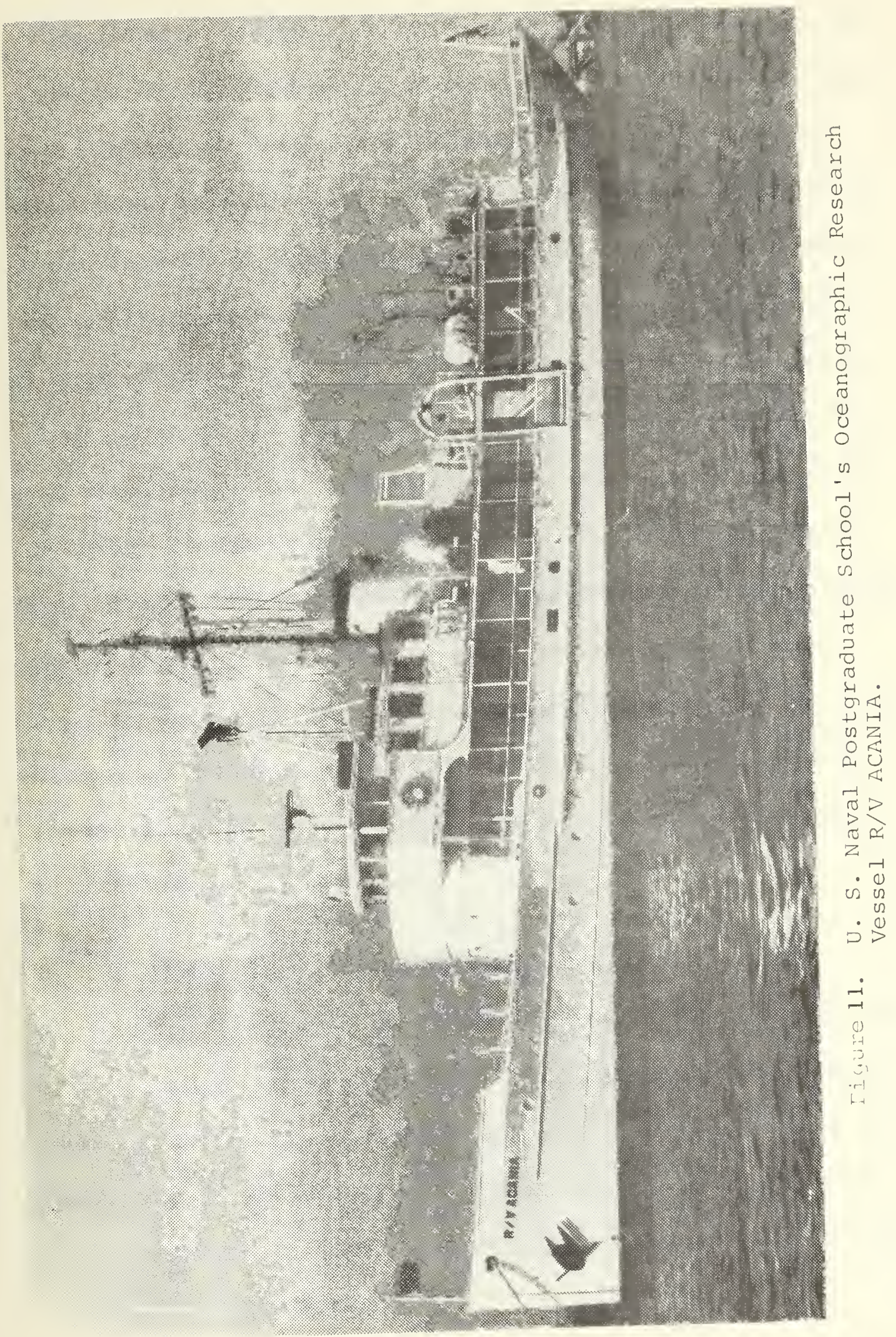



is located at the Monterey County Airport, and the second, WH-29, at the base of the steel tower at the end of the Monterey Coast Guard pier [Wollard and Rose, 1963]. The published gravity difference between the two stations is $22.5 \mathrm{mgal}$. The readings obtained by the author showed a $22.1 \mathrm{mgal}$ difference. The discrepancy of $0.4 \mathrm{mgal}$ is probably due to the recent construction of a new terminal at the airport and in the inability to locate the exact position of the benchmark. Since the absolute gravity reading at the airport is less than that at the pier, and since the addition of a new concrete foundation on top of the airport benchmark would introduce a greater gravity reading and therefore a decreased difference between the two stations, it is felt that the readings were within the tolerance of $0.1 \mathrm{mgal}$. Upon completion of the calibration check, the gravity meter was connected to the armored cable onboard the ACANIA. A trial run was conducted and successfully completed in the shallow waters adjacent to the Coast Guard pier.

\section{B. STATION SELECTION AND LOCATION}

Station selection within the area between Pt. Lobos and Pt. Sur was originally based on a grid of $0.5 \mathrm{nmi}(0.9 \mathrm{~km})$ interval between stations with the constraints of the $100 \mathrm{fm}(183 \mathrm{~m})$ contour to the west and the practical depth limitation of the research vessel of not less than $5 \mathrm{fm}(9 \mathrm{~m})$ to the east. It was intended to bracket the fault scarp 

identified by Dohrewend [1971] and by the author from shipboard PDR traces. It was felt that this particular scarp runs into the western tributary of the Carmel Canyon as previously mentioned.

It later became necessary to modify the $0.5 \mathrm{nmi}$ grid due to equipment malfunctions and decreased ship availability. A final grid of approximately $0.5 \mathrm{nmi}$ spacing in the northern portion of the area, and approximately $1.0 \mathrm{nmi}(1.9 \mathrm{~km})$ spacing in the southern portion resulted in a total of 68 ocean bottom stations. It is believed that the fault scarp was bracketed a total of seven times (i.e., seven stations on each side for a total of 14 stations). Figure 12 illustrates the ocean bottom and land station densities; the coordinates of each station are given in Appendix B.

\section{SURVEY OPERATIONS}

\section{Measurement Procedures}

The survey included a total of four 12 -hour ship-days over a 2 month period from 29 May 1973 to 27 July 1973.

Prior to getting underway each day, a base station reading was taken at the ship's mooring location approximately $25 \mathrm{~m}$ south of the Coast Guard pier in Monterey Harbor, Monterey, California.

Conditions permitting, this check was repeated at the conclusion of the day's operation in order to determine meter drift.

Upon arrival at a particular station the meter was lowered directly to the bottom at an approximate rate of $30 \mathrm{~m} / \mathrm{min}$. Bottom 



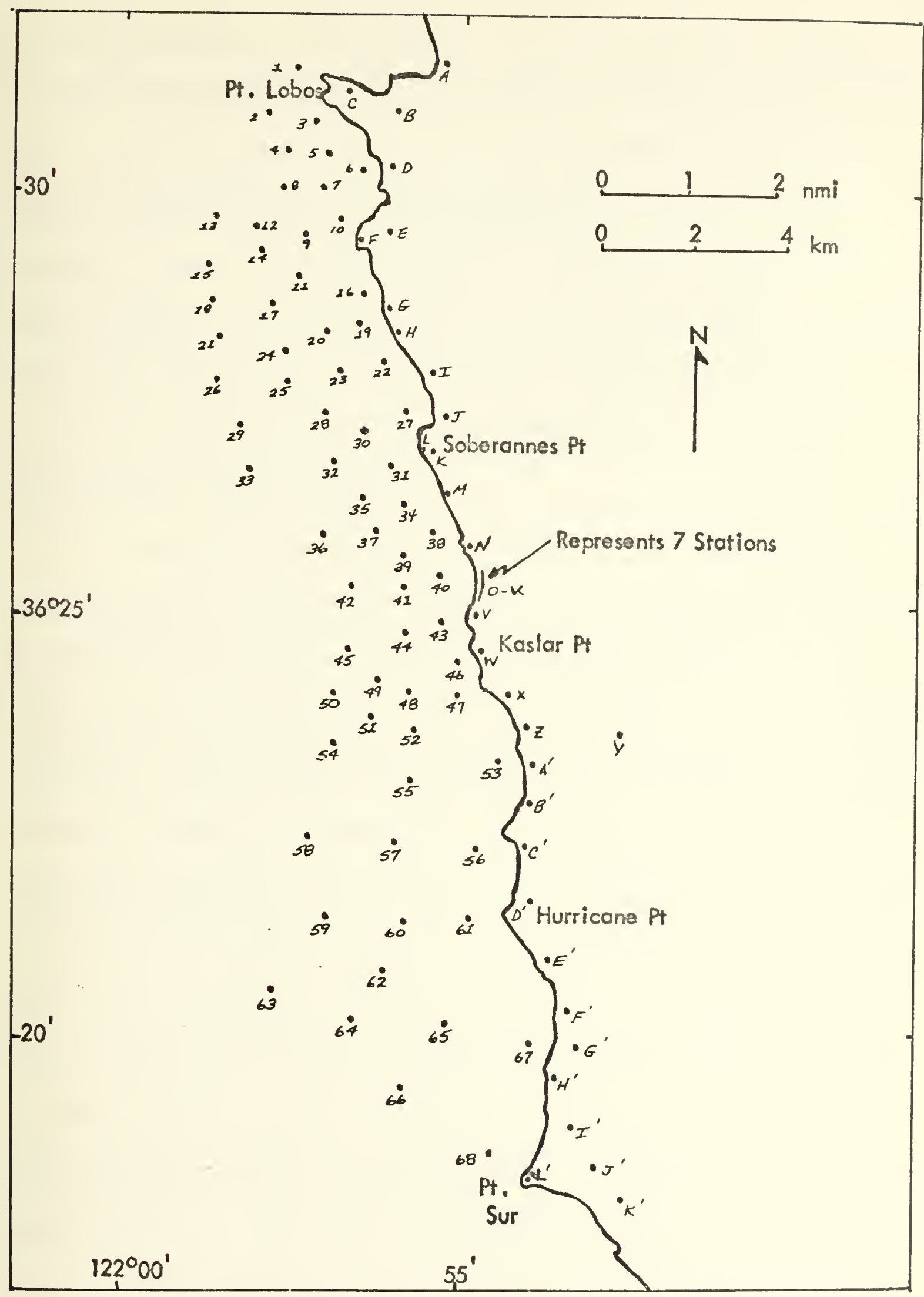

Figure 12. Ocean Bottom and Land Station Density and Location 

arrival was monitored through the use of the depth nulling galvanometer on the control box. Originally the operating procedure called for obtaining a pressure sensor depth reading while the meter was suspended at the sea surface. This was found to be impractical due to motion induced by sea and swell. Subsequently, a check of the depth reading was taken when the meter was in the two-block position at the A-frame. The depth reading here was essentially the same as that obtained just prior to the meter entering the water. This value was used as the surface depth counter reading.

Once the meter reached the bottom it was necessary for the winch operator to continually pay out cable to allow for ship drift and preclude dragging the meter on the bottom. The control box operator would obtain an ocean bottom pressure depth sensor reading and, concurrently, a reading of the ship's fathometer was recorded. Next, a check of the flood and tilt indicators was required. If the meter was tilted more than $15^{\circ}$ from the horizontal it was necessary to reposition it at a different location. This occurred a number of times throughout the survey, particula rly in shallow rocky areas. No flood indication ever occurred. After the meter was leveled and the mass unclamped, a gravity counter reading was taken. It is worth noting here that the time involved in taking a reading as well as the accuracy of the reading was a function of meter depth and sea state. Even at depths as great as $90 \mathrm{~m}$, the influence of the water motion above the meter could be 

discerned. This effect varied directly with the sea state and inversely with depth and required, in some cases, an averaging procedure to obtain a reading.

Once the gravity reading was recorded and the mass clamped, the meter was raised to the surface. During periods of strong winds it became apparent that the ship had drifted a noticeable distance from the original lowering position and it was necessary to maneuver the ship back as near as possible to this position in order to attempt to lift the meter off the bottom vertically to prevent dragging it. Because of various difficulties, this procedure was not always successful. It is felt that the meter was dragged over the bottom for short distance on a few occasions, apparently with no damage.

Under ideal conditions of calm, windless seas, the entire operation of obtaining a reading took approximately 15 min.; under adverse conditions the time increased to $30 \mathrm{~min}$.

\section{Navigation}

All navigation was conducted by the crew of the research vessel. This was necessary since it required both the author and a co-worker to operate the gravity equipment.

Visual navigation was utilized throughout the entire survey for bearing information, while radar provided a check of range on all fixes. Normally, a three-point fix was obtained at each station from three lines of bearing. In areas where this was not possible, radar 

ranges were used to supplement bearing information. Examination of the station charts indicated that three-line fix triangles were accurate to within a $0.1 \mathrm{nmi}(0.19 \mathrm{~km})$ or less on a side. In the north-south direction this would introduce a maximum error of 0.14 mgal to the final complete Bouquer anomaly (CBA) values.

\section{Equipment Reliability}

On seven separate occasions it became necessary to reterminate the electrical connections located at the bitter end of the armored cable. A rubber boot with two watertight clamps at either was designed to prevent salt-water leakage to the electrical terminals. It is believed that at operational depths increased pressures caused a leakage through the clamps at the ends of the boot. Various salt-water seals were attempted but none proved entirely satisfactory. After each retermination a re-occupation of either base station WH 29 or the ship's mooring location was accomplished to determine if the absolute base counter reading had changed. No such change was ever obs erved.

\section{COASTAL SURVEY}

A coastal gravimetric survey was conducted concurrently with the ocean bottom survey for the purpose of tieing-in the complete Bouguer a nomaly (CBA) values obtained on the continental shelf with those obtained by the U. S. Geological Survey (USGS) along the California coast. It was also felt that the gravity readings along the coast 

would provide a verification of the ocean bottom readings and facilitate in the identification of any trends.

A total of 38 stations were occupied using a LaCoste and Romberg Model G-08 gravimeter on loan from USGS at Menlo Park, California. The meter has a 7000 mgal range and an optimum accuracy of \pm 0.01 mgal [LaCoste and Romberg, 1970] (Fig. 13). Station selection was based on the ability to accurately define the elevation of any given location and on the accessibility of that location. For this reason the majority of the stations selected were located at USGS monumented benchmarks as noted on USGS topographical charts. The remainder of the stations were located at road intersections where elevation was noted on the chart or along the beach as close as possible to the water level. The beach locations were selected so as to bracket the location of the Palo Colorado fault. Station elevation relative to mean sea level at these locations was later calculated from tidal information. Prior to use within the study area, a calibration run was made from USGS headquarters in Menlo Park (USGS $1 \mathrm{JD}$ ) to Skeggs Point (USGS B-388), spanning a range of $137.2 \mathrm{mgal}$ [Chapman, $1966 \mathrm{a}$ ]. Reduction of the data from the calibration run yielded a 137.13 mgal range for a difference of $-0.07 \mathrm{mgal}$. A subsequent tie-in was made at base station WH-29 at the Coast Guard pier to determine a counter reading on the meter corresponding to the known absolute gravity value at WH-29. This value was determined to be 3405.63 counter units. 



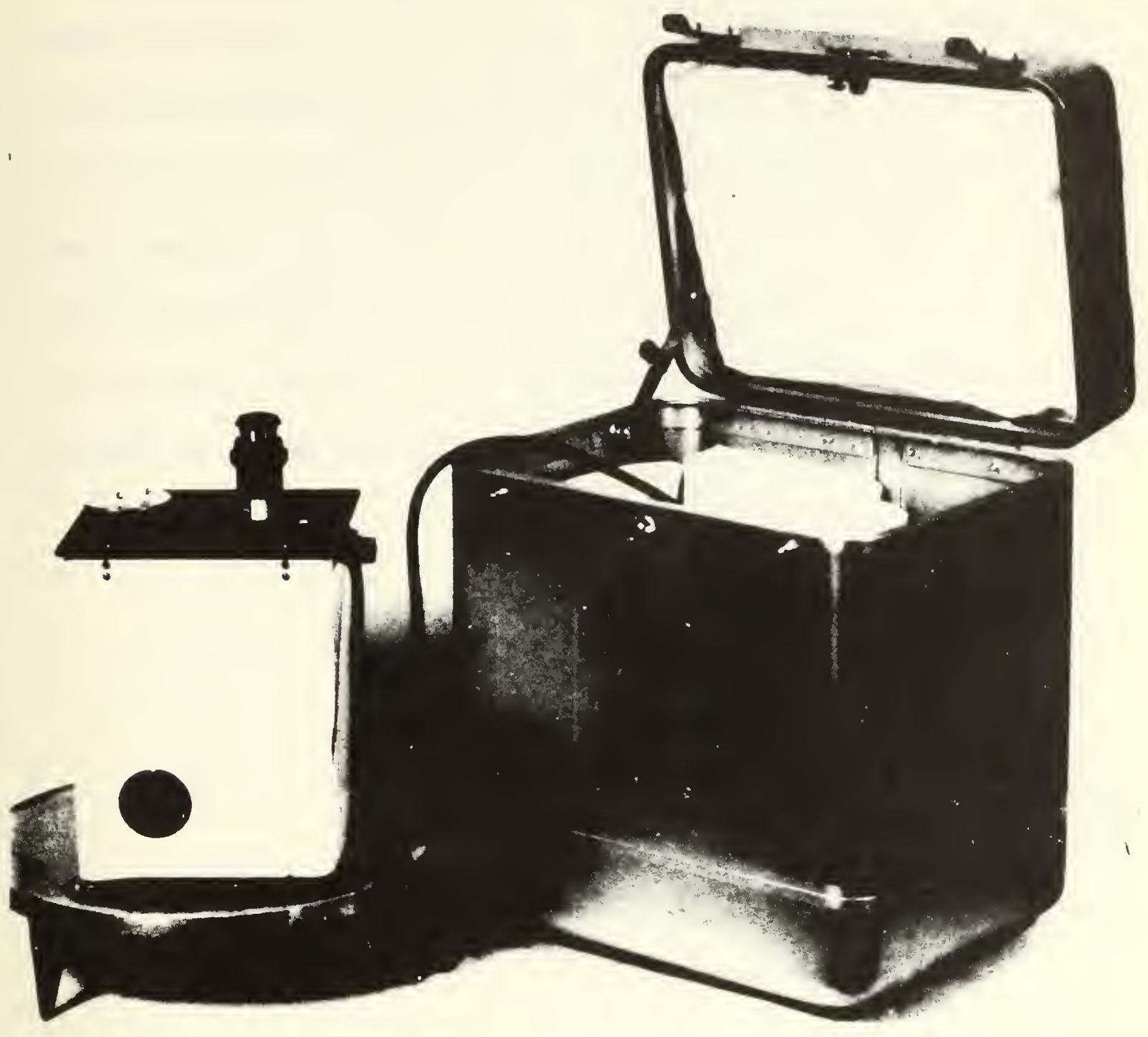

Figure 13. LaCoste and Romberg Model G-08 Geodetic Land Gravimeter 


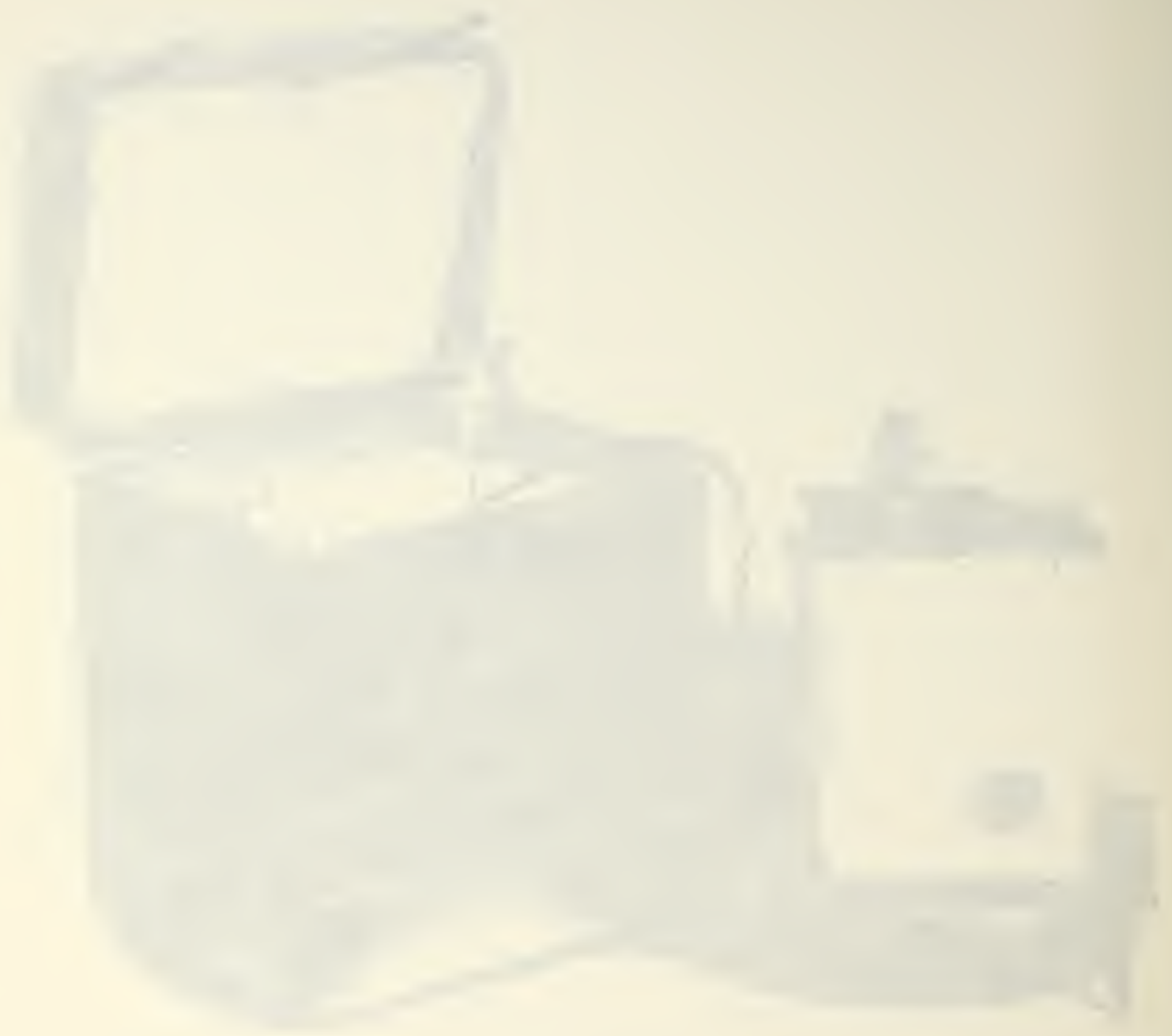


This process was necessary since readings prior to and subsequent to each day's survey were difficult to accurately obtain. Water motion around the Coast Guard pier coupled with the sensitivity of the instrument caused considerable oscillation of the spirit level of the meter and only average values could be obtained. This factor made the determination of any meter drift impossible. Counter readings varied randomly about 3405.63 with a maximum deviation of 0.11 counter units. Therefore, meter drift was not considered measurable and 3405.63 was used as a base reading for all land gravimetry. 



\section{DATA REDUCTION}

The data obtained from both the underwater survey and the coastal survey had to be converted from counter units to milligals. Corrections were then made for elevation, topography, earth curvature, earth tides, and latitude. This process is necessary in order to obtain gravity values which can be compared with measurements obtained at any location on the surface of the earth. These values are used to calculate the CBA. There are intermediate anomalies which may be useful within a particular region but the CBA is the ultimate goal for most surveys, this one included. The following section is devoted to the methods used to obtain it.

\section{A. OBSERVED GRAVITY}

Observed gravity (OG), for the purposes of this paper, is defined as the value of gravity at a given location corrected for earth tide, meter drift, and curvature of the earth.

In order to convert counter readings from the meter to observed gravity, it is first necessary to convert counter readings to equivalent milligal readings. This is done through the use of a conversion table for each individual meter which gives calibration factors for each 100-increment counter reading [LaCoste and Romberg, Inc., 1970]. Since all of the author's counter values fell within the range of 3300 - 

3400 , only the one calibration factor of 1.03985 was required. The next step involves transforming the equivalent milligal reading to an uncorrected observed gravity $\left(\mathrm{OG}_{0}\right)$. In order to do this a base value of absolute gravity and the corresponding counter reading must be known. For the entire survey the absolute gravity at base station WH_29 of $979891.7 \mathrm{mgal}$ [Wollard and Rose, 1963] was used as a reference. The counter reading corresponding to this value was 3323.66 as measured prior to the start of the survey. The above steps can be combined to produce the formula for obtaining uncorrected observed gravity:

$$
\mathrm{OG}_{0}=979891.7+\left(\mathrm{CV}_{0}-3323.66\right)(1.03985) \mathrm{mgal},
$$

where $\mathrm{CV}_{0}$ is the control box counter reading recorded at each station.

It became apparent at the conclusion of one day's work that a tare had occurred at some point during the day. A tare is defined as a sudden jump in the readings between observations. Scrutiny of the data worksheets lead to the conclusion that the tare occurred when the gravity meter struck the A-frame during a heavy roll of the ship. This conclusion was verified when the original data for that day was reduced to CBA values and a sudden jump in the values was noted. Subsequently, the counter reading corresponding to the absolute gravity of WH-29 had to be modified. Measurement at WH-29 resulted in a new value of 3327.67 , a difference of 4.01 units from the original 3323.66. The value of 3327.67 was utilized as the base reading from 

the time when the tare occurred until the conclusion of the survey.

Equation (1) was modified accordingly.

\section{Instrument Drift Correction}

On only one of the 4 days was it possible to obtain meter drift readings. Instrument malfunction on two of the days precluded obtaining a final reading at the ship's mooring location, and the tare, discussed previously, occurred on one of the other days.

Calculation of meter drift (D) is possible when two readings taken at the same location (the ship's mooring location in this case) over a time span are corrected for the variables of earth and ocean tides. On the one day, meter drift was calculated to be $0.07 \mathrm{mgal}$ over a 12 hour period; this value was assumed to be negligible.

To determine the drift over the entire 4 days of the survey, all readings taken at the mooring location were corrected for earth and ocean tides. Between the first and third days, a drift of +0.18 mgal was calculated. However for the interval from the beginning of the third day to the end of the fourth day, the drift was determined to be $-0.19 \mathrm{mgal}$. This resulted in a net $\mathrm{drift}$ of $-0.01 \mathrm{mgal}$ for the 4 day interval. Since the reading precision of the gravity counter on the control box is 0.10 units, it was felt that the non-linear jumps which occurred within the 4 day period were probably a result of reading error. For this reason, coupled with the fact that the 4 day variation was only $-0.01 \mathrm{mgal}$, meter drift corrections were neglected. 



\section{Earth Tide Correction}

Since the earth is a non-rigid body, gravitational forces, primarily as a result of attractional forces from the moon and the sun, act to deform its shape. The adjustment made for this deformation is known as the earth tide correction (ET). The variation is cyclic with a range of $0.3 \mathrm{mgal}$ encompassing the tidal period. All calculation of earth tides were computed using a USGS computer program modified to be compatible with the NPS IBM 360 computer system.

\section{Curvature Correction}

A discussion of the Bouguer correction is found in a later section of this paper. This correction assumes that gravity measurements were taken over a flat surface. This is valid only in those cases where terrain effects on the gravity are computed out to short dis tances. However, for this survey, the large variations in topography necessitated considering the terrain effects as far distant as $167 \mathrm{~km}$ from the station. At these distances it becomes necessary to compensate for the curvature of the earth. The following USGS equation for curvature correction (CC) was utilized:

$$
\begin{aligned}
C C= & -1.376 \times 10^{-4}\left(Z_{-} Z_{t}\right)+3.049 \times 10^{-9}\left(Z_{-} Z_{t}\right)^{2}-1.110 \times 10^{-17} \\
& \left(Z-Z_{t}\right) \mathrm{mgal},
\end{aligned}
$$

where $\mathrm{Z}$ is gravimeter depth in meters (measured positively downward), and $Z_{t}$ is the height of the tide (measured positively upward) relative 

to mean sea level in meters. For ocean bottom stations $(Z>0)$ this correction is negative; for land stations $\left(Z_{-} Z_{t}<0\right)$ the correction is positive.

Observed gravity (OG) then is given by:

$$
O G=O G_{0}+D+E T+C C
$$

\section{B. THEORETICAL GRAVITY}

The reference spheroid utilized for this survey was chosen so as to be compatible with the work of the USGS and the California State Division of Mines and Geology. The constants used for the equation of the ellipsoid were those of the 1930 International Spheroid [Dobrin, 1960]. The formula for the theoretical gravity (GTH) with the constants incorporated is:

$$
\begin{aligned}
\mathrm{GTH}= & 978049.0\left(1+0.0052884 \sin ^{2} L-0.0000059 \sin ^{2} 2 L\right) \\
& \text { mgal, }
\end{aligned}
$$

where $\mathrm{L}$ is the latitude. This formula points out the necessity of accurate navigation since a north-south variation of $1 \mathrm{~km}$ results in a difference in GTH of $0.81 \mathrm{mgal}$.

\section{TOTAL UNDERWATER REDUCTION}

Up to this point the reduction of data for either a land station or an ocean bottom station is similar with the one exception of the sign of the curvature correction (plus for land, minus for underwater). The remainder of the data reduction exhibits some unique differences 

depending upon whether the measurement was made on land or on the ocean bottom. This is particularly true for the terrain correction which not only is the most time consuming, but also the most difficult to fully comprehend.

The majority of the literature dealing with the reduction of gravity data is written from the standpoint of a land reduction. Although this survey involved both land and ocean bottom environments, it was primarily an ocean bottom survey, and the following sections are written from that viewpoint. Land reduction methods a re included in a separate section. Many of the methods and concepts described were derived from a paper by Andrews [1973].

\section{Corrections}

\section{a. Initial Bouguer Correction}

The Bouguer correction assumes that measurements were made on an infinitely flat surface with no regional terrain irregularities. The initial Bouguer correction $\left(B C_{1}\right)$ has the effect of removing the gravitational attraction of the water above the meter and replacing it with air. The 'Bouguer plate' of water above the meter is assumed to be of uniform composition and thickness with infinite length. Its gravitational effect is given by:

$$
\mathrm{BC}_{1}=2 \pi \mathrm{G} \sigma_{\mathrm{w}} \mathrm{Z},
$$

where $G$ is the universal gravitational constant $\left(6.67 \times 10^{-8} \mathrm{~cm}^{3} /\right.$ $\left.\mathrm{g}-\sec ^{2}\right), \quad \sigma_{\mathrm{w}}$ is the density of the water, and $\mathrm{Z}$ is the meter depth. 

For water of density $1.027 \mathrm{gm} / \mathrm{cm}^{3}$ and $\mathrm{Z}$ in meters, equation (5)

reduces to:

$$
\mathrm{BC}_{1}=(0.0430) \mathrm{Z} \text { mgal. }
$$

This correction is positive since the water is attracting the gravimeter mass upward.

\section{b. Free-Air Correction}

The free-air correction (FAC) is the vertical gradient of gravity at MSL as determined in free space multiplied by some change in elevation. The general formula for this correction is:

$$
F A C=2 \operatorname{GM}\left(Z-z_{t}\right) / R^{3},
$$

where $M$ is the mass of the Earth, $R$ is the radius of the Earth, and $\mathrm{Z}_{\mathrm{t}}$ is the tidal height. For an Earth of mass of $5.976 \times 10^{27} \mathrm{gm}$ and radius $6371 \mathrm{~km}$ [MacDonald, 1966] equation (7) reduces to:

$$
F A C=-0.3083\left(Z-Z_{t}\right) \text { mgal, }
$$

where both $Z$ and $Z_{t}$ are in meters. The correction is negative $(Z>0$ for bottom stations) since, in essence, the meter is being positioned further from the center of the Earth. The FAC is the largest single correction to be applied, and from equation (8) it can be seen that accurate measurements of station depth and ocean tides are of prime importance.

A pressure transducer, mounted on the inside of the bottom hemisphere of the gravimeter and with an external opening to the outside, provides an indication of depth in the form of counter units on the 

control box. The counter reading at the sea surface is subtracted from the reading at the bottom, the difference being directly proportional to depth. The proportionality constant is determined at the time of calibration of the pressure sensor unit and was provided by the manufacturer.

Tidal information was based on tidal heights at Carmel Bay with Los Angeles as the reference station [U. S. Department of Commerce, 1973]. The tide tables are based on a reference datum of mean lower low water (MLLW), and in order to relate tidal heights to MSL, it was necessary to determine the difference in height between the two. This value was found to be $0.884 \mathrm{~m}$ (Coast and Geodetic Survey Nautical Chart 5476).

\section{c. Secondary Bouguer Correction}

The gravimeter at this point may be envisioned as being positioned at MSL directly above its original position. The Bouguer plate directly below, originally filled with water, now consists of air. In order to be compatible with land measurements, the Bouguer plate must be filled with rock. The general formula for this secondary Bouguer correction $\left(\mathrm{BC}_{2}\right)$ is:

$$
B C_{2}=2 \pi G \sigma_{r}\left(Z-Z_{t}\right) \text {, }
$$

where $\sigma_{r}$ is the density of the rock. Using a common value of 2.67 $\mathrm{gm} / \mathrm{cm}^{3}$ [Dobrin, 1960] for the density of the crustal rock, equation (9) reduces to: 



$$
\mathrm{BC}_{2}=0.119\left(Z-Z_{t}\right) \text { mgal, }
$$

where $Z$ and $Z_{t}$ are again in meters. This correction is positive since mass is being added beneath the reference ellipsoid.

The initial Bouguer correction $\left(\mathrm{BC}_{1}\right)$, the free-air correction ( FAC), and the secondary Bouguer correction $\left(\mathrm{BC}_{2}\right)$ are often combined to produce the elevation correction (EC) [Nettleton, 1971]:

$$
\mathrm{EC}=\mathrm{BC}_{1}+\mathrm{FAC}+\mathrm{BC}_{2}
$$

Using densities of $\sigma_{\mathrm{w}}=1.027 \mathrm{gm} / \mathrm{cm}^{3}$ and $\sigma_{\mathrm{r}}=2.67 \mathrm{gm} / \mathrm{cm}^{3}$, equations (6), (8), and (10) combine and reduce to:

$$
\mathrm{EC}=\left(0.1964 \mathrm{Z}_{\mathrm{t}}-0.1534 \mathrm{Z}\right) \mathrm{mgal},
$$

where $Z_{\text {and }} Z_{t}$ are in meters. Figure 14 illustrates the corrections necessary to determine EC.

\section{d. Terrain Correction}

In applying the preceding corrections it was assumed that gravity measurements were made on an infinitely flat bottom with an overlying Bouguer plate of uniform composition and thickness and infinite length. Regional terrain irregularities were neglected. This assumption may be valid at some location such as certain areas of the continental shelf in the northern Gulf of Mexico. However, it does not hold true in the area between Pt. Lobos and Pt. Sur where the continental shelf is transected by deep submarine canyons to the north, south, and west, and where, to the east, the Santa Lucia Range rises abruptly. Therefore, a topographic or terrain correction (TC) is necessary. 



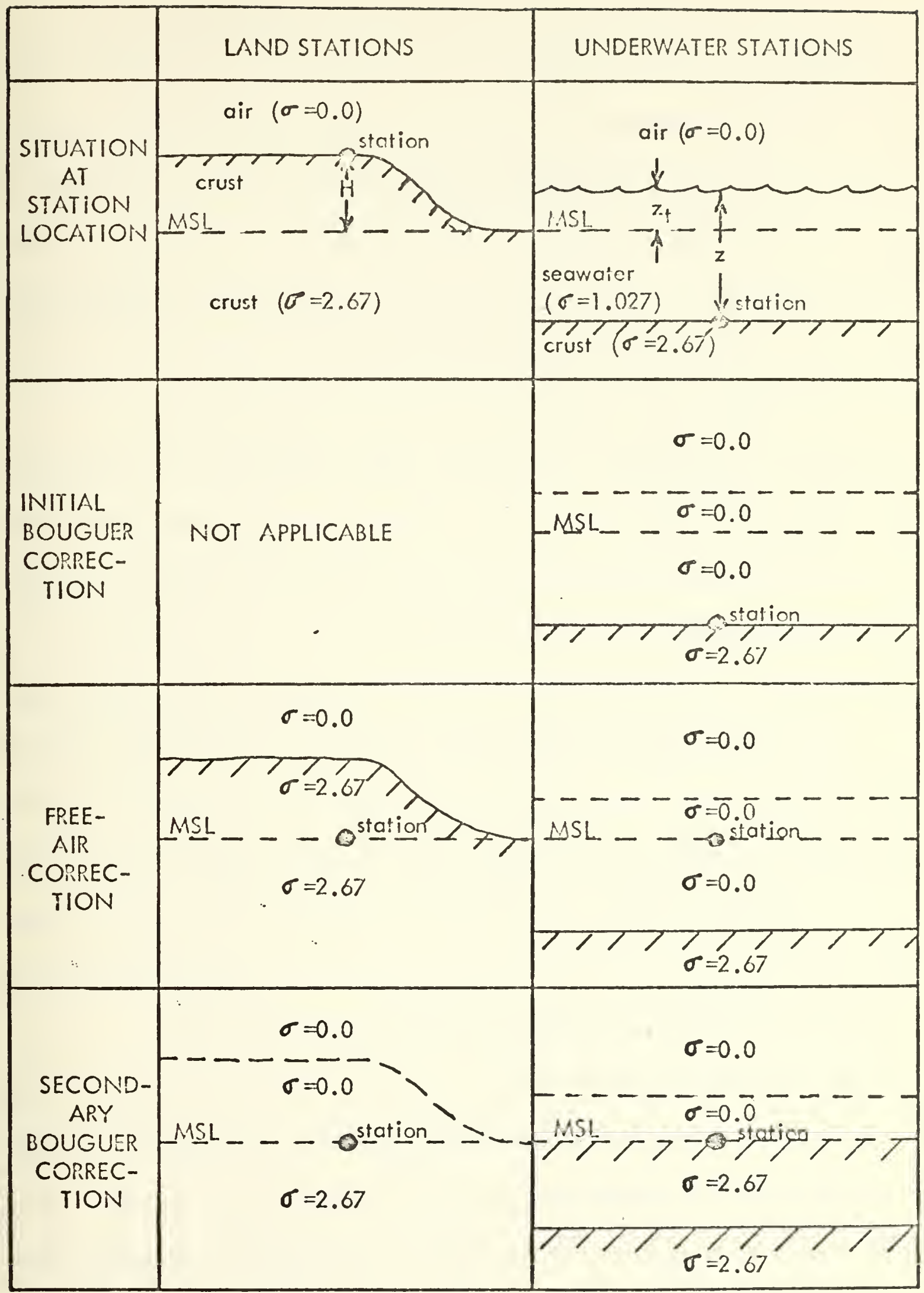

Figure 14. Schematic Representation of the Steps Necessary to Compute the Elevation Correction ( $\sigma=$ density in grams per cubic centimeters) 

The effects of the terrain correction can be visualized in either of two ways. The first stems from the fact that the assumption of a flat, infinite Bouguer plate was made requiring that the Bouguer correction be modified to fit the regional topography in the form of the terrain correction. The second way is to reduce the topography to a flat bottom prior to any other correction. This second method seems to be the more logical and was the one followed by the author.

All mass above the horizontal plane of the meter due to topographic or bathymetric relief introduces, at the meter, a vertical component of gravitational attraction in the upward direction. Likewise, an absence of mass below the meter has the same effect. Thus, removing the mass above the meter elevation and filling in the voids below the meter elevation will have an additive effect on the observed gravity. Since some of the mass surrounding the station level is immersed in water (or both water and air when in proximity to the shoreline), and since the voids below the station level are filled with water, modifications of the gravitational attraction, as found in tables, becomes necessary.

The terrain correction is normally calculated by employing a circular graticule or template divided into zones with each zone further divided into a number of compartments. of varying dimensions. The center of the graticule is placed over the station on a chart displaying topographic or bathymetric relief, and the average elevation or 

depth relative to station level is visually estimated for each compartment. It is then possible through use of tables of weighting factors for each compartment to determine the vertical component of the gravitational attraction of each compartment at the station by summing the values in all of the compartments. The result is the terrain correction for the individual station.

For the survey, a total of 15 zones ( $A$ through O) out to a radian distance of $166.7 \mathrm{~km}$ were utilized. This distance necessitated the use of four separate graticules to fit four different scale charts (1:24,000; $1: 40,000 ; 1: 210,663 ; 1: 820,000)$. The tables us ed to determine the attraction of each compartment were obtained from USGS and are based on the original Hayford and Bowie [1912] tables with the modifications of Bullard [1936] and Swick [1942].

Bottom gravity stations require, once the average elevation or depth for each compartment has been determined, that the tables be modified. The first step requires filling in the voids below the station with rock (Fig. 15, AREA A). However, the rock would be displacing the water that already exists there, so an adjustment to the tables (which assume a $2.67 \mathrm{gm} / \mathrm{cm}^{3}$ density for the compartments) is necessary. Taking the density of the water as $1.027 \mathrm{gm} / \mathrm{cm}^{3}$ this modification is in the form of a multiplication factor as given by:

$$
\frac{\sigma_{r}-\sigma_{W}}{\sigma_{r}}=\frac{2.67-1.027}{2.67}=0.615
$$





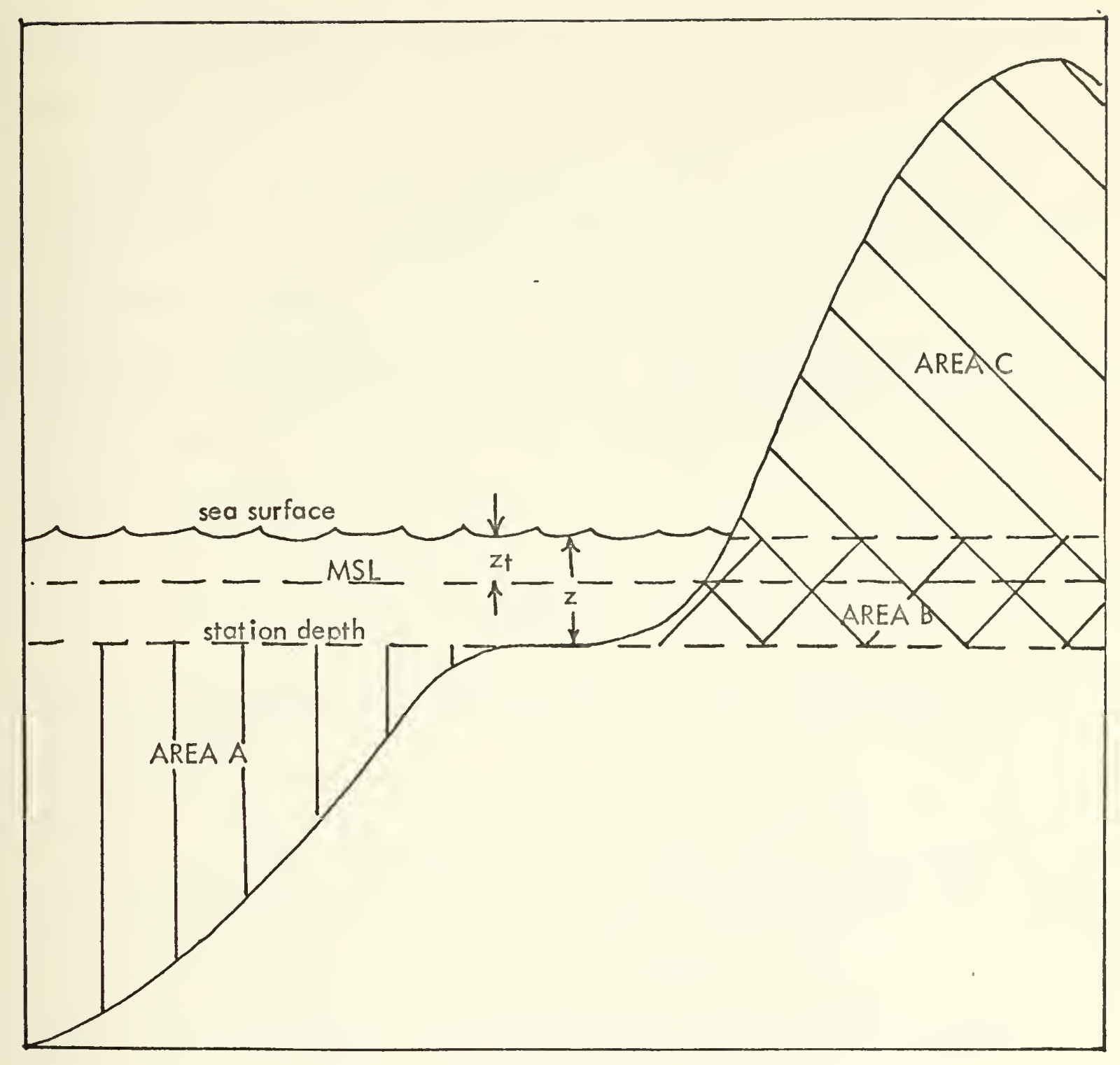

Figure 15. Schematic Diagram Showing Areas Involved in Terrain Corrections for Ocean Bottom Stations 

The second step requires removing the material above station elevation (AREA $B$ and $C$ ). The density of the rock is again assumed to be $2.67 \mathrm{gm} / \mathrm{cm}^{3}$, and as this is the density upon which the tables are based, no correction is required. However, AREA B is now filled with air whereas the infinite Bouguer plate calls for water. It is therefore necessary to refill this area with water. Assuming a density for water of $1.027 \mathrm{gm} / \mathrm{cm}^{3}$, the modification to the tables is the multiplication factor:

$$
\frac{\sigma_{\mathrm{w}}}{\sigma_{\mathrm{r}}}=\frac{1.027}{2.67}=0.385 \text {. }
$$

This adjustment must be subtracted as mass is being added to an area above the meter.

If a compartment located within AREA B is underwater (i. e., on the continental shelf), it has been determined that the terrain correction is probably unnecessary for a bottom slope of $3^{\circ}$ or less [Grant and West, 1965]. This proved to be the case in the author's a rea where the shelf slope is $1.5^{\circ}$ or less over $90 \%$ of the area [Dohrewend, 1971]. For example, for a station at a depth of $61 \mathrm{~m}$ below MSL and a compartment in zone $\mathrm{H}$ (outer radius $5.2 \mathrm{~km}$, inner radius $3.5 \mathrm{~km}$ ) with an average elevation of $300 \mathrm{~m}$ above MSL, an error of $0.0019 \mathrm{mgal}$ for that particular compartment would be introduced. Although this portrays an average situation, it is the author's opinion that the determination of average compartment 

elevation/depth introduces a far larger error. This belief is substantiated by Brooks [1973] who assumed an error of \pm 0.02 mgal per zone, with a total terrain correction error of $\pm 0.30 \mathrm{mgal}$ for a survey area having relatively flat topography. Between Pt. Lobos and Pt. Sur, an area where relief is substantially greater, a more realistic value of $\pm 0.5 \mathrm{mgal}$ per terrain correction should be utilized. For this survey, application of equation (14) was neglected. The corrections as calculated for each station are listed in Appendix A.

\section{Gravity Anomalies}

The departure of a corrected gravity value from the theoretical value of gravity at a given location is defined as a gravity anomaly. The type of the anomaly depends on the corrections that have been applied to the observed gravity. Using the corrections obtained thus far, it is now possible to calculate the various intermediate gravity a nomalies, and finally, the complete Bouguer anomaly.

\section{a. Free-Air Anomaly}

Application of the free-air correction (FAC) to observed gravity results in the free-air anomaly (FAA). In essence, this a nomaly brings all observed gravity readings to the level of the reference ellipsoid (MSL), at the same time neglecting the effects of both the surrounding topography and the material within the Bouguer plate. The free-air a nomaly is defined as:

$$
F A A=O G+F A C-G T H
$$



b. Simple Bouguer Anomaly

Application of the elevation correction from equation (11)

to observed gravity results in the simple Bouguer anomaly $\left(S B A_{1}\right)$ :

$$
\mathrm{SBA}=\mathrm{OG}+\mathrm{EC}-\mathrm{GTH} .
$$

The SBA can be viewed as a modification to the FAA with the inclusion of the effects of the Bouguer plate on observed gravity:

$$
\mathrm{SBA}=\mathrm{FAA}+\mathrm{BC}_{1}+\mathrm{BC}_{2} .
$$

In areas where the topography is relatively flat and uniform, the SBA is adequate for gravity survey correlations.

\section{c. Complete Bouguer Anomaly}

Inclusion of the terrain correction (TC) to the SBA yields the complete Bouguer anomaly (CBA). This anomaly considers all corrections to observed gravity and may be used to correlate separate gravity surveys from other locations. The plotted isolines of CBA, used in conjunction with magnetic data, seismic data, and any other available geological data, are a tool whereby density variations and non-conformities in the near surface structure can be inferred. The complete Bouguer anomaly is given by:

$$
\mathrm{CBA}=\mathrm{OG}+\mathrm{EC}+\mathrm{TC}-\mathrm{GTH},
$$

or from the simple Bouguer anomaly:

$$
\mathrm{CBA}=\mathrm{SBA}+\mathrm{TC} \quad \text {. }
$$

A listing of the various gravity anomalies for each station can be found in Appendix B. 

D. PARTIAL UNDERWATER REDUCTION TO COMPARE WITH SEA_SURFACE GRAVIMETRY

At times it is convenient to compare ocean bottom gravity measurements with those taken on the surface using a sea surface gravimeter. This can be done in conjunction with a sea-surface survey to check the accuracy of the surface values since they are subject to errors resulting from the accelerations of the surface vessel caused by sea and swell.

\section{Elevation Correction}

The concepts involved in the computation of this elevation correction ( $E C^{\prime}$ ) are similar to the ones used in obtaining the elevation correction in equation (11) for underwater reduction, except that the last step involves replacing the air contained in the Bouguer plate with water rather than rock. The elevation correction for an ocean bottom station when it is to be compared with a sea surface station directly above at MSL is:

$$
\mathrm{EC} C^{\prime}=\mathrm{BC}_{1}+\mathrm{FAC}+\mathrm{BC}_{3},
$$

where

$$
\mathrm{BC}_{3}=2 \pi \mathrm{G} \sigma_{\mathrm{w}}\left(\mathrm{Z}-\mathrm{Z}_{\mathrm{t}}\right) .
$$

Using $1.027 \mathrm{gm} / \mathrm{cm}^{3}$ for the density of water, equation (21) reduces to:

$$
\mathrm{BC}_{3}=0.0430\left(\mathrm{Z}-\mathrm{Z}_{\mathrm{t}}\right) \mathrm{mgal},
$$

where $\mathrm{Z}$ and $\mathrm{Z}_{\mathrm{t}}$ are in meters. Substitution of equations (6), (8), and (22) yield: 



$$
E C^{\prime}=\left(0.2653 Z_{t}-0.2223 Z\right) \mathrm{mgal},
$$

where $\mathrm{Z}$ and $\mathrm{Z}_{\mathrm{t}}$ are in meters.

The above effectively places the meter at MSL.

\section{Mass-Adjusted Free-Air Anomaly}

The mass-adjusted free-air anomaly (MFAA) is analogous to the simple Bouguer anomaly of equation (16), and is perhaps a mis nomer since a more appropriate term would seem to be 'mass-adjusted simple Bouguer anomaly'. Contours of the MFAA again allow correlation of an ocean bottom survey with a sea surface survey. The simple formula for the MFAA is:

$$
M F A A=O G+E C^{\prime}-G T H,
$$

or as a modification to the FAA:

$$
\mathrm{MFAA}=\mathrm{FAA}+\mathrm{BC}_{1}+\mathrm{BC}_{3}
$$

Values of MFAA for each station are listed in Appendix B.

\section{E. LAND REDUCTION}

The reduction of land stations is, for the most part, a simplification of that for underwater stations. Observed gravity is obtained in a similar manner but with a different base station counter reading and different calibration factors. Theoretical gravity is identical as it is a function of latitude alone.

\section{Corrections}

\section{a. Bouguer Correction}

The Bouguer correction (BC) for land stations effectively removes the mass between station elevation and the surface of the 

reference ellipsoid (MSL) (i.e., the mass contained in the Bouguer plate). The general formula for this correction is:

$$
\mathrm{BC}=-2 \pi \mathrm{G} \quad \sigma_{\mathrm{r}} \mathrm{H} \quad,
$$

where is the density of the rock being removed and $h$ is the station elevation. ( $\mathrm{h} \geq 0)$ Using a density of $2.67 \mathrm{gm} / \mathrm{cm}^{3}$, equation (26) reduces to:

$$
\mathrm{BC}=-0.1119 \mathrm{~h} \text { mgal, }
$$

where $\mathrm{h}$ is in meters. This correction is now negative since it removes mass below the meter.

b. Free-Air Correction

The free-air correction repositions the gravimeter from station elevation to MSL. Modification of equation (8), the free-air correction for underwater stations, gives the correction:

$$
\mathrm{FAC}=0.3083 \mathrm{~h} \text { mgal, }
$$

where $\mathrm{h}$ is in meters. This correction is now positive since the meter is being repositioned closer to the center of the earth.

Combining equations (27) and (28) produces the elevation correction for land stations:

$$
\mathrm{EC}=0.1964 \mathrm{~h} \quad \mathrm{mgal},
$$

where $\mathrm{h}$ is in meters.

\section{c. Terrain Correction}

As in the terrain correction (TC) for underwater stations, for land stations the concept is to reduce the surrounding topography 

to produce a flat, infinite surface on the same horizontal plane as the station.

For compartments which overlie land alone, the modified Hayford-Bowie tables can be used intact. This correction is positive. For compartments which overlie water, it is necessary to modify the correction due to existing density differentials. Calculation of the attraction of each compartment involves two steps. First, it is necessary to fill in the depression between station level and the ocean bottom with rock. This correction is positive. However, after this is carried out, a portion of the rock will have displaced a wedge of water from MSL to the bottom; the previous correction will have been too large. The next step requires removing the effect of this displaced water. Assuming a density for water of $1.027 \mathrm{gm} / \mathrm{cm}^{3}$, the modification to the tables is again in the form of a constant multiplication factor:

$$
\frac{\sigma_{\mathrm{w}}}{\sigma_{\mathrm{r}}}=\frac{1.027}{2.67}=0.385 \text {. }
$$

This correction must be subtracted as the attraction of the water below station elevation is being removed.

In actual practice, since some of the land stations were relatively close to MSL, and the depth of the ocean water within the compartment was far greater (especially in the outer zones) than the station elevation, the following multiplication factor was applied to the values read from the tables, assuming standard densities: 



$$
\frac{\sigma_{\mathrm{r}}-\sigma_{\mathrm{w}}}{\sigma_{\mathrm{w}}}=\frac{2.67-1.027}{2.67}=0.615 \text {. }
$$

The error introduced using this simplication results from the assumption that a small wedge of water extends from MSL to station elevation when, in fact, it is actually air. This error was determined to be negligible. For stations of high elevation and for compartments in shallow waters, equation (30) was utilized.

\section{Gravity Anomalies}

Employing the correct signs land station gravity anomalies are calculated from equations (15), (16), and (18), using equations (28) and (29) to determine FAC and EC. 



\section{DATA PRESENTATION AND ANALYSIS}

The procedures and discussion thus far have dealt primarily with obtaining and reducing of gravity values. The interpretation of results in terms of the geologic structure below the surface, a more qualitative analysis, is discussed in this section.

\section{A. GENERAL DISCUSSION}

The CBA gravity values were plotted on a USGS topographic map of the area (scale $1: 24,000)$ and CBA isolines were drawn by hand at a 2 mgal interval. The decision to adopt a 2 mgal interval was based upon a desire to depict the greatest detail while still maintaining the general trend. Transference and reduction of the gravity map on the topographic chart to a larger scale map was accomplished through the use of a pantograph on a $3 / 16$-scale reduction. This proved to be satisfactory in maintaining the detail and the general trends of the gravity map (Fig. 16).

The accuracy of this map is dependent upon two factors: (1) the accuracy of the CBA values themselves, and (2) the contouring of the gravity field in the construction of the isoline pattern. From former surveys utilizing the HG6 Model gravimeter [Brooks, 1973; Cronyn, 1973; Souto, 1973] and from the author's own analysis, the accuracy in determination of $\mathrm{CBA}$ values is $\pm 1.04 \mathrm{mgal}$ for sea stations and 



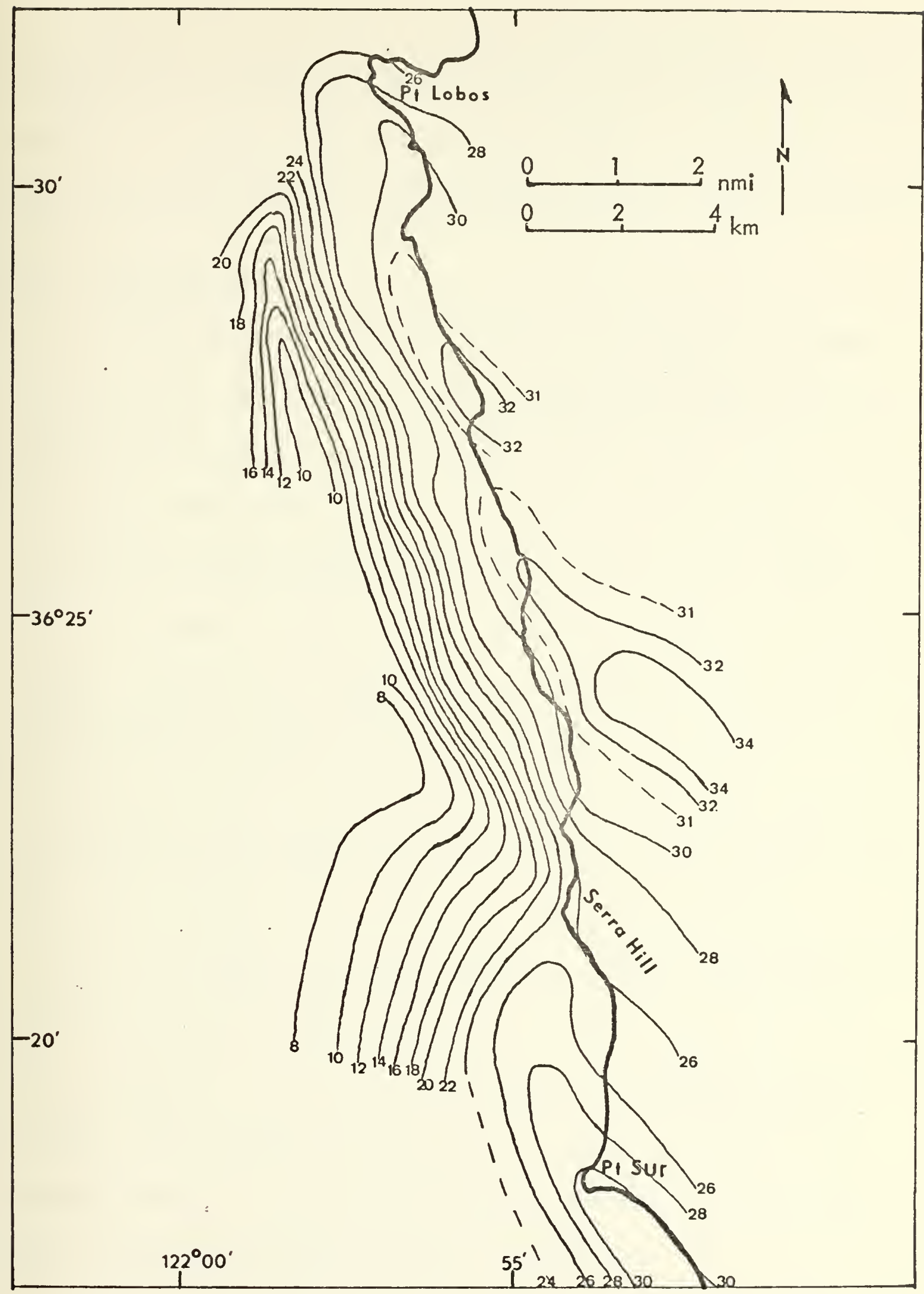

Figure 16. CBA Distribution for the Continental Shelf and Adjacent Coastline Between Pt. Lobos and Pt. Sur (values in milligals, contour interval $2 \mathrm{mgal}$ ) 

t0. $72 \mathrm{mgal}$ for land stations. Table II delineates possible error sources and the reduction step to which they relate. The contouring of the isolines is the author's interpretation of the 'best fit' of the gravity values and is therefore subject to error since the process is partly subjective.

\section{B. CBA ANALYSIS}

Assuming that the effects of elevation, topography, and latitude have been correctly removed, the anomalies in the map of the gravity field are caused by horizontal variations of the density within the crust and upper mantle of the earth. The magnitude of the anomaly is dependent upon the density contrasts, the location of the contrast relative to the gravity station, and the form or sharpness of the geologic discontinuity. If there is no density contrast, no anomaly will exist. The interpretation of a CBA map in terms of subsurface geologic structure is not unique from utilization of gravity data alone. Other sources of information such as seismic data, drill core data, or specific geologic data from outcrops must be available. From this information density values can be inferred and actual depths to a density contrast can be obtained and subsequently related to the subsurface structure of the surrounding area. The degree of uniqueness is dependent upon the validity of the accepted geological data. In the case of this survey specific geological data was not available; therefore, it was necessary, when making a final analysis, to generalize. 



\begin{tabular}{|c|c|c|c|}
\hline $\begin{array}{l}\text { INITIAL } \\
\text { ERROR } \\
\text { SOURCE }\end{array}$ & $\begin{array}{l}\text { DATA } \\
\text { REDUCTION } \\
\text { STEP }\end{array}$ & $\begin{array}{c}\text { ERROR IN } \\
\text { COASTAL } \\
\text { SURVEY } \\
\text { (Land Gravimetry }\end{array}$ & $\begin{array}{c}\text { ERROR IN } \\
\text { CONTINENTAL } \\
\text { SHELF SURVEY } \\
\text { (Bottom } \\
\text { Gravimetry) }\end{array}$ \\
\hline $\begin{array}{l}\text { GRAVIMETER } \\
\text { ACCURACY }\end{array}$ & $\begin{array}{l}\text { OBSERVED } \\
\text { GRAVITY }\end{array}$ & \pm 0.04 & \pm 0.10 \\
\hline $\begin{array}{l}\text { OPERATOR } \\
\text { READING } \\
\text { ACCURACY }\end{array}$ & $\begin{array}{l}\text { OBSERVED } \\
\text { GRAVITY }\end{array}$ & \pm 0.01 & \pm 0.10 \\
\hline NAVIGATION & $\begin{array}{l}\text { THEORETICAL } \\
\text { GRAVITY }\end{array}$ & \pm 0.05 & \pm 0.14 \\
\hline $\begin{array}{l}\text { ELEVATION/ } \\
\text { DEPTH } \\
\text { CALCULATIONS }\end{array}$ & $\begin{array}{c}\text { FREE_AIR } \\
\text { AND } \\
\text { BOUGUER } \\
\text { CORRECTIONS }\end{array}$ & \pm 0.12 & \pm 0.20 \\
\hline $\begin{array}{c}\text { ELEVATION / } \\
\text { DEPTH } \\
\text { CALCULATIONS }\end{array}$ & $\begin{array}{c}\text { TERRAIN } \\
\text { CORRECTION }\end{array}$ & \pm 0.50 & \pm 0.50 \\
\hline TOTAL & $\begin{array}{l}\text { COMPLETE } \\
\text { BOUGUER } \\
\text { ANOMALY }\end{array}$ & \pm 0.72 & \pm 1.04 \\
\hline
\end{tabular}

TABLE II.

POSSIBLE ERRORS IN COMPLETE BOUGUER ANOMALY CALCULATION (Values in Milligals) 

The CBA values along the California coast usually do not range far from a value of about 0 mgal. They decrease eastward to high negative values of $-200 \mathrm{mgal}$ or les in the vicinity of the Sierra Nevada and Great Basin provinces [Chapman, 1966]. From a gravity profile analysis conducted by Thompson and Talwani [1964] for a cross-section approximately $160 \mathrm{~km}$ to the northwest of the survey area, the regional trend of the gravity anomaly along the profile from the Pacific Basin to the continental shelf is highly negative, going from approximately $250 \mathrm{mgal}$ to less than $50 \mathrm{mgal}$. Thomps on and Talwani relate this strong negative gradient to an increase in thickness of the crust as the continental margin is approached. Although this particular profile was to the north of the author's area of interest, the regional trend which it exhibits could be expected to be similar to the one within the study area. However, from the author's CBA map, the trend of the gravity anomaly is opposite, showing a strong positive west to east gradient. This apparent contradiction can be related to local anomalies and is believed to be caused, at least in part, by a rapid rise of the granitic basement just offshore from Pt. Lobos to Pt. Sur. From the CBA map partially closed gravity highs are evident in the vicinity of Soberanes Pt., Kaslar Pt., and Pt. Sur (location of these points is shown in Fig. 2). These highs are generally oriented northwest-southeast and are congruent with the trend of the local geology. They may represent granitic outcroppings, particularly the 

most northern high which parallels the geographic trend of Pt. Lobos. An alternative explanation is that these highs may be associated with the fault zones which transect the area. This is especially true for the $34 \mathrm{mgal}$ high at Kaslar Pt., the axis of which is nearly parallel to the Palo Colorado fault. The position of this high coincides with the 30 mgal high plotted on the Santa Cruz Sheet of Bishop and Chapman [1967]. The $30 \mathrm{mgal}$ high at Pt. Sur exhibits generally lower gravity values within the semi-closed isoline system in comparison to the other highs and is possibly an indication of the lower density Franciscan assemblage which is reported to exist in this area on the southwest side of the Sur-Nacimiento fault zone.

Offshore of Hurricane Pt. a definite ridging of the isolines is evident. The orientation of the isolines to the north of this ridge is northwest-southeast while to the south they exhibit a northeast-southwest trend. The location of this ridge coincides with the offshore extension of the Serra Hill fault as reported by Greene et al. [1973] (Fig. 4). Judging from the gravity data alone, no further faulting occurs between this ridge south to Pt. Sur. Since it is generally accepted that the Sur-Nacimiento fault zone leaves the coast north of Pt. Sur, the structure associated with this gravity ridge may be related to its offshore extension. The conclusion that this isoline configuration is the reflection of a fault is supported by both the gradient and the orientation of the isolines which appear to indicate 

either strike-slip or dip-slip motion where the southwestern side has descended relative to the northeastern side. Gilbert [1971] states that the fault which leaves the coast near Hurricane Pt. has a dip $50-60^{\circ} \mathrm{NE}$ with an estimated $300 \mathrm{~m}$ vertical displacement. This would call for a normal fault where the Sur-Nacimiento fault zone is usually associated with thrusting. Page [1970] contends that the formation and movements of the Sur fault are more complex and that it cannot be described as a simple thrust fault. Other mechanisms must be introduced to understand its present state. He contends that thrust faulting was only the initial stage in its development. Subsequent normal faulting is believed to have occurred as a result of the collision of the East Pacific Rise crest and the westward moving North American Continent. Possible strike-slip motion followed when Pacific spreading became oriented to a northwest-southeast direction. This occurred at approximately the same time that the San Andreas fault became active. Further evidence for strike-slip motion can be obtained from an examination of the bathymetry in the Pt. Sur area (Fig. 1). The continental shelf is at its widest at a point almost due west of Pt. Sur. The ridging of the depth contours could have been influenced by compressional forces that existed when the oceanic crust came into contact with the Salinian Block, or it could be viewed as an elongation associated with right-lateral strike-slip motion where the southwestern block has moved northwesterly in relation to the northeastern block. 

From the CBA map it is seen that the Hurricane Pt. ridging abruptly terminates as the coastline is reached. No explanation can be put forth as to why this is so. Serra Hill rises sharply at this point and gravity measurements were taken only along its western edge. More data are needed in this area, particularly along the eastern side and top of Serra Hill.

Southwest of $\mathrm{Pt}$. Lobos there is strong evidence from the gravity field of a partially closed $10 \mathrm{mgal}$ low. The gradient to the east of this low is very steep, attaining maximum values of $12-13 \mathrm{mgal} / \mathrm{km}$. This is a strong indication of a rapid rise in the basement, most probably associated with faulting. The direction of ridging of the isolines to the north and orientation of the partial low can be projected into the western tributary of the Carmel Canyon. The form of the 10 through $20 \mathrm{mgal}$ isolines to the west of this low is unknown beyond the limits shown on the map. It is possible that these isolines continue south and connect with the open isolines west of Pt. Sur. If this is the case, a large low of 8 mgal or less would result. Insufficient data precluded projection of the open isolines.

Just to the east of the 10 mgal low and coincident with its orientation, the extension of either the Palo Colorado fault zone [Dohrewend, 1971] or the Sur fault zone [Greene et al., 1973] leads into the western tributary of the Carmel Canyon. Dohrewend obtained PDR traces of a fault scarp extending for $6 \mathrm{~km}$ of approximate $20 \mathrm{~m}$ relief at a 

depth of 82-101 m. He correlates this scarp with the offshore extension of the Palo Colorado fault and projects it onshore just north of Kaslar Pt. (Fig. 5). A bathymetric profile survey was conducted from the ACANIA in an attempt to substantiate the location of this fault scarp. Profile locations and the plotted position of the fault scarp are shown in Fig. 17. The profiles a re reproduced in Fig. 18-23. An attempt to locate the position of the scarp south of profile A-A' was unsuccessful and lack of time prevented a more thorough search. The fault scarp is easily recognizable in profiles $A_{-} A^{\prime}, B_{-} B^{\prime}$, and $D_{-} D^{\prime}$. In profiles $F_{-} F^{\prime}$ and $H_{-} H^{\prime}$ the original scarp has trended into the western tributary of the Carmel Canyon while a new scarp emerges on the shoreward side of profile $F-F^{\prime}$. This scarp is barely recognizable in profile $\mathrm{H}_{-} \mathrm{H}^{\prime}$ as it leads into the eastern tributary of the Carmel Canyon. In both profiles granitic outcroppings are evident between the two canyons.

\section{TWO DIMENSIONAL PROFILES}

The evidence of faults leading into the tributaries of the Carmel Canyon lead to the construction of three separate two-dimensional modeling profiles, the locations of which are shown in Fig. 24. It was hoped that the depth to the basement could be determined. The computer program used in this effort, based on an earlier model by Talwani, was developed by Cady [1972] of the USGS. The model requires that the regional trend be filtered out of the total gravity 



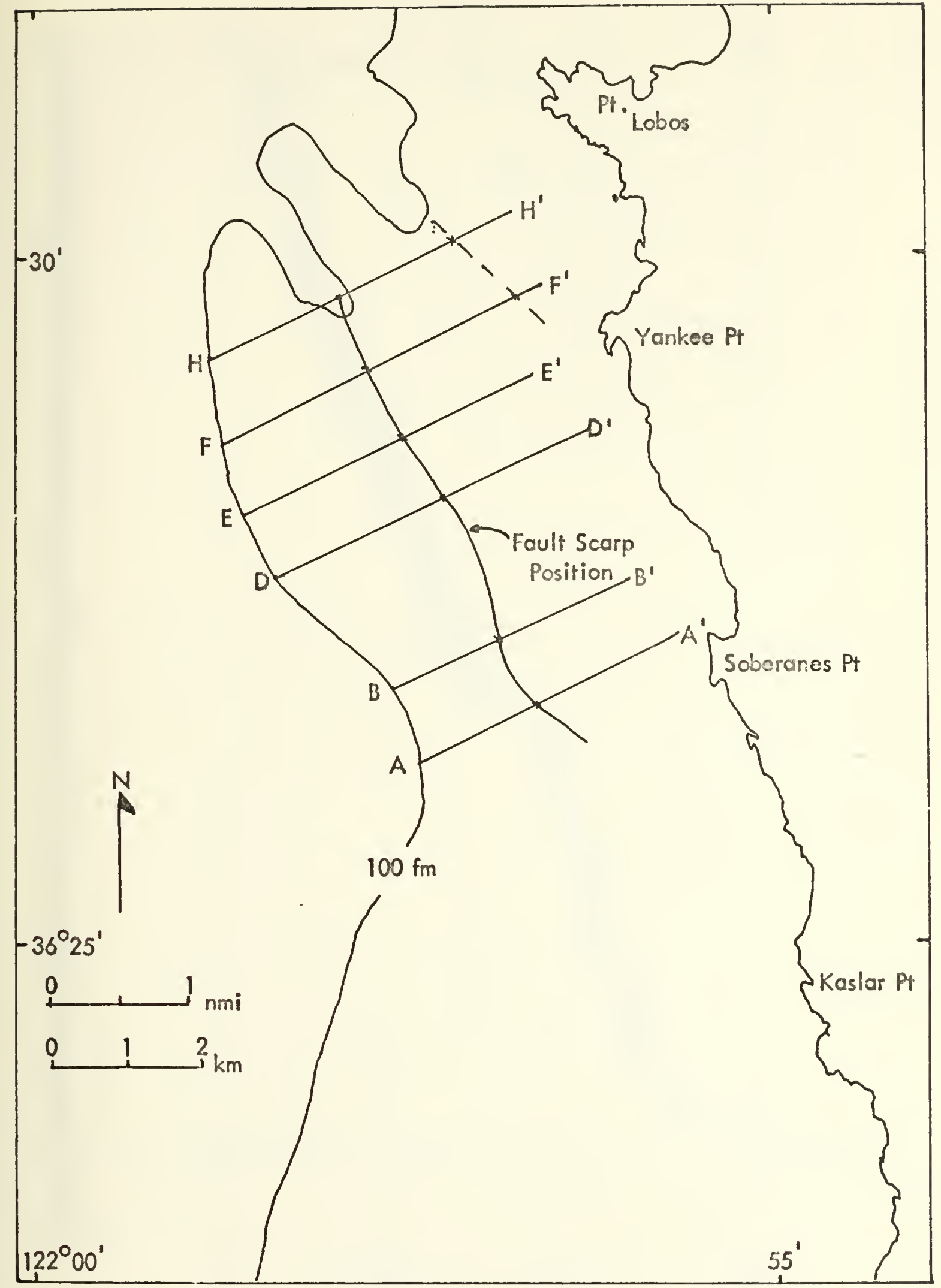

Figure 17. PDR Profile Locations and Fault Scarp Position from a Bathymetric Study 



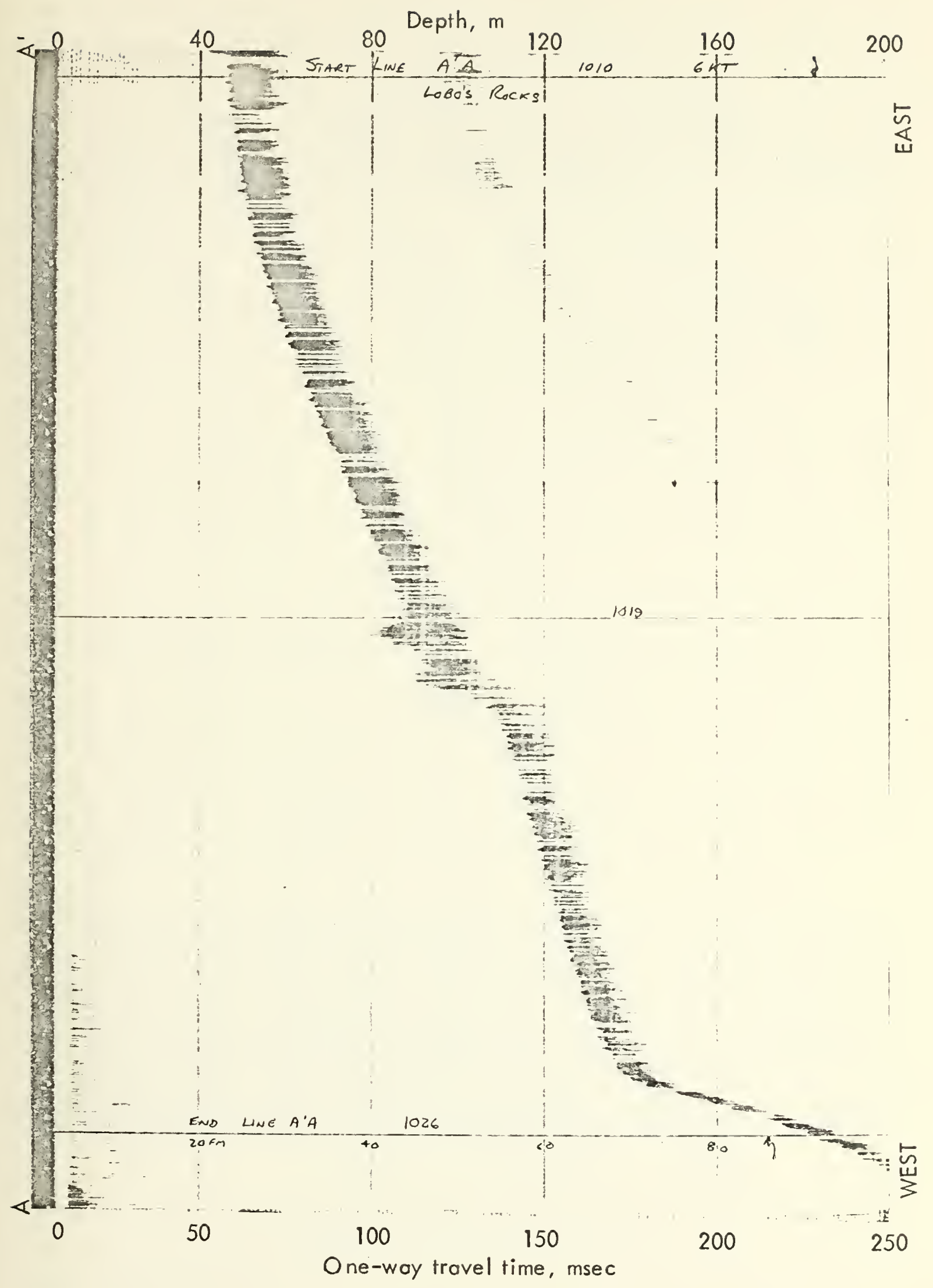

Figure 18. PDR Profile A-A' 



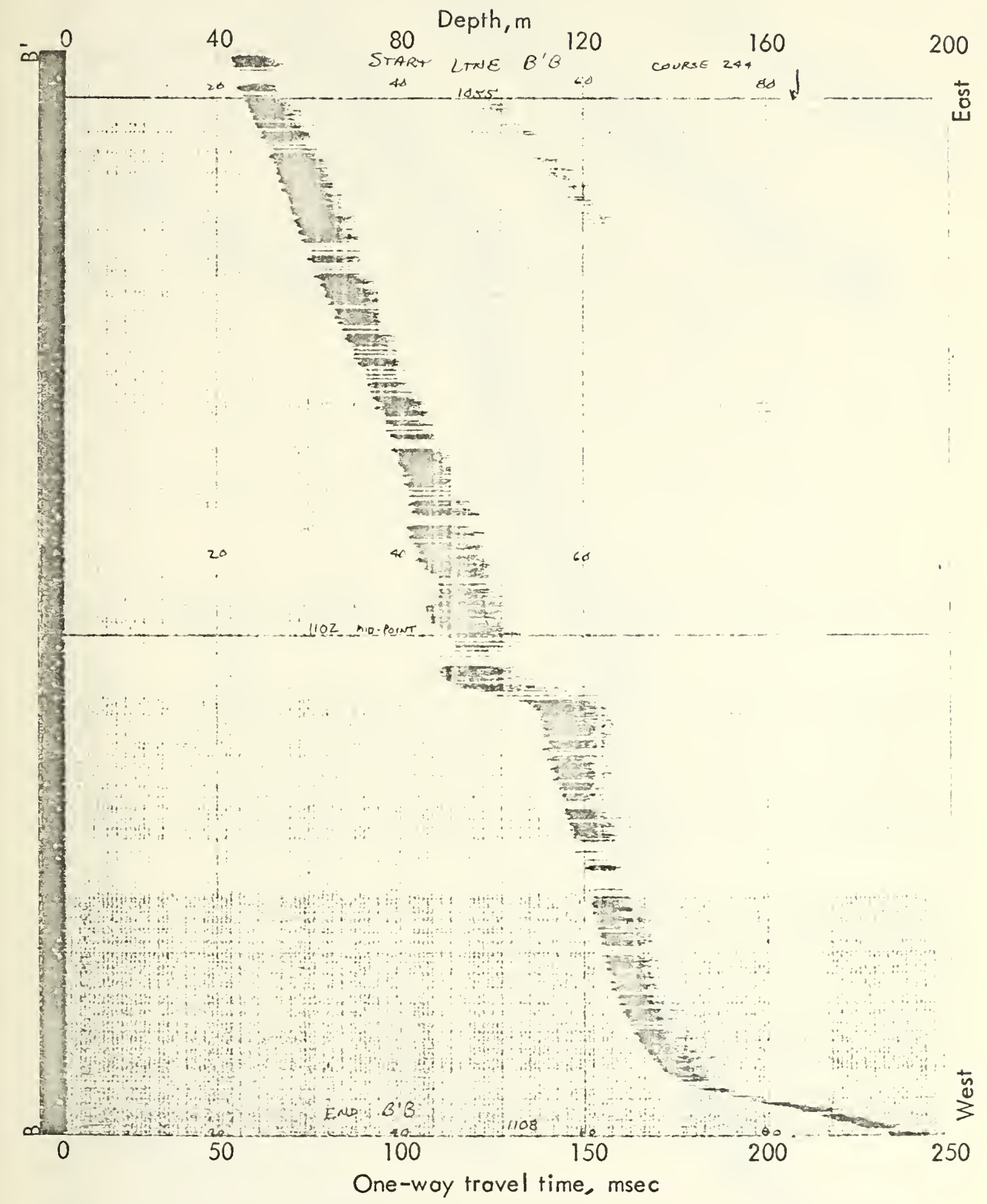

Figure 19. PDR Profile B-B' 



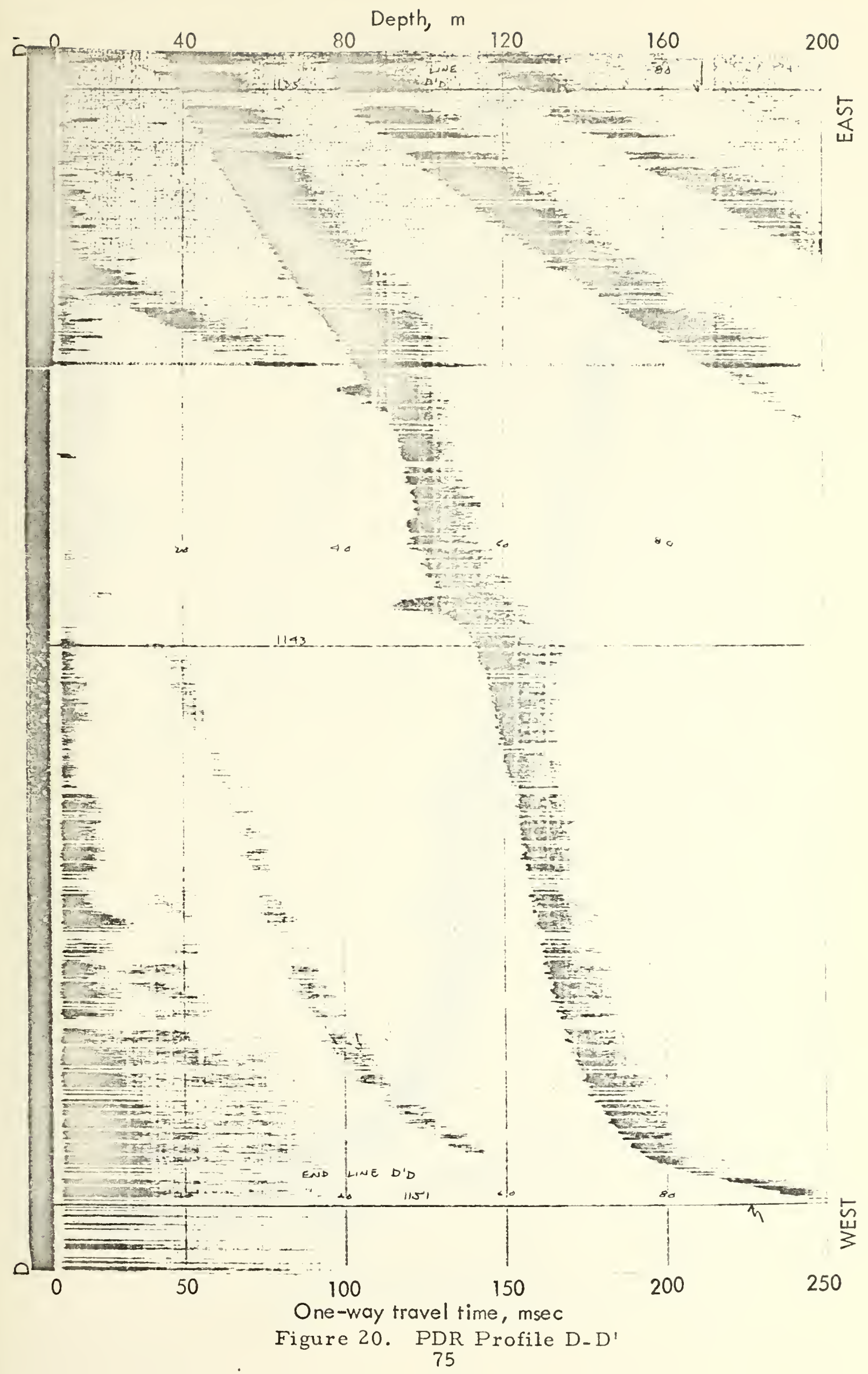





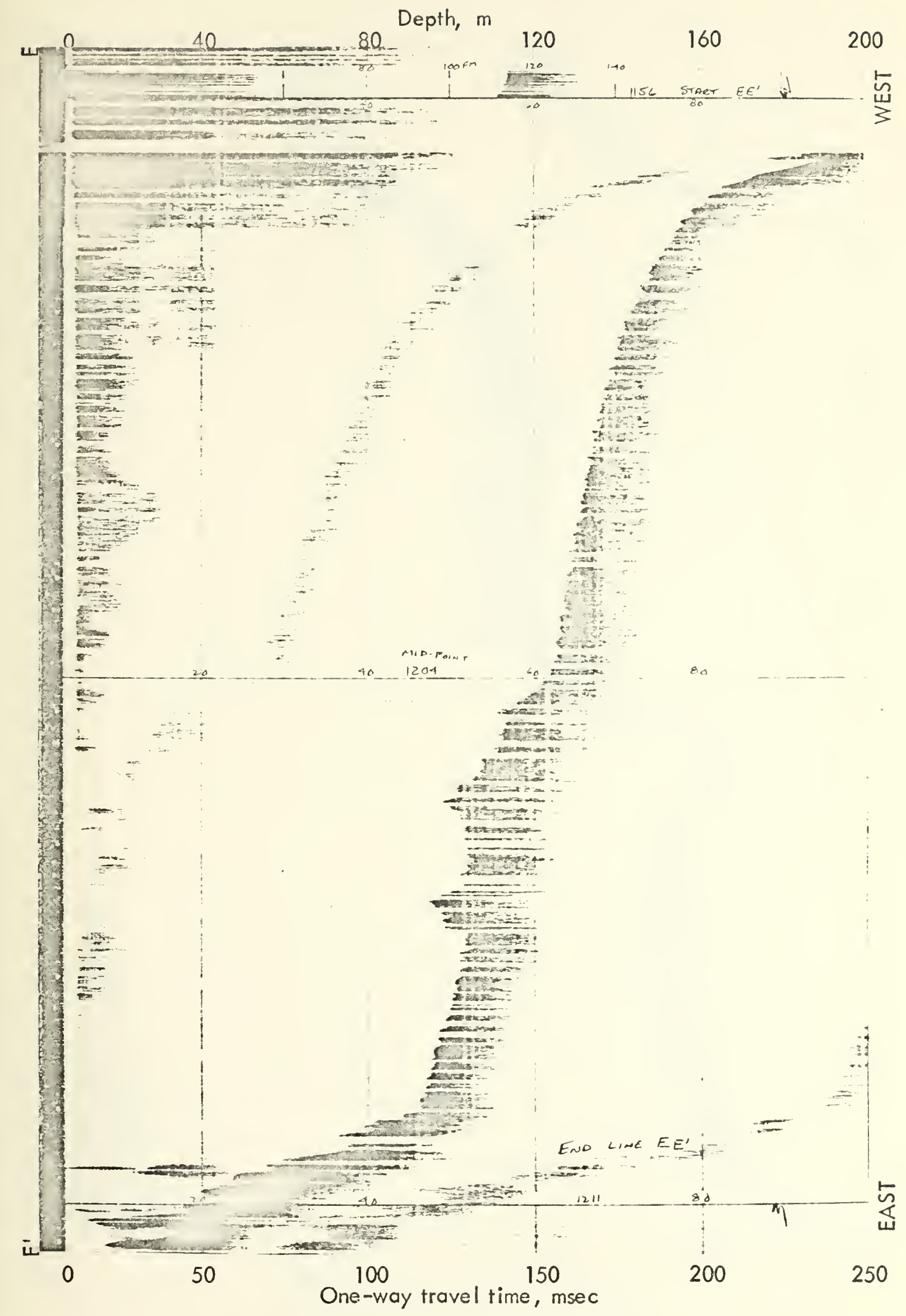

Figure 21. PDR Profile E-E' 



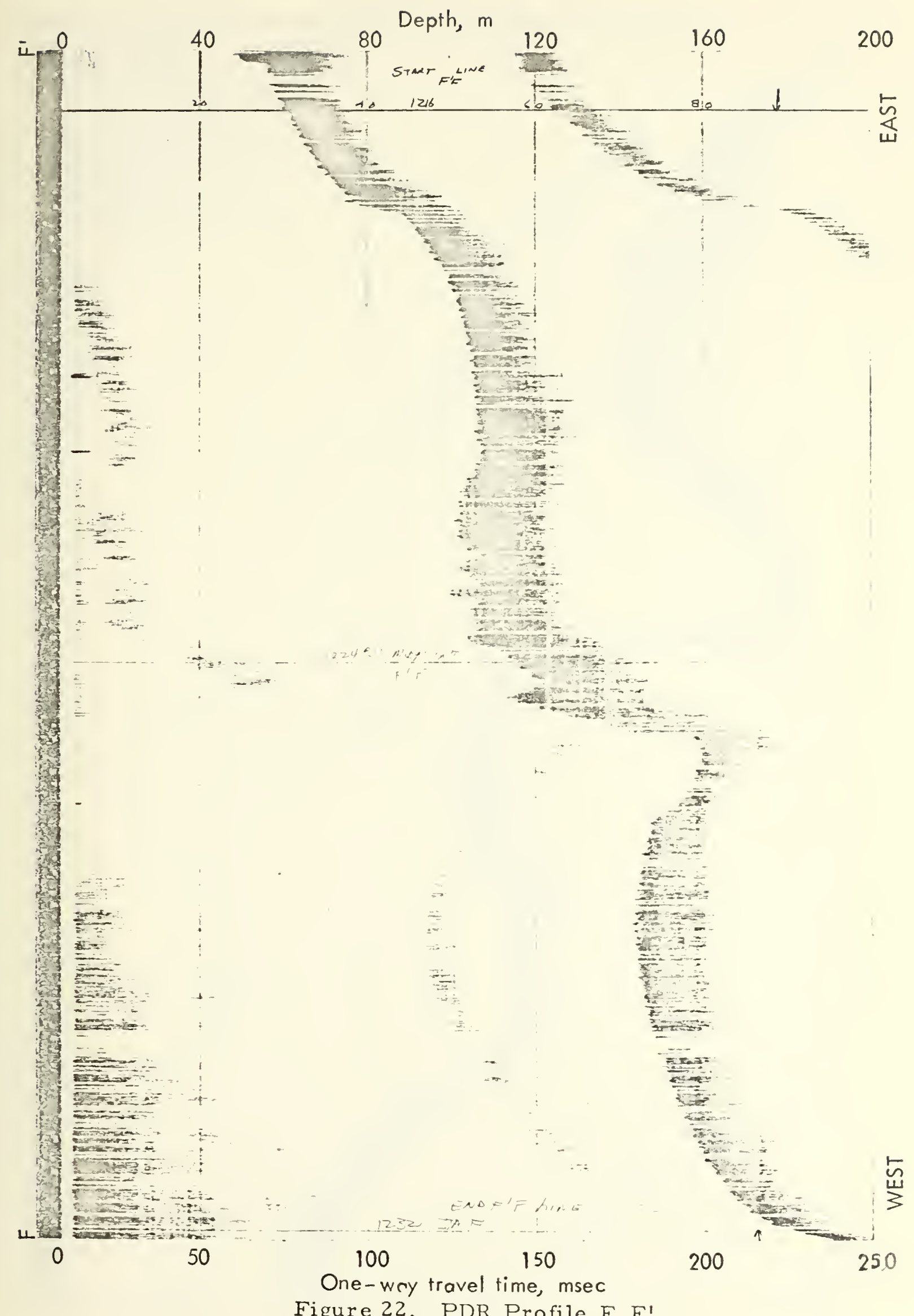

Figure 22. PDR Profile F-F' 



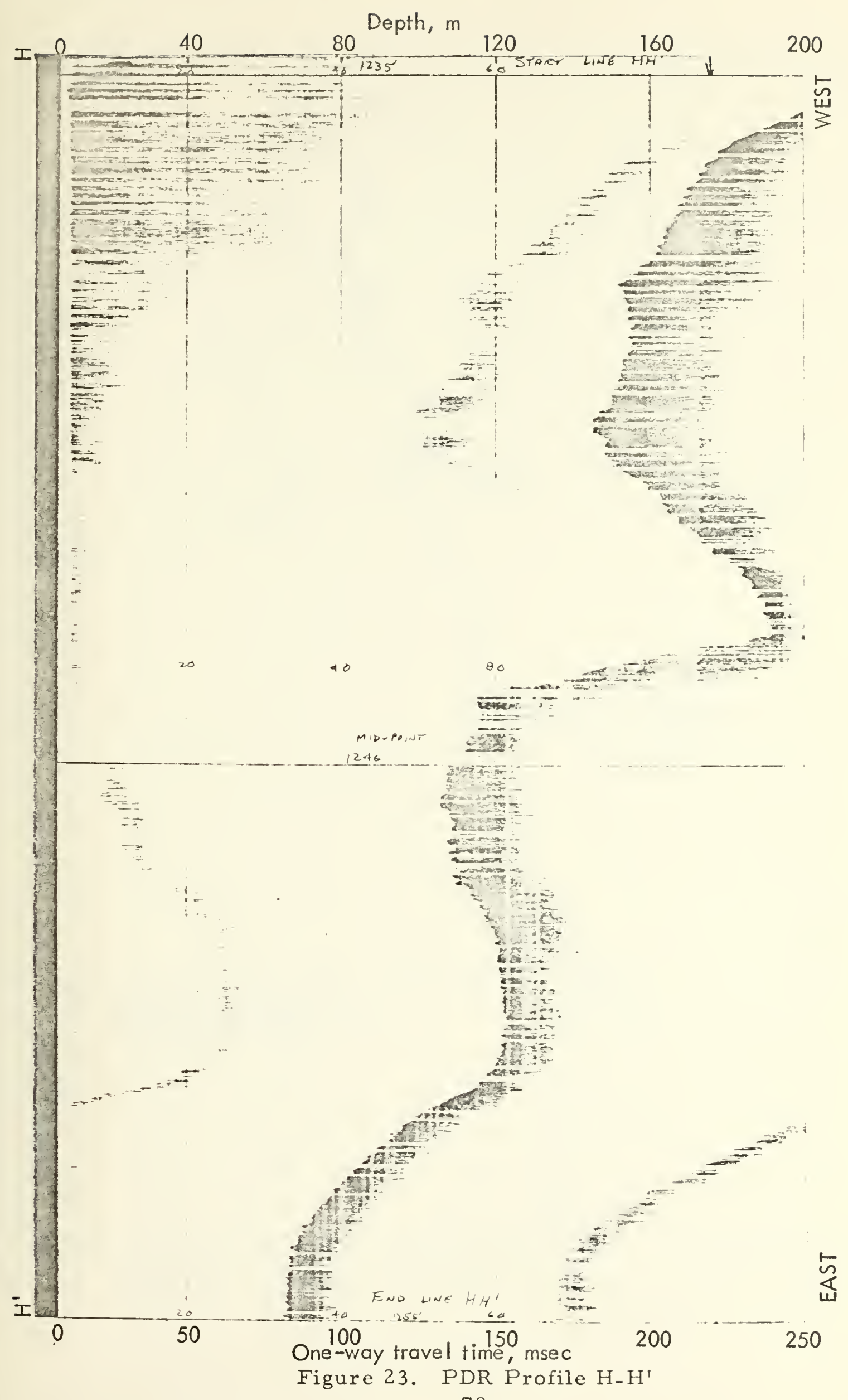





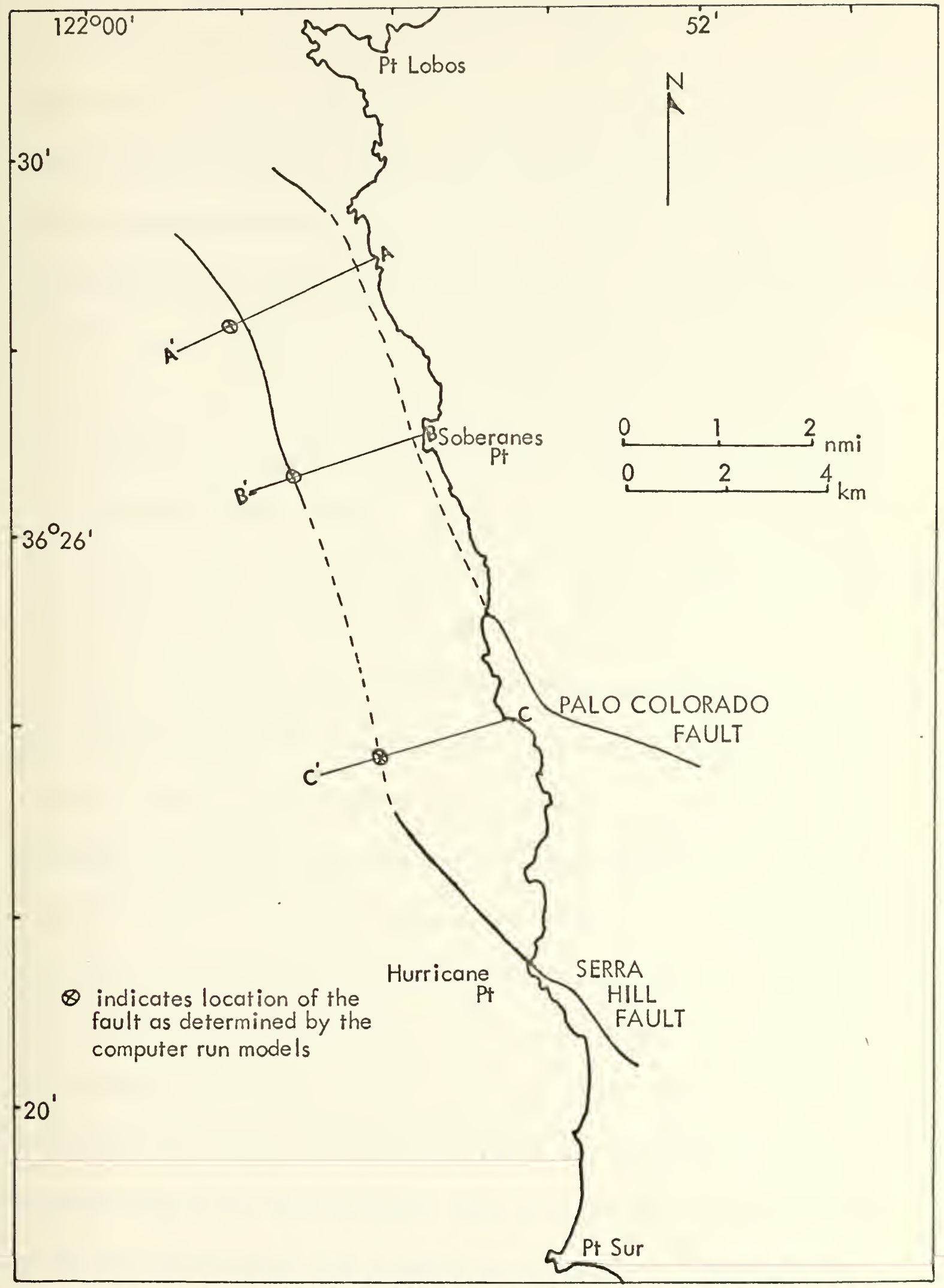

Figure 24. Location of Two-Dimensional Modeling Profiles 

a nomaly. In this case, however, the length of the profiles ranged from 3.48 to $3.90 \mathrm{~km}$ and for such short distances it is impossible to determine a regional trend. If a regional trend, such as the one determined by Thompson and Talwani [1964] is assumed, the gradient of the gravity anomaly input to the model would be increased slightly but would not appreciably alter the end result. In order to successfully run the computer program it is necessary to input the depth to the basement at one or more points along the profile. In all three cases the basement, assumed to be quartz diorite with a mean density of $2.806 \mathrm{gm} / \mathrm{cm}^{3}$ [Daly, Manger, and Clark, 1966], was located at surface level at the eastern boundary of each profile. This is in agreement with actual coastal conditions found between Pt. Lobos and Pt. Sur [Trask, 1926]. Dohrewend [1971] reports that the fault brings at least $200 \mathrm{~m}$ of Plio-Pleistocene sedimentary rocks into high angle contact with the Cretaceous Santa Lucia quartz diorite. He also states that Miocene marine rocks outcrop in the southern portion of the study area and consist of claystone and shale. This unit is characteristically overlain unconformably by marine mud and siltstones. Because Miocene marine sedimentary rock was the deepest unit that Dohrewend could distinguish seismically, he was unable to measure its thickness. The Plio-Pleistocene marine rocks which are found on the southwestern side of the fault probably have a composition similar to that of the Miocene marine unit found to the south (i.e., claystone and 

shale). An approximation of the density of nearly horizontal and undisturbed Miocene shale is $2.06 \mathrm{gm} / \mathrm{cm}^{3}$ [Daly et al., 1966]. This was the second density value used in the model. The difference between the two assumed density values, $0.746 \mathrm{gm} / \mathrm{cm}^{3}$, constitutes the density contrast parameter input. The results of the computerrun models are illustrated in Fig. 25, 27, and 29, while Fig. 26, 28, and 30 give the respective model-calculated and the observed gravity profiles of each cross section.

Although by no means the only solution, these models represent the best fit utilizing the above assumptions and existing data. Various density contrasts ranging from 0.0 to $0.840 \mathrm{gm} / \mathrm{cm}^{3}$ were tried but all attempts introduced errors greater than that which resulted from the $0.746 \mathrm{gm} / \mathrm{cm}^{3}$ contrast. The RMS errors for each model are given in Fig. 26, 28, and 30. It is apparent that the greatest errors for each profile occurred at the boundaries. The program was designed for much longer profiles where the errors occurring at the boundaries would be averaged out over the length of the profile. For short distances these errors become readily apparent.

The position of the fault break for each section is shown on Fig. 24. The correlation between these points and the location of the off shore fault scarp as mapped by the author from the PDR profiles is quite good. This is also true for the proposed offshore extension of the Serra Hill fault across model profile C-C'. The computed minimum 



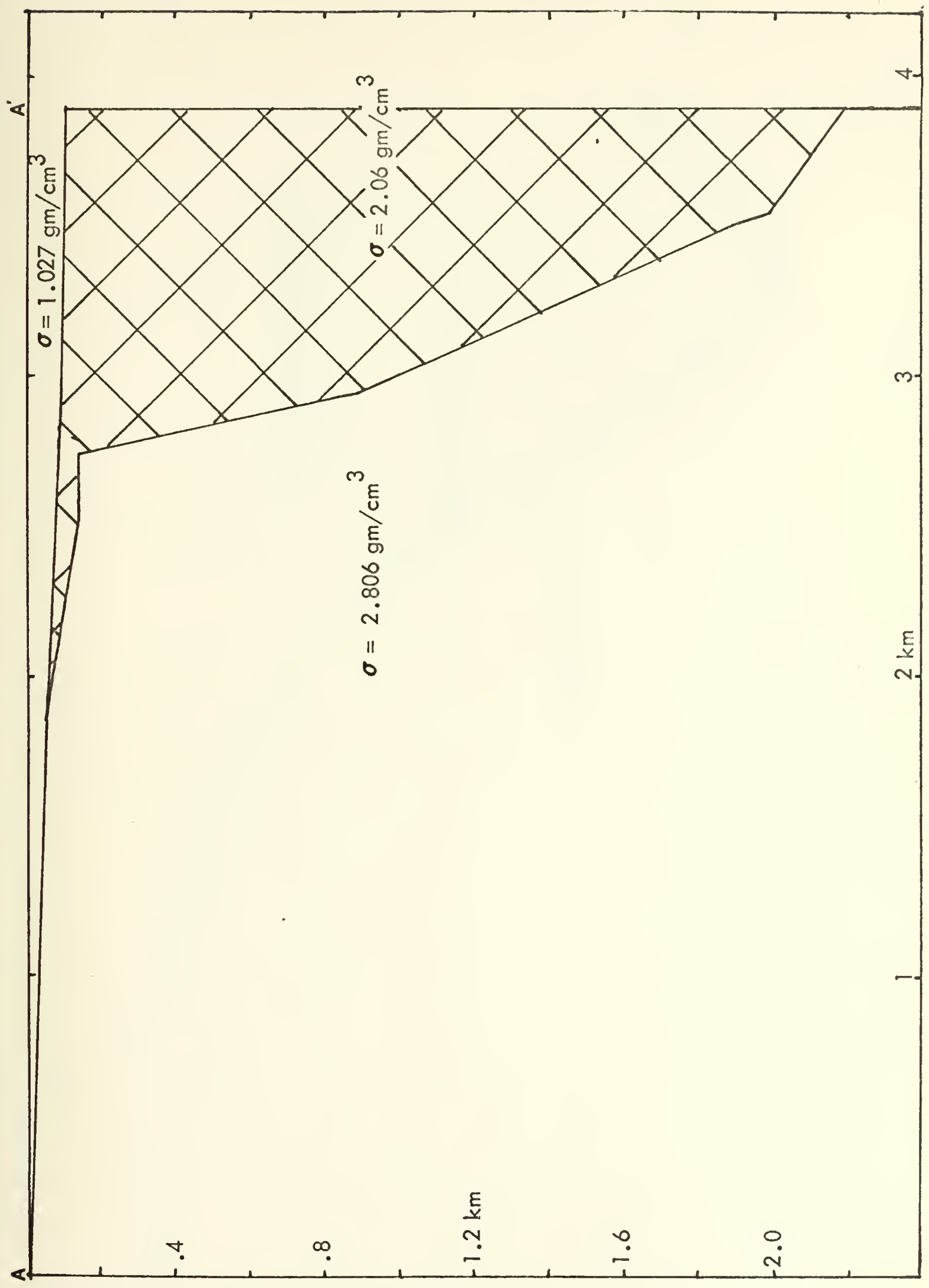

Figure 25. Depth to Basement of Profile Model A-A' 



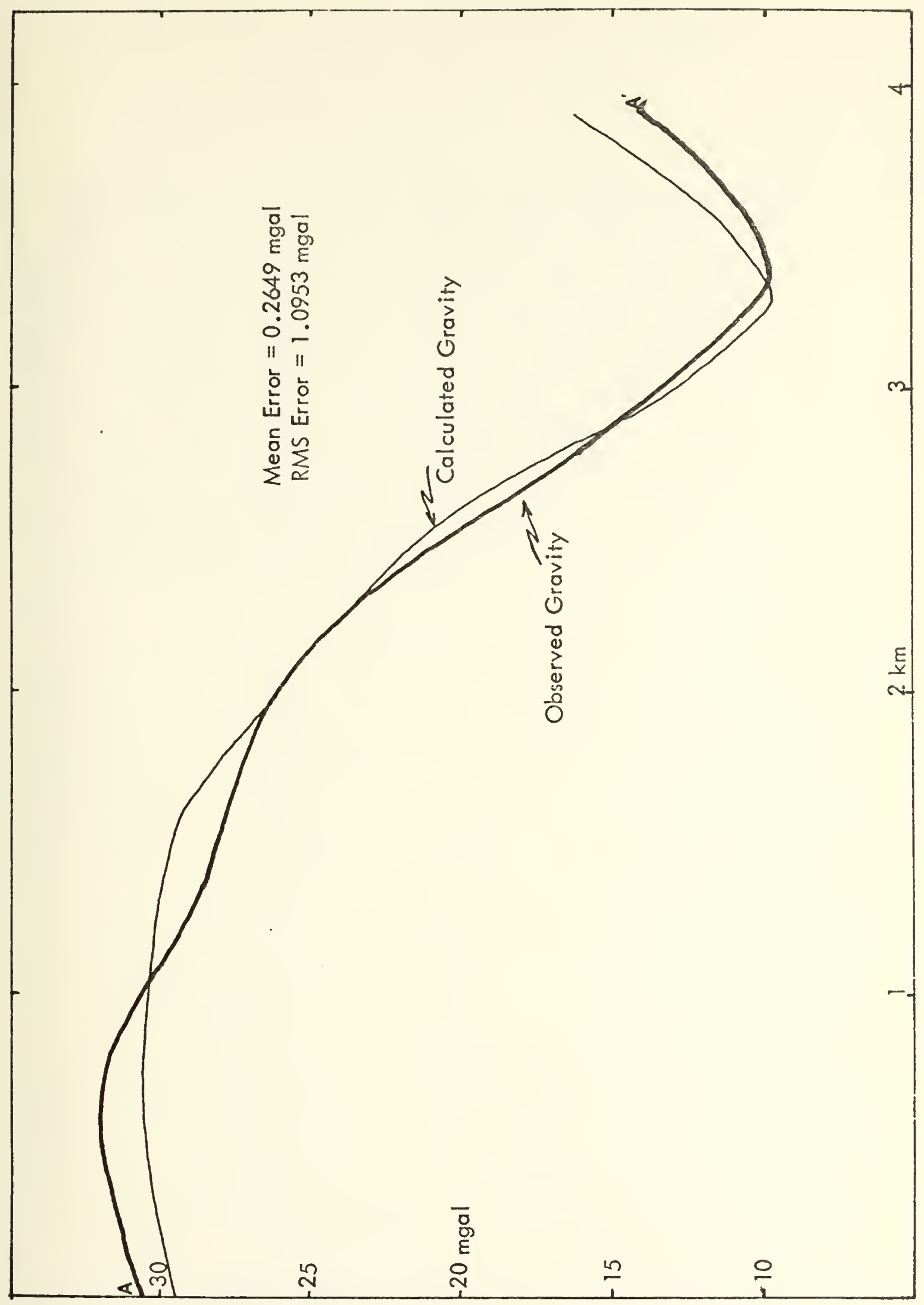

Figure 26. Calculated and Observed Gravity for Profile A-A' 



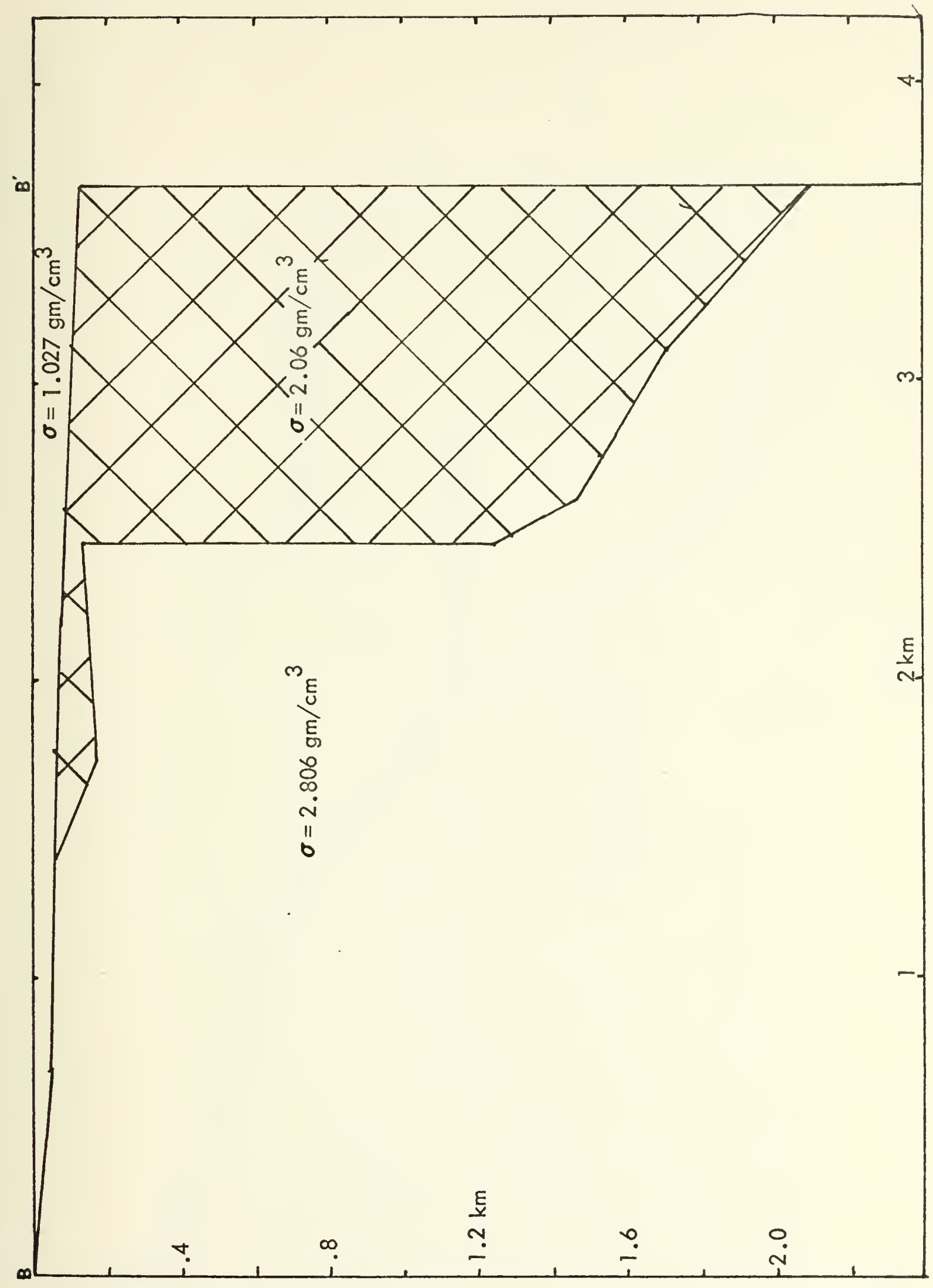

Figure 27. Depth to Basement of Profile Model B-B' 



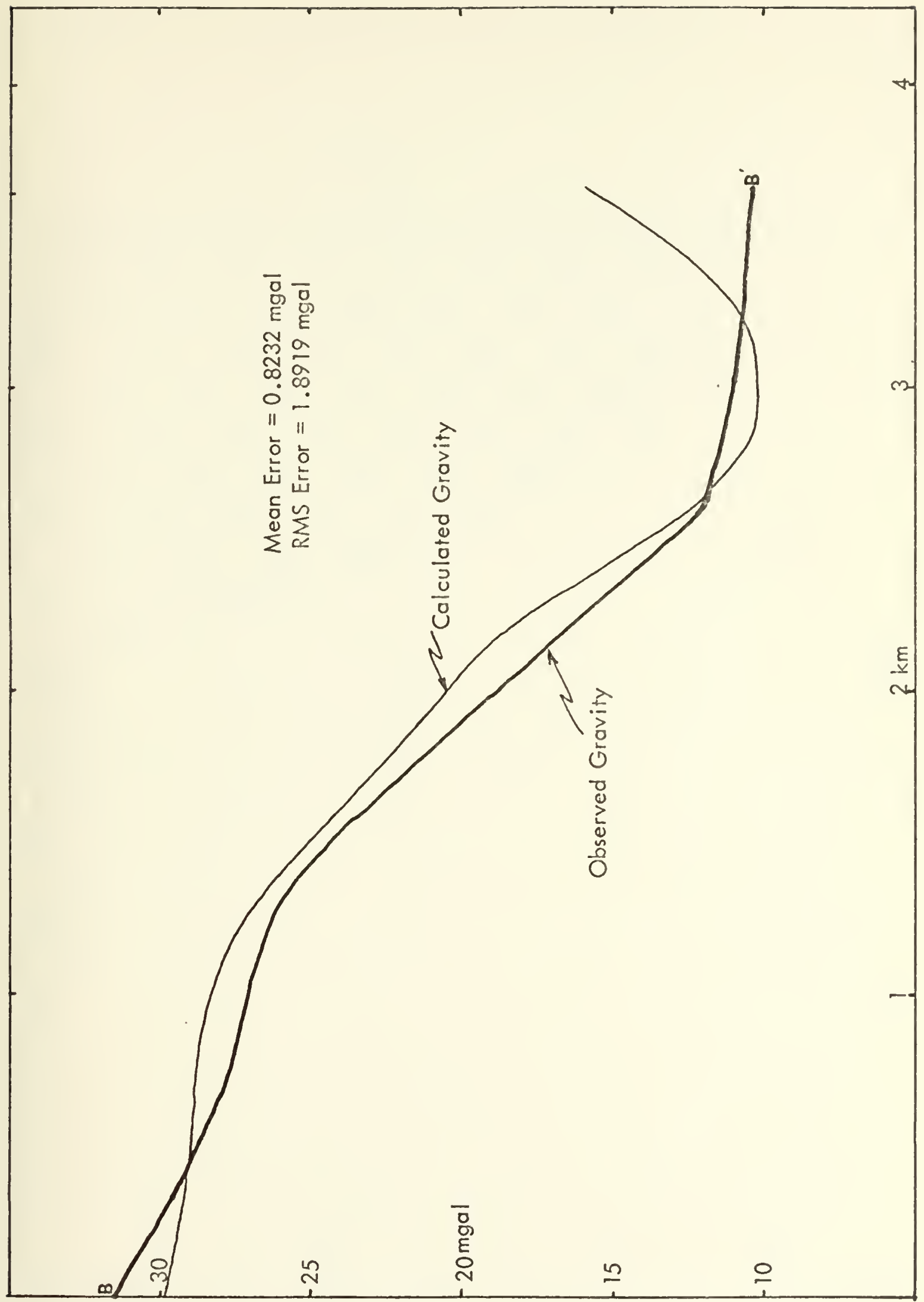

Figure 28. Calculated and Observed Gravity for Profile B-B' 



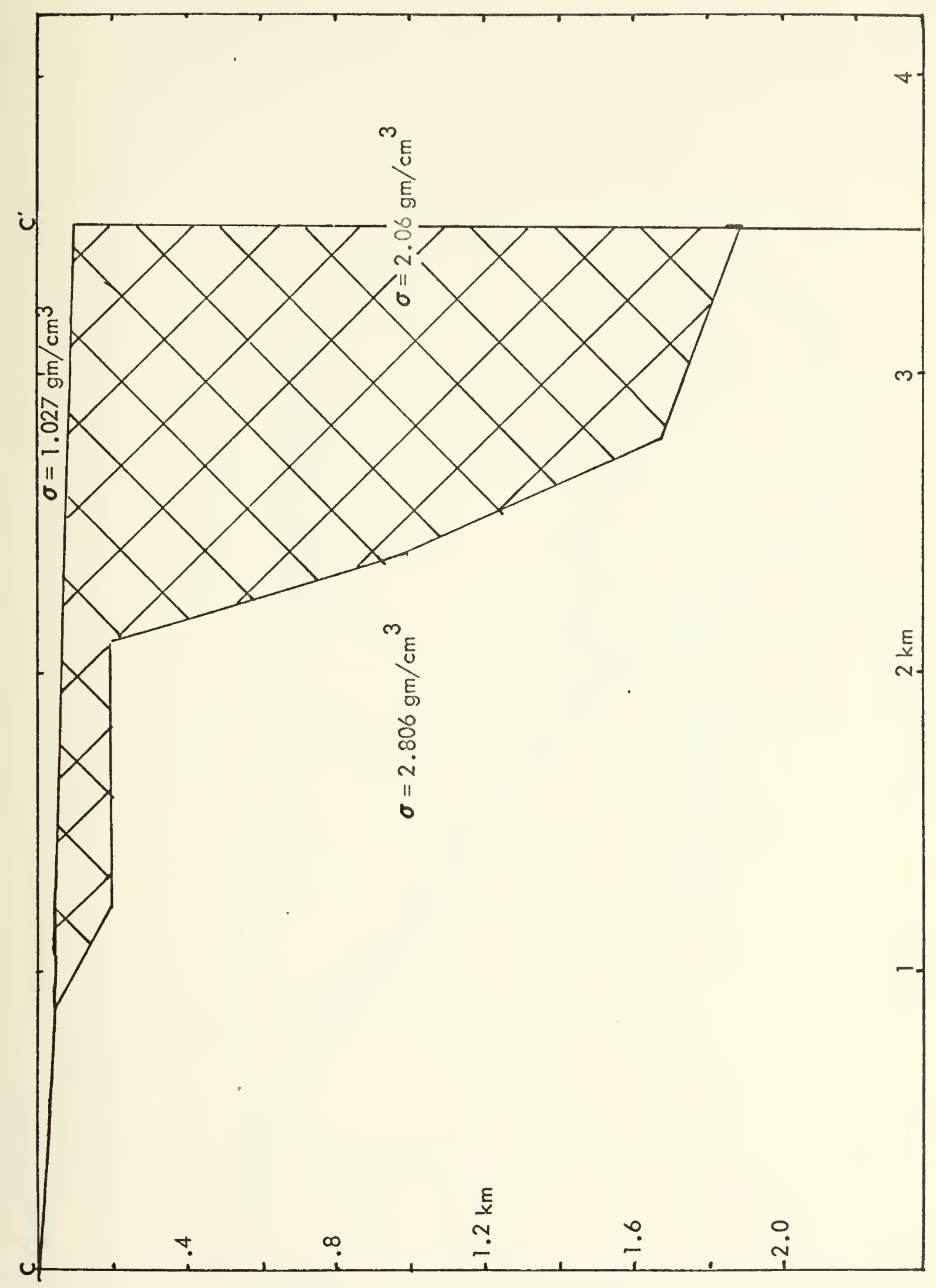

Figure 29. Depth to Basement of Profile Model C-C' 



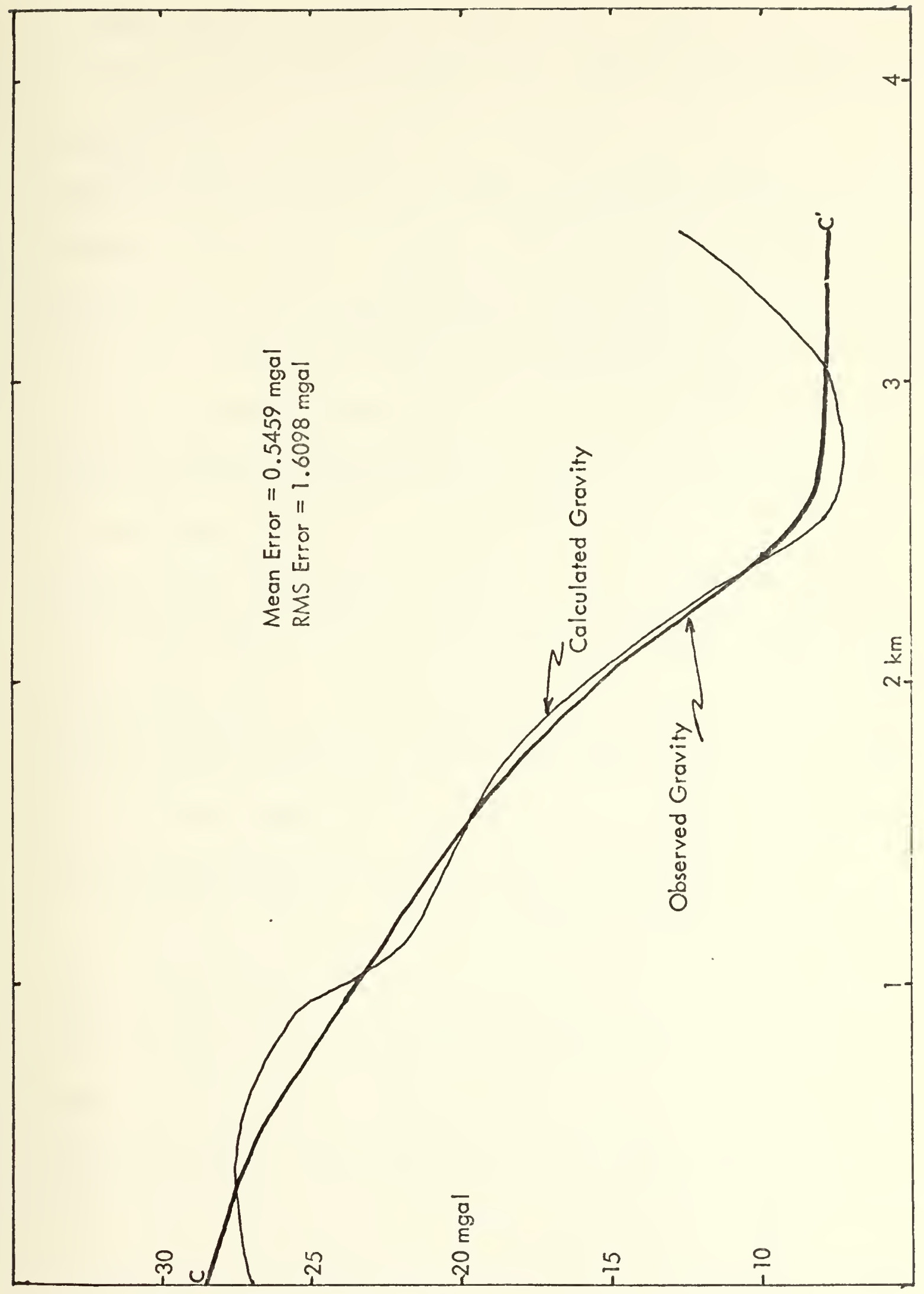

Figure 30. Calculated and Observed Gravity for Profile C-C' 

displacement of the basement ranges from $1.5 \mathrm{~km}$ for model profile C. $C^{\prime}$ to $2.1 \mathrm{~km}$ for model profile $\mathrm{A}_{-} \mathrm{A}^{\prime}$. These values are much greater than the ones proposed by Dohrewend [1971] and Greene et al. [1973] whose conclusions were based on seismic data alone. However, Thompson and Talwani [1964] for a 40 mgal negative residual anomaly in the vicinity of the continental slope suggest that this relative low is caused by a thickness of about $3 \mathrm{~km}$ of sedimentary rocks. The western most stations of model profile $A_{-} A^{\prime}$ were located on the continental slope and the deep depth to basement could at least be partially related to the similar relative low southwest of Pt. Lobos. The fault which separates this sedimentary boundary is believed to be the primary cause of the deep basement. The model itself gives the appearance of dip-slip motion where the southwestern block has dropped relative to the northeastern block. Strike-slip motion could also be a cause of the vertical separation; most likely, as with the Sur fault, it is a combination of both dip-slip and strike-slip motion.

The most eastern scarp shown on PDR profiles $F_{-} F^{\prime}$ and $H_{-} H^{\prime}$ (Fig. 17) is probably the northern extension of the fault running into the eastern tributary of the Carmel Canyon in the north which Greene et al., [1973] believe to connect with the onland Palo Colorado fault. It was hoped that some indication of this structure would be found in the profile models; however, no such structure was evident. One explanation is that a fault may indeed exist in this location but lacks the density contrast necessary to bring it out in the model. 



\section{CONCLUSIONS}

From interpretation of the two-dimensional profiles and the gravity anomaly pattern, the author concludes that the offshore extension of the Serra Hill fault as mapped by Greene et al. [1973] (Fig. 4) and the fault trending into the western tributary of the Carmel Canyon are one in the same (Fig. 31). This conclusion is based on similar minimum displacements of the basement on the southwest side of each fault. Dohrewend [1971] projects the offshore Palo Colorado fault into the western tributary of the Carmel Canyon (Fig. 5). If this were true it could be expected that the isoline pattern in the vicinity of Kaslar Pt., the location of the onland Palo Colorado fault, would indicate a basement displacement closely approximating the one found just south of the western tributary. No such correlation was found. Instead, the isolines indicate a continuation further south to the vicinity of Hurricane Pt. and the Serra Hill fault.

The fault scarp leading into the eastern tributary of the Carmel Canyon is probably associated with the offshore extension of the Palo Colorado fault. The close proximity of this scarp to the shoreline precluded locating its position south of PDR profile $F-F^{\prime}$ and the gravity data offered no additional information. The decreased CBA gradient in the vicinity of the onland Palo Colorado fault is also evident near the eastern tributary of the Carmel Canyon and may be indicative of a small density contrast across this fault. 



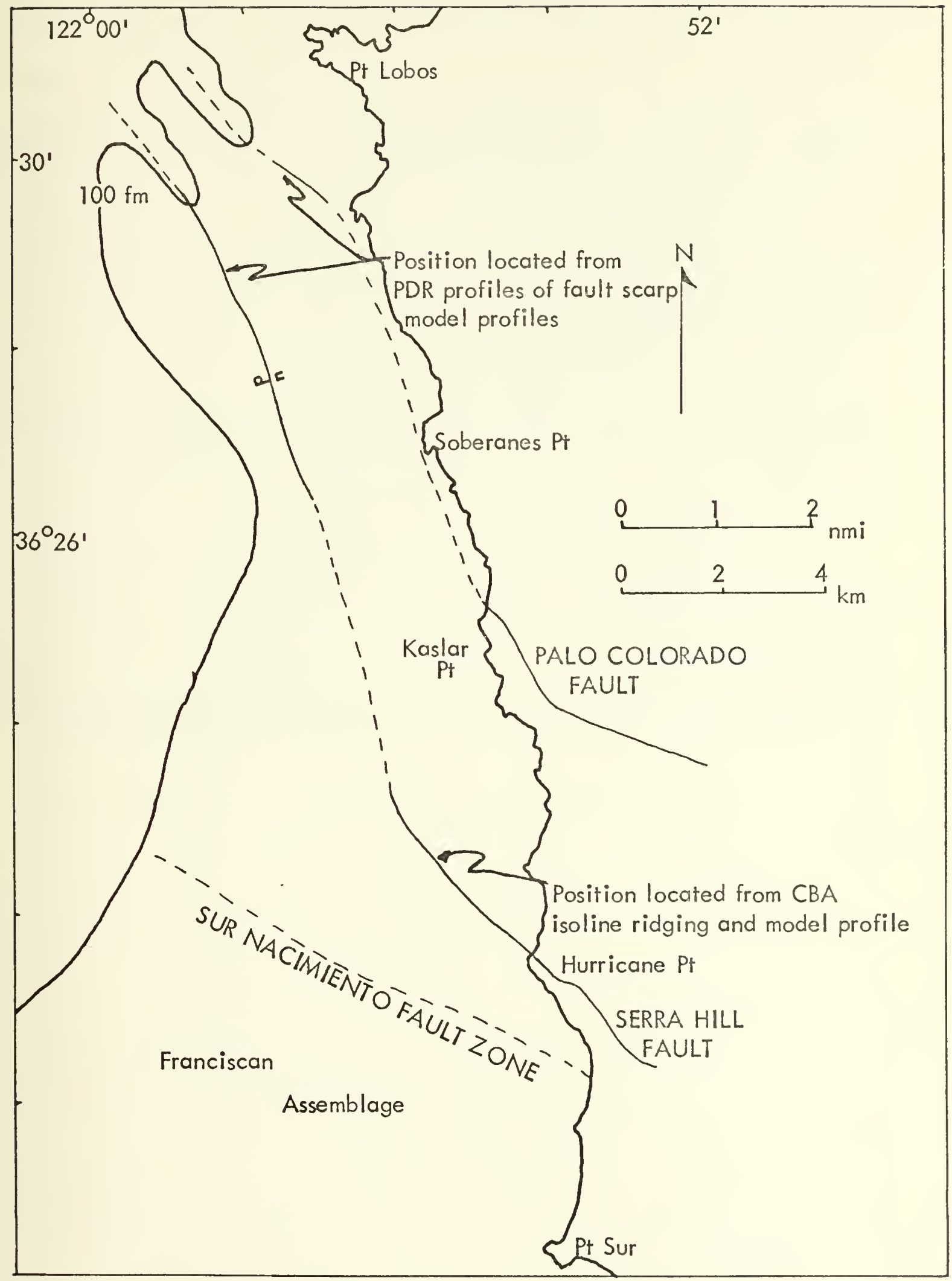

Figure 31. Summary Fault Map Indicating Proposed Locations 

If the Sur-Nacimiento fault zone leaves the California coast north of Pt. Sur, there is no indication of this trend from an analysis of the gravity data. However, onshore on the southern side of Serra Hill there is an outcrop of Franciscan assemblage reported by Page [1970] to be found only to the southwest of the Sur-Nacimiento fault zone. It is concluded that this fault zone leaves the coast in the vicinity of this outcrop and may in part be correlated with the gravity is oline ridging just to the north. What becomes of the Sur-Nacimiento fault zone after it leaves the coast is still unknown. In the author's viewpoint there are two possibilities: (1) the Sur-Nacimiento fault zone connects at some location to the north with the Palo Colorado-Serra Hill fault complex, or (2) it proceeds out to the west undetected from the gravity data. There is a gap in the gravity data in the central portion of the survey area which may possibly hold the answer to this question. 



\section{FUTURE WORK}

It is suggested that additional gravity measurements be made to the west of Pt. Lobos and in particular on the ridge located between the two tributaries of the Carmel Canyon. This would perhaps result in a better determination of the orientation of the gravity isolines in this area. More measurements are also required in the central portion of the area to perhaps tie-in the Hurricane Pt. ridging with the partially enclosed low to the north. Land gravity measurements are also required on the top and eastern side of Serra Hill to attempt to explain why the Hurricane Pt. ridging is terminated at the coast.

It is also recommended that a detailed bathymetric survey be conducted within the entire area. In conjunction with this, either deep penetration coring or dredging should be accomplished particularly on the widened shelf area west of Pt. Sur to determine the boundaries of the Franciscan assemblage and thus the Sur-Nacimiento fault zone. A correlative magnetic study within the area would be helpful and of particular use in the two-dimensional profile studies. Finally, seasurface gravimetry would be of use in those areas too deep for bottom gravimetry. Particular attention should be given to the western extension of the Monterey Canyon located $12 \mathrm{~km}$ to the west of Soberanes Pt. This would be a logical location for the Sur-Nacimiento fault zone if it does proceed out to the west after leaving the coast. 

DATA REDUCTION CORRECTION VALUES FOR INDIVIDUAL STATIONS (values in mgal)

Sta G CESERVEC G THECRETICAL EC FAC EC TC

$1 \quad S T \subseteq S C T .24 C$

$2975 S C E . C \in 8$

$3 \quad \subseteq 7 \subseteq \subseteq C C . C \& C$

$457550 \varsigma .154$

5 s7scce.IC2

$6 \operatorname{STSSCL.S1C~}$

.7 s79sC4.SE 1

8 S79SCS. $3 C$ c

c ST9SCE.7โE

10 s79sC4.5s1

11 S7SSC7.715

$1297956 \ddot{C . C 13}$

$1357 \subseteq 5 C 3.3 \in c$

14 STSCCE.CES

$1597 S S C S . C 3 t$

1t $5799 C 2.4 \varepsilon E$

17 S79SCZ.CSS

$1 \varepsilon$ ऽ

ls $57 \subseteq c C 4 . C \equiv 2$

$20 \quad 979904.037$

$215798 \subseteq 4.71 T$

22 S7SSC1.tES

23 STSCC $3 . S 2 \varepsilon$

$24 \quad$ STSC $1.6 \angle \varepsilon$

$25 \$ 79857.348$

LE S7SEST.443

$27 \quad$ ऽ $7 \& \varsigma \subseteq . C 3 \varepsilon$

$2 \varepsilon \quad \varsigma 798 \varsigma \varepsilon .343$

टS $\quad 57 \varepsilon \subseteq \bar{c}, t \in 4$
$97 \subseteq \varepsilon \varepsilon C .359$

$97987 t .132$

975875.097

$57 \subseteq 874.580$

979874.493

S7S\&74.235

979873.976

$\$ 79873.890$

575873.028

979873.286

S $75 \& 72.338$

975873.200

s79873.545

S7S872.769

979872.597

579871.593

979871.907

975871.907

975871.476

979871.390

575871.304

975870.873

$\$ 79870.787$

575871.131

979870.614

575870.614

975870.183

575870.097

૬ $7 \& \in \varsigma .839$

\begin{abstract}
E. $5 \varepsilon-17.02$
$9.91-19.71$

$7.46-14.84$
\end{abstract}

$-8.47$

t. $\subseteq 4$

$-5.80$

5. 84

$-7.38$

E. $6 T$

$11.42-22.73$

$-11.31$

5.41

$7.27-14.47$

$-7.19$

5. 44

$4.3 C \quad-8.54$

$-4 \cdot 24$

$5.54-18.58$

$-5.44$

6.26

$12.01-23.90$

$-11.89$

$5.6 c$

$8.83-17.57$

$-\varepsilon .74$

$5 . \overline{3} \mathrm{C}$

$6.30-12.53$

$-6 \cdot 2$

$5.1 \varepsilon$

$11.58-23.84$

$-11.87$

$5.4 c$

$17.08-33.59$

$-16.51$

5.55

$15.33-30.52$

$-15.1$

$15.27-30.39$

$-15.12$

5.73

$25.87-51.50$

$-25.63$

$-4.71$

$4.7 t-5.47$

$15 . \equiv 3-30.49$

$-15.17$

$-15.75$

$-7.21$

$5 . \& 5$

5.62

5. $\subseteq \mathrm{C}$

$15.53-31.68$

$$
7.28-14.49
$$

$-1 \mathrm{C} .00$

$5 . \subseteq 1$

$10 . C 2-20.02$

$18.87-37.56$

$-18.69$

E. TC

$5.7 t$

$$
5.5 C-10.94
$$

$-5.44$

$1 C .91-21.78$

$-10.88$

5.75

5.75

5.71

$t .2 c$

$5 . t \epsilon$

$14.25-28.35$

$14.24-28.42$

$18.2 C-36.23$

$3.38-6.73$

$12.60-25.07$

$1 \varepsilon .04-35.52$
$-14.10$

$-14.1$

$-18.03$

$-3.35$

$-12.47$

5.42

5.54

5.

t. 74

$5.3 \mathrm{C}$

$-17.885 .4 \mathrm{c}$ 

sta e cesefvel G thecretical BC FAC EC TC

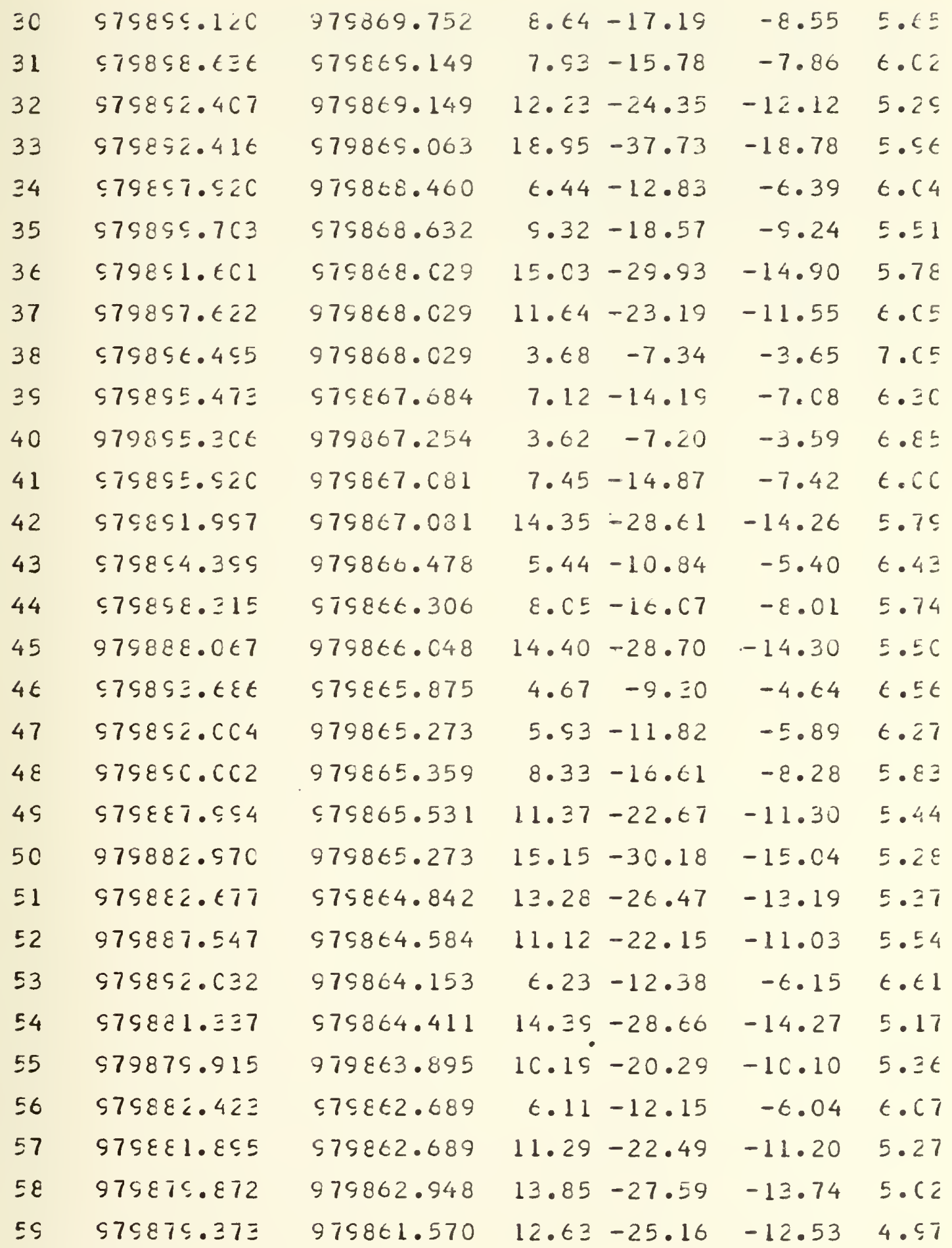



sta g cesérvec g trecretical ec fac ec tC

\begin{tabular}{|c|c|c|c|c|c|c|}
\hline b & ९ $7 \varsigma \varepsilon \varepsilon \beth . \varepsilon \beth 7$ & 975861.570 & 8.89 & -17.73 & -8.84 & $5 . \bar{c} \equiv$ \\
\hline 2 & $97 \subseteq \varepsilon \& 4.27 T$ & 975861.484 & 5.71 & -11.35 & -5.65 & $5.7 \varepsilon$ \\
\hline & $9758 \varepsilon \equiv .1 \varepsilon t$ & 975860.623 & 10.10 & $-20 \cdot 14$ & $-1 C .04$ & $E . C 4$ \\
\hline & $57587 \subseteq .234$ & STS 860.365 & 14.68 & $-29 \cdot 26$ & -14.58 & 4.53 \\
\hline & $57 \subseteq \& 81.4 \equiv \varsigma$ & C 7S\&5S.84S & $1 C .83$ & -21.58 & $-1 c .75$ & 4.51 \\
\hline & $9798 \varepsilon 7 . ૯ S 2$ & S7985s.676 & 7.26 & -14.47 & -7.21 & 5.24 \\
\hline & $\varsigma 7 \subseteq \& \varepsilon \subseteq .7 \subseteq C$ & 979858.844 & 8.57 & -17.07 & $-8 \cdot 50$ & $5 \cdot(4$ \\
\hline & $9798 E 2 . t 7 \epsilon$ & 979859.504 & 3.61 & -7.18 & -3.57 & $\epsilon . c \varepsilon$ \\
\hline & $5.15 \varepsilon$ & 975857.525 & 5.55 & -11.06 & -5.51 & 5.1 \\
\hline
\end{tabular}



Sta G CBSERVED G theoretical BC FAC EC TC

\begin{tabular}{|c|c|c|c|c|c|c|}
\hline A & $\varsigma 7 \varsigma \& 96 . \geqq 81$ & 579875.873 & -0.85 & 2.35 & 1.50 & $5.5 t$ \\
\hline & 575893.355 & 979875.356 & -2.73 & 7.52 & 4.80 & 5.41 \\
\hline & $\subseteq 7 \subseteq \& 82.1 C 1$ & S7S875.528 & -7.84 & 21.63 & 13.79 & 5.57 \\
\hline & $\varsigma 7 \varsigma \& 9 C . C \& 8$ & ऽ.7૬874.235 & -4.50 & 12.42 & 7.91 & $5.5 \mathrm{C}$ \\
\hline & 975884.599 & 979873.114 & -7.67 & 21.16 & 13.49 & $6 \cdot 14$ \\
\hline & $\subseteq 7 \varsigma \& \varsigma 1 . C 76$ & S79873.028 & -3.58 & 5.88 & 6.30 & $5 . \subseteq 5$ \\
\hline j & $97 \varsigma \& 89.591$ & 579871.821 & -3.56 & 10.91 & 6.55 & $6.1 C$ \\
\hline & S7૬\&ऽ 3.724 & s79871.390 & -1.88 & 5.17 & 3.30 & 6.14 \\
\hline & $97 \subseteq 887.258$ & 575870.700 & $-4 \cdot 50$ & 12.42 & 7.51 & 7.36 \\
\hline & 975889.407 & 979870.011 & -2.83 & 7.81 & 4.98 & $7.7 \varepsilon$ \\
\hline & ડ $7 \varsigma દ 85.427$ & 579869.322 & -4.40 & 12.13 & 7.73 & 6.78 \\
\hline & S7S\&91.470 & 579869.322 & -1.53 & 4.23 & 2.70 & $6 . t t$ \\
\hline$\Lambda$ & S7૬\&8૬. 242 & 575868.632 & -1.71 & 4.70 & 3.00 & 7.28 \\
\hline V & 975832.151 & 979867.857 & -5.49 & 15.14 & $s .65$ & 7.41 \\
\hline O & ૬7૬\& ऽ . CSO & 979867.340 & -0.03 & 0.08 & 0.05 & 8.74 \\
\hline$P$ & $\varsigma 7 ૬ \varepsilon ૬ 1.140$ & 975867.254 & -0.03 & 0.08 & 0.05 & 8.74 \\
\hline Q & ૬૫૬દ૭ . 120 & 579867.163 & -0.03 & 0.08 & 0.05 & 7.11 \\
\hline & $975 \& 91.350$ & 979867.081 & 0.0 & 0.0 & 0.0 & 7.11 \\
\hline & S7૬\&91.270. & s7s\&૯6.995 & 0.0 & 0.0 & 0.0 & $7.0 \mathrm{C}$ \\
\hline & ૬૪૬દ91.250 & 979866.823 & -0.03 & 0.09 & $c .06$ & $\epsilon \cdot \varepsilon C$ \\
\hline J & $57 \subseteq 885.603$ & 579866.651 & -3.27 & 9.03 & 5.76 & $6.4 t$ \\
\hline V & $97 \subsetneq 888.332$ & 979860.651 & -1.67 & 4.61 & 2.94 & 6.47 \\
\hline W & $97 \varsigma \varepsilon 78.993$ & 979865.962 & -5.63 & 15.52 & 9.89 & 6.51 \\
\hline$x$ & ૬ 7૬દ 78.185 & 575865.273 & -5.80 & 15.99 & 10.19 & $7.4 t$ \\
\hline Y & ९ ૬દ55.742 & 579864.756 & $-18 \cdot 45$ & 50.89 & 32.44 & $11.4 \mathrm{C}$ \\
\hline Z & s7sદ78. E3t & $57585+.842$ & $-5 \cdot 12$ & 14.11 & 8.99 & 9.15 \\
\hline$A^{\prime}$ & s7sદ73.428 & 579864.153 & -7.64 & 21.07 & $1 \equiv .43$ & 7.51 \\
\hline$B^{\prime}$ & 975836.231 & 979863.464 & -0.04 & 0.11 & $C .07$ & 7.25 \\
\hline$C^{\prime}$ & $\varsigma 7 \varsigma \varepsilon \in 7.251$ & S7૬862.775 & -5.41 & 25.96 & 16.55 & 5.7 \\
\hline
\end{tabular}



sta g ceservec g thecretical ec fac ec tc

\begin{tabular}{|c|c|c|c|c|c|c|}
\hline & $7 S E 51 . C 79$ & 575861.742 & -16.54 & 45.62 & 25.08 & 8.16 \\
\hline & $\varsigma 7 \varsigma \& 4 \varsigma .45 \mathrm{~L}$ & 579860.795 & .15 .07 & 41.57 & $2 t .50$ & $11 \cdot 63$ \\
\hline & $\varsigma 7 \varsigma \varepsilon \in 4.4 \varepsilon 6$ & $\varsigma 79859.935$ & -7.44 & 20.51 & 13.07 & 7.50 \\
\hline G & $97 \subsetneq \varepsilon t \varsigma .45 t$ & 579855.332 & -4.30 & 11.85 & 7.55 & $6.7 t$ \\
\hline & $97987 \mathrm{C} .301$ & 579858.988 & -4.71 & 12.98 & $\varepsilon .27$ & $5.7 \mathrm{~s}$ \\
\hline & $\varsigma 7 \varsigma \varepsilon \in \varepsilon .1 \varsigma 7$ & $579 \varepsilon 57.955$ & -5.53 & 16.37 & $1 C .43$ & $t . \varsigma 3$ \\
\hline & $\varsigma 7 \subseteq \varepsilon \in \varsigma . € 55$ & 979857.353 & -5.01 & 13.83 & 8.81 & 6.28 \\
\hline & STSE7C.745 & c79856.665 & -4.26 & 11.76 & 7.49 & $5.7 \varepsilon$ \\
\hline & S7SE巨E.117 & $579 \& 57.095$ & $-12 \cdot 31$ & 33.96 & 21.64 & $10 . E$ \\
\hline
\end{tabular}



FAA MFAA

SEA

CBA

$(\mathrm{m})$

$136 \quad 31.57 \quad 12157.53$

$43 t 3 C .52$

$5363 C .5$

7 3t $3 \mathrm{C} \cdot 13$

$83 t 3 C .65$

$S \quad 3 t<5.4 \varepsilon$

$10 \quad 36 \quad 25.67$

$113 t 25.0 C$

12 at $2 \subseteq .5$

14 zt 25.28

$153 t \quad 25.15$

12158.87

16 17

\section{1} 1

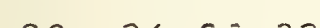

$12156.5 C$

21 $36<\varepsilon \cdot 23$

$22 \quad 3 t<7.57$

$23 \quad 3627.50$

$243 t<\varepsilon .12$

$25 \quad 3 t<7.80$

LE $3 t \quad 27.78$

12158.63

$27 \quad 36 \quad 27.48$

$2 \varepsilon \quad 3 t \quad 27.40$

is $36 \quad 27.23$
12157.80

12157.22

12157.67

12157.05

12156.47

12157.08

12157.72

12157.45

12156.83

12157.50

$1215 \varepsilon .12$

12158.68

$12157.5 \varepsilon$

12157.87

12158.80

12156.53

12157.17

12158.65

12156.13

12156.78

12157.67

12157.55

$12155 . \varepsilon C$

121 E. . C

55.2

63.5

48.1

73.7

46.5

27.7

61.5

77.4

$56 . s$

40.6

$77: 3$

110.2

98.9

98.5

$16 t .5$

$3 C .7$

58. 8

102.7

$47 . \mathrm{C}$

6.9

121.7

35.4

70.6

91.5

92.1

117.4

21.8

$81 \cdot 2$

$1<1 \leq \varepsilon .32$
$9.86 \quad 14.6 \quad 18.41$

$17.7 \quad 22.13$

$2 \mathrm{C} \cdot 3$

$23 . t C$

$1 \varepsilon .2$

23.26

21.2

24.42

$22 \cdot 5$

$24 \cdot 43$

17.2

$21 \cdot 54$

$18 \cdot 2$

23.52

$2 \mathrm{C} \cdot 1$

23.5 s

$22 \cdot 3$

$25 . C \varepsilon$

$18 \cdot \overline{2}$

23.51

$4 \cdot 3$

$11.5 \mathrm{C}$

(1).6

$-5.18$

7 . $\varepsilon$

14.64

$2 \mathrm{C} .53$

11.4

18.14

Ż. 76

$-15.06$

$-C .7$

10.21

16.71

21.02

23.7

$25.7 \varepsilon$

31.65

0.70

c. 2

16. $\mathrm{C} 2$

5.1

$12 \cdot 2 \mathrm{C}$

2 1.72

$-3.73$

$2 z \cdot 1$

25.34

17. St

18.06

$18 \cdot 2$

$22 \cdot 65$

$\equiv 1 . \mathrm{Cs}$

12.63

$-3.7$

4.73

$28.4 \mathrm{C}$

$-14.14$

22.5

$25 . \equiv 4$

1C. 44

is. 85

17.4

22.27

31.63

11.36

1C. 1

16.35

27.53

2.15

c.

12.55

21. 81

$-1 \cdot t 9$

0.7

8. $8 \mathrm{C}$

18.05

$-5.40$

24.0

$25.5 \mathrm{C}$

14.17

2र. 12

IC. 2

15.78

32.24

3.18

$-3 \cdot 1$

21. C E

1C. 44

$116.4-13.10$ 

$3 C \quad 36 \quad 27.18 \quad 121 \quad 56.53$

$31 \equiv \epsilon$ ¿t.78 $121 \mathrm{Et.10}$

$3236 \quad 26.78 \quad 12156.55$

$33 \quad 3 \epsilon \quad \angle \epsilon . C E \quad 1215 \varepsilon .22$

$34 \quad 3 t<t .3 C \quad 12155.50$

$35 \quad 3626.4 C \quad 12156.25$

36 36 $\angle E .55 \quad 12157.05$

$37 \quad 36 \quad 25.98 \quad 12156.30$

$3 \varepsilon \quad 3 t<E . S E \quad 121 \quad 55.4 \mathrm{C}$

$39 \quad 3 t<5.7 \overline{2} 12155.85$

$4 \mathrm{C} \quad 3625.47 \quad 12155.3 \mathrm{C}$

$413 \epsilon \quad 25.2 E \quad 12155.87$

$42362 E .3 \mathrm{C} \quad 12156.62$

43 इt $24.92 \quad 1<1 \leq 5.33$

$4436 \quad 24.8 C \quad 121 \quad 55.82$

$45 \quad$ इt $24.6 C \quad 12156.67$

$46 \quad 3624.45 \quad 12155.05$

47 Et $24.05 \quad 12155.00$

$4 \varepsilon \quad 26 \quad 24.1 C \quad 12155.63$

$49 \quad 3 t 24.25 \quad 12156.25$

$5 \mathrm{C} 3624 . \mathrm{C} 512156.85$

$51 \quad 36 \quad 2 \equiv .78 \quad 12156.30$

$52 \quad 36 \quad 23 . t 3 \quad 12155.72$

$53 \quad z 6 \quad 23.2 \varepsilon \quad 121 \quad 54.52$

$54 \quad 3 \epsilon \quad 23.47 \quad 121 \quad 56.52$

55 zद $23 . C E \quad 12155.72$

st $3 t \quad 22.75 \quad 12154.72$

$57 \quad 36 \quad 22.3 \mathrm{C} \quad 121 \leq 6.00$

5E $3 t \quad 22.43 \quad 121 \quad 57.27$

59 26 $21.50 \quad 12157.03$
$51 \cdot 1$

78.5

122.3

41.6

60.2

$97 . \mathrm{C}$

$75 \cdot 1$

$23 . \varepsilon$

46.0

23.3

48.2

92.7

35.1

52.1

$93 . \mathrm{C}-6.68$

18.51

30.1

38.3

$53 . \varepsilon$

14.91

8.03

73.5

$97.8-12.49$

$85 . \varepsilon-8.63$

71.8

C. 81

40.1

92 .

65.7

39.4

$72.5-3.28$

$89.4-10.66$

81.5
15.50

$-11.73$

$-4.27$

7.58

$-7.36$
$17 \cdot C$

$1 \varepsilon \cdot 1$

5.7

$-2.8$

$2 \mathrm{C} \cdot 2$

17.7

2. $C$

12.5

23.2

17.5

$2 z .5$

18.1

$4 . ?$

20.1

$2 \mathrm{C} \cdot 4$

1. 3

$21 \cdot 1$

18.2

12.7

t. 1

$-4 \cdot 1$

$-1.3$

$7 . \mathrm{C}$

19.0

$-\equiv .7$

1.4

$11 . C$

z. C

$-3 . C$

$-C .3$
20.81

$21 \cdot t 3$

11.14

4.57

23.07

21.8?

8.67

$18 . C 5$

24. E 1

20.71

$24.4 t$

21.42

$10 . t E$

22.52

24 . C C

$7.7 \mathrm{c}$

23.17

$20 . \varepsilon 4$

16.36

11.17

2. $t t$

4.65

11.53

$21 \cdot 73$

$2 \cdot t t$

5.52

13.65

8. CC

$3.1 \varepsilon$

5.27
26.46 27.65

16.43

10.5 3

2S. 11

27.34

14.45

24.10

$\Xi 1 . \varepsilon t$

27.01

$\equiv 1.31$

27.42

16.45 $2 \varepsilon .55$ 25.74

13.22 25.73 27.11 22. 19 16.61 7.94 10.02 17.47 टE. 34 $7.8 ?$ 11.28 19.76 13.27 8. $2 \mathrm{C}$ 10.24 

sta latitloe lcngitude depth faA maA sea cBa

\begin{tabular}{|c|c|c|c|c|c|c|c|c|c|}
\hline$\in C$ & $3 t$ & 21.45 & 121 & 55.77 & 57.5 & $4 \cdot 54$ & 5.5 & $13.4 \equiv$ & $18 . t t$ \\
\hline 61 & 36 & $=1.43$ & 121 & $54 . \& 7$ & 36.8 & 11.44 & $14 . t$ & 17.14 & 22.92 \\
\hline 62 & $\Xi t$ & $z C . \& 2$ & 121 & 56.15 & 65.3 & 2.42 & $8 . C$ & $12 \cdot 53$ & 17.57 \\
\hline & $3 t$ & $2 c \cdot t 3$ & 121 & 57.75 & 94.8 & $-1 C .39$ & $-2 \cdot 2$ & 4.25 & $5.2 \overline{2}$ \\
\hline & $3 t$ & 20.25 & 121 & $5 t .58$ & 69.9 & 0.01 & $t \cdot c$ & $10 \cdot \varepsilon .4$ & 15.75 \\
\hline & $3 t$ & $2 C .12$ & 121 & $55.2 \mathrm{C}$ & $4 t .5$ & 13.55 & 17.6 & 20.81 & $26 . C E$ \\
\hline & $3 t$ & $15.4 \bar{z}$ & 121 & 55.87 & 55.3 & 10.07 & $14 . \varepsilon$ & $18 \cdot 64$ & 23.68 \\
\hline & $3 t$ & $2 C . C 7$ & 121 & 54.00 & 23.3 & $1 \epsilon .00$ & $18 . c$ & $19.6 \mathrm{C}$ & ¿E. $6 \varepsilon$ \\
\hline & & $1 \varepsilon . \in \varepsilon$ & 121 & 54.57 & 35.8 & 16.57 & $1 \subseteq .7$ & 22.12 & 27.28 \\
\hline
\end{tabular}



sta latitlloe longitude elev faA sea cBa

$\begin{array}{lllllllll}\text { A } \quad 36 & 31.48 & 121 & 55.37 & 7.6 & 22.86 & 22 . C 1 & 27.57\end{array}$

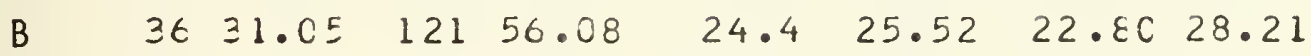

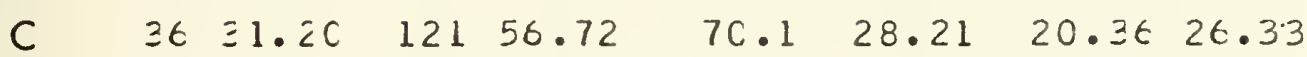

D $\quad 36 \quad \begin{array}{llllllll}0.3 & 121 & 56.10 & 40.2 & 28.27 & 23.77 & 29.67\end{array}$

E $\quad 36 \quad \angle S . E \equiv \quad 121 \quad 56.25 \quad 68.6 \quad 32.65 \quad 24.97 \quad 31.11$

F $\quad 36 \quad 25.47 \quad 121 \quad 56.60 \quad 32.0 \quad 27.93 \quad 24.34 \quad 30.29$

G $\quad 36 \quad 2 \varepsilon .6 C \quad 121 \quad 56.12 \quad 35.4 \quad 28.68 \quad 24.7 \geq \quad 30.83$

$\begin{array}{lllllllll}H & 36 & <\varepsilon .3< & 121 & 56.12 & 16.8 & 27.51 & 25.63 & 31.77\end{array}$

$\begin{array}{llllllllll}1 & 36 & 27.8 z & 121 & 55.53 & 40.2 & 28.97 & 24.47 & 31.83\end{array}$

J $\quad \begin{array}{llllllll}36 & 27.35 & 121 & 55.33 & 25.3 & 27.20 & 24 . \equiv 7 & 32.15\end{array}$

$\begin{array}{lllllllll}K & 36 & 26.87 & 121 & 55.47 & 39.3 & 28.24 & 23.84 & 30.62\end{array}$

L $\quad 36 \quad z t . S C \quad 121 \quad 55.63 \quad 13.7 \quad 26.38 \quad 24.8531 .51$

$\begin{array}{lllllllll}M \quad 36 & 26.40 & 121 & 55.27 & 15.2 & 25.31 & 23.61 & 30.89\end{array}$

$N \quad 36$ zE.8Z. $121 \quad 54.92 \quad 49.1 \quad 29.44 \quad 23.5531 .36$

$\begin{array}{lllllllll}0 & 36 & 2 E .5 C & 121 & 54.75 & 0.2 & 23.84 & 23.8 \mathrm{C} & 32.54\end{array}$

$\begin{array}{lllllllll}P & 36 & 25.42 & 121 & 54.77 & 0.3 & 23.97 & 23.94 & 32.58\end{array}$

Q $36 \quad 25.28 \quad 12154.78 \quad 0.324 .04 \quad 24 . C 131.12$

$\begin{array}{lllllllll}R & 36 & z E . \Xi z & 121 & 54.77 & 0.0 & 24.27 & 24.27 & 31.38\end{array}$

S $\quad 36 \quad 2 E .23 \quad 121 \quad 54.82 \quad$ C.0 $24.27 \quad 24.27 \quad 31.27$

T $3625.1212154 .83 \quad 0 . \equiv 24.52 \quad 24.4531 .29$

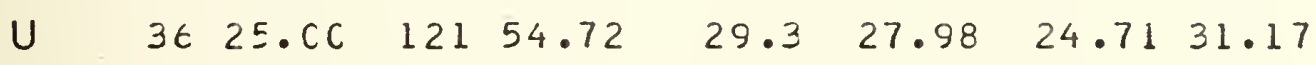

$V \quad 36 \quad 25 . C 2 \quad 121 \quad 54.83 \quad 14.5 \quad 26.29 \quad 24.62 \quad 31.09$

$W \quad \begin{array}{lllllllll}6 & 24.57 & 121 & 54.78 & 50.3 & 28.55 & 22.52 & 29.43\end{array}$

$\begin{array}{lllllllll}X & 36 & 24 . C \varepsilon & 121 & 54.33 & 51 . \varepsilon & 28.90 & 23.1 C & 30.56\end{array}$

$Y \quad$ zt $i \equiv .7 i \quad 121 \quad 52.68 \quad 164.9 \quad 41.87 \quad 23.42 \quad 34.82$

$\begin{array}{lllllllll}Z & 36 & 23.73 & 121 & 54.08 & 45.7 & 28.10 & 22.59 & 32.14\end{array}$

$\begin{array}{lllllllll}A^{\prime} \quad \equiv 6 & 2 \equiv .25 & 121 & 53.58 & 68.3 & 30.34 & 22.7 C & 20.61\end{array}$

$\begin{array}{lllllllll}B^{\prime} & 36 & 22.8 C & 121 & 54.08 & 0.4 & 22.88 & 22.84 & 30.13\end{array}$

$\begin{array}{lllllllllll}C^{\prime} & 36 & 22.33 & 121 & 54.07 & 84.1 & 30.44 & 21 . C 2 & 26.80\end{array}$ 

sta latitlde longitude elev faA sea cba

$\begin{array}{lllllllll}D^{\prime} & 36 & 21.58 & 121 & 53.92 & 147.8 & 34.96 & 18.41 & 26.57 \\ E^{\prime} & 36 & 2 C .57 & 121 & 53.71 & 134.7 & 30.23 & 15.16 & 26.79 \\ F^{\prime} & 36 & 2 C .32 & 121 & 53.42 & 66.4 & 25.06 & 17.62 & 25.12 \\ G^{\prime} & 36 & 19.92 & 121 & 53.38 & 38.4 & 21.98 & 17.68 & 24.44 \\ H^{\prime} & 36 & 15.65 & 121 & 53.62 & 42.1 & 24.29 & 19.55 & 25.38 \\ I^{\prime} & 36 & 1 \varepsilon .58 & 121 & 53.43 & 53.0 & 26.61 & 20.67 & 27.60 \\ J^{\prime} & 36 & 1 \varepsilon .57 & 121 & 53.10 & 44.8 & 26.13 & 21.12 & 27.40 \\ K^{\prime} & 36 & 1 \varepsilon .07 & 121 & 52.62 & 38.1 & 25.84 & 21.57 & 27.35 \\ L^{\prime} & 36 & 1 \varepsilon .3 \equiv & 121 & 53.85 & 110.0 & 31.98 & 19.67 & 30.56\end{array}$





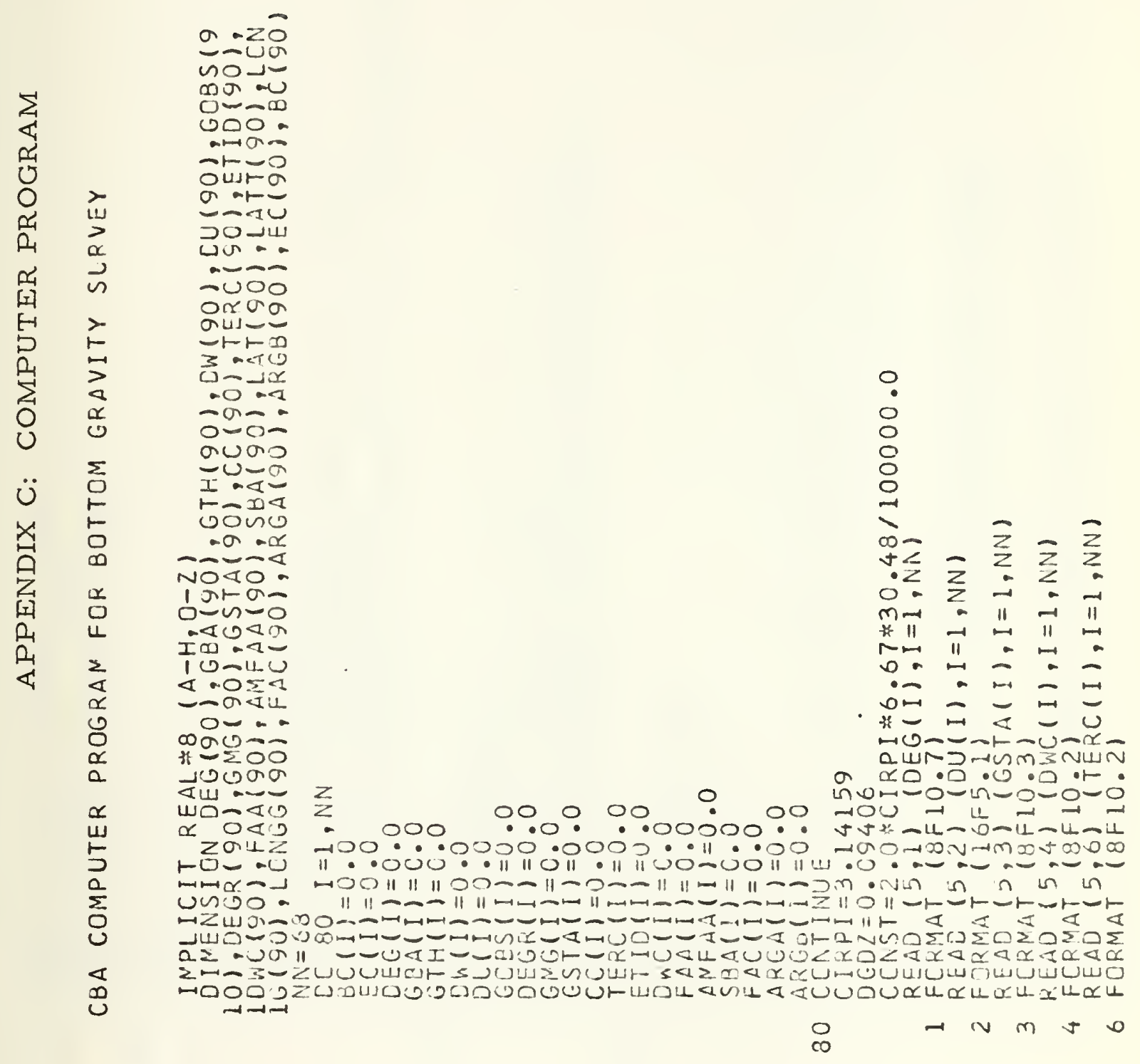





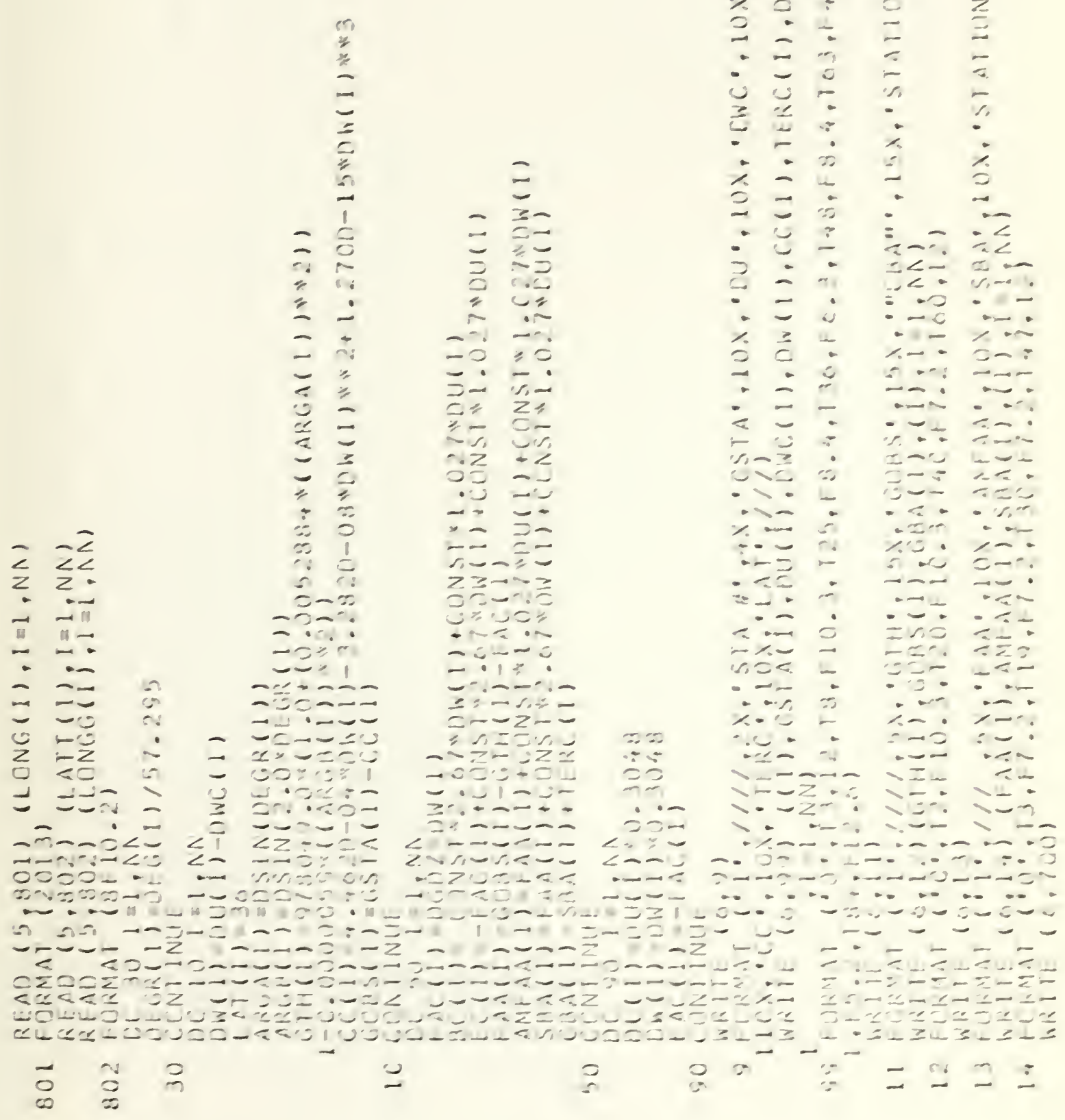





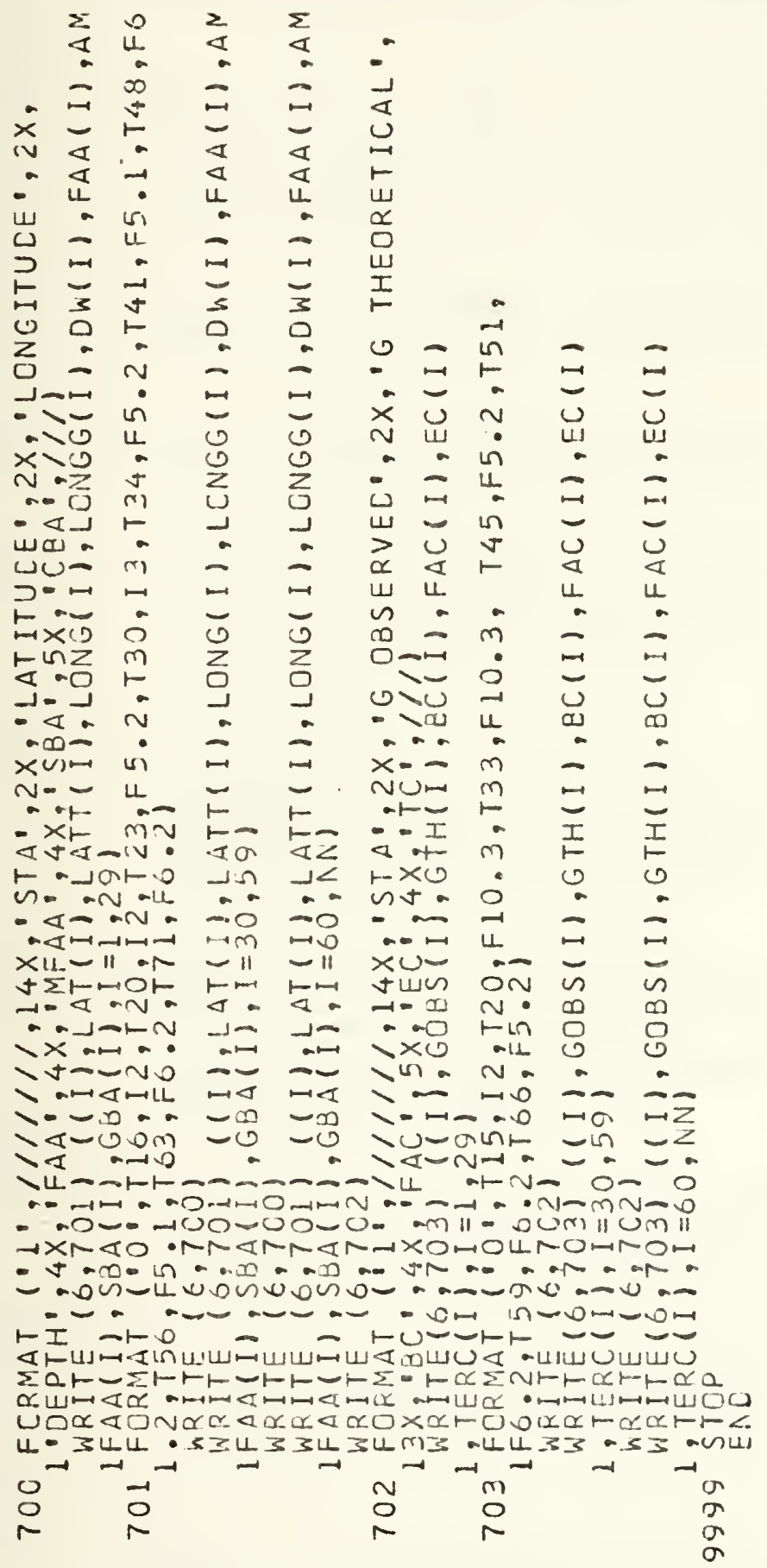





\section{REFERENCES CITED}

1. Andrews, R. S., 1973. Corrections for Underwater Gravimetry. Naval Postgraduate School, Department of Oceanography, Monterey, Ca. (paper submitted for publication)

2. Brooks, R. A., 1973. A Bottom Gravity Survey of the Shallow Water Regions of Southern Monterey Bay and Its Geological Interpretation. M.S. Thesis, Naval Postgraduate School, Monterey, Ca. 57 p. (unpublished report)

3. Bullard, E. C., 1936. Gravity Measurements in East Africa. Phil. Trans. Roy Soc. (London). Ser. A, 235(757): p. 445-531.

4. Cady, J., 1972. Gravity and Magnetics: 2-Dimensional Program. U. S. Geological Survey, Menlo Park, Ca. (unpublished report)

5. Chapman, R. H., 1966a. The California Division of Mines and Geology Gravity Base Station Network (CDMG Spec. Rpt. No. 90). California Office of State Printing, San Francisco, Ca. $49 \mathrm{p}$.

6. Chapman, R. H., 1966b. The Gravity Field in Northern California, in Geology of Northern California: E. H. Baily, editor, Bulletin 190, California Division of Mines and Geology, Ferry Building, San Francisco, Ca. p. 395-405.

7. Colomb, H. P., 1973. Recent Marine Sediments on the Central California Continental Shelf Between Point Lobos and Point Sur. M.S. Thesis, Naval Postgraduate School, Monterey, Ca. 44 p. (unpublished report)

8. Cronyn, B. C., 1973. An Underwater Gravity Survey and Inves tigation of Northern Monterey Bay. M.S. Thesis, Naval Postgraduate School, Monterey, Ca. 57 p. (unpublished report)

9. Daly, R. A., G. E. Manger, and S. P. Clark, Jr., 1966.

Density of Rocks, in Handbook of Physical Constants: S. P. Clark, editor, New York, Geol. Soc. Amer. Memoir 97, p. $20-26$.

10. Dobrin, M. B., 1960. Introduction to Geophysical Prospecting, 2nd. Ed. McGraw-Hill Book Co., Inc., New York. 446 p. 

11. Dohrewend, J. C., 1971. Marine Geology of the Continental Shelf Between Point Lobos and Point Sur, California:

A Reconnaissance. M.S. Thesis, Stanford University, Stanford, Ca. 60 p. (unpublished report)

12. Ellsworth, W. L., 1971. Geology of the Continental Shelf, Point Lobos to Point Sur, California. M.S. Thesis, Stanford University, Stanford, Ca. 33 p. (unpublished report)

13. Gilbert, W. G., 1971. Sur Fzult Zone, Monterey County, California. Ph. D. Thesis, Stanford University, Stanford, Ca. 80 p. (unpublished report)

14. Grant, F. S., and G. F. West, 1965. Interpretation Theory in Applied Geophysics. McGraw-Hill Book Co., Inc., San Francisco, Ca. 583 p.

15. Greene, H. G., 1970. Geology of Southern Monterey Bay and Its Relationship to the Ground Water Basin and Salt Water Intrusion. Open-file Report, U. S. Geological Survey, Menlo Park, Ca. 50 p. (unpublished report)

16. Greene, H. G., W. H. K. Lee, D. S. McCulloch, and E. E. Brabb, 1973. Faults and Earthquakes in the Monterey Bay Region, California. Misc. Field Studies Map MF-518, U. S. Geological Survey, Menlo Park, Ca. 14 p.

17. Hayford, J. F., and W. Bowie, 1912. The Effect of Topography and Isostatic Compensation Upon the Intensity of Gravity (U.S.C. \& G.S. Spec. Pub. No. 10). U. S. Government Printing Office, Washington, D. C., 132 p.

18. LaCoste, L. J. B., 1967. Measurement of Gravity at Sea and in the Air. Rev. Geophys., v. 5, p. 477-526.

19. La Coste and Romberg, Inc. 1970. Operating and Repair Manual, Models HD and HG Underwater Gravimeters. La Coste and Romberg, Inc., Austin, Tex. (unpublished report)

20. MacDonald, G. J.F., 1966. Geodetic Data, in Handbook of Physical Constants. S. P. Clark, editor, New York, Geol. Soc. Amer. Memoir 97, p. 219-221.

21. Martin, B. D., 1964. Monterey Submarine Canyon, California: Genesis and Relationship to Continental Geology. Ph. D. Thesis, University of Southern California, Los Angeles, Ca. 249 p. (unpublished report) 

22. Martin, B. D., and Emery, K. O., 1967. Geology of Monterey Canyon, California. American Assoc. Petroleum Geologists Bull., v. 51, p. $2231-2304$.

23. Nettleton, L. L., 1971. Elementary Gravity and Magnetics for Geologists and Seismoligists. Society of Exploration Geophysists, Tulsa, Okla. $121 \mathrm{p}$.

24. Page, B. M. , 1970. Sur-Nacimiento Fault Zone of California: Continental Margin Tectonics. Geol. Soc. America Bull., v. 81, p. 667-690.

25. Phifer, D. W., 1972. Recent Marine and Thrust Faulting in the Santa Lucia Mountains of Soberanes Point Quadrangle Monterey County, California. Student Report, Naval Postgraduate School, Monterey, Ca. 35 p. (unpublished report)

26. Shepard, F. P., 1948. Investigation of the Head of Monterey Submarine Canyon. Scripps Institute of Oceanography. Submarine Geology Report 1. 15 p.

27. Souto, A. P. D., 1973. A Bottom Gravity Survey of Carmel Bay, California. M.S. Thesis, Naval Postgraduate School, Monterey, Ca. 57 p. (unpublished report)

28. Swick, D. H., 1942. Pendulum Gravity Measurements and Isostatic Reductions (U.S.C. \& G.S. Spec. Pub. No. 232). U. S. Government Printing Office, Washington, D. C. 82 p.

29. Thompson, G. A., and M. Talwani, 1964. Crustal Structure from Pacific Basin to Central Nevada. Jour. Geophys. Research, v. 69, no. 22, p. 4813-4837.

30. Trask, P. D., 1926. Geology of Point Sur Quadrangle, California. University of California Publications Bulletin of the Department of Geological Sciences, v. 16, no. 6, 186 p.

31. U. S. Department of Commerce. 1973. Tide Tables, High and Low Water Predictions, 1973, West Coast of North and South America Including The Hawaiian Islands. U. S. Government Printing Office, Washington, D. C. $226 \mathrm{p}$.

32. Wollard, G. P. and J. C. Rose, 1963. Internation Gravity Measurements. George Banta Cc., Inc., Menasha, Wisc. $518 \mathrm{p}$. 

1. Defense Documentation Center

Cameron Station

Alexandria, Virginia 22314

2. Library, Code 0212

2

Naval Postgraduate School

Monterey, California 93940

3. Department of Oceanog raphy

Naval Postgraduate School.

Monterey, California 93940

4. Oceanographer of the Navy

Hoffman Bldg \#2

2461 Eis enhower Ave.

Alexandria, Virginia 22314

5. Office of Naval Research

Code $480-D$

Arlington, Virginia 22217

6. Professor Robert S. Andrews

Department of Oceanography, Code $58 \mathrm{Ad}$

Naval Postgraduate School

Monterey, California 93940

7. Professor Joseph J. von Schwind

Department of Oceanography, Code 58Vs

Naval Postgraduate School

Monterey, California

8. Lieutenant Walter B. Woodson, USN

USS Gallant (MSO_489)

Fleet Post Office

San Francisco, California

9. Dr. Howard Oliver

United States Geological Survey

345 Middlefield Road

Menlo Park, California 94025 

10. Dr. S. L. Robbins

United States Geological Survey

345 Middlefield Road

Menlo Park, California 94025

11. Mr. H. Gary Greene

United States Geological Survey

345 Middlefield Road

Menlo Park, California 94025

12. Gravity Section

Naval Oceanographic Office

Washington, D. C. 20390

13. Mr. H. B. Parks

LaCoste and Romberg, Inc.

6606 North Lamar

Austin, Texas 78752

14. Master R/V ACANIA

Department of Oceanography

Naval Postgraduate School

Monterey, California 93940

15. Lieutenant Clayton H. Spikes

3303 Sycamore Place

Carmel, California 93921

16. Dr. Robert E. Stevenson

Scientific Liaison Office of ONR

Scripps Institution of Oceanography

La Jolla, California 92037

17. Captain W. B. Woodson, Jr., USN (Ret)

Paradise Avenue

Middletown, Rhode Island

18. Library, Code 3330

Naval Oceanographic Office

Washington, D. C. 20370

19. Dr. Gary Griggs

University of California, Santa Cruz

Division of Natural Sciences

Santa Cruz, California 95060 



\begin{tabular}{|c|c|}
\hline REPORT DOCUHENTATION PAGE & $\begin{array}{l}\text { READ INSTRUCTIONS } \\
\text { BEFORE COHPLEXING FORM }\end{array}$ \\
\hline 2. GOVT ACCESSION NO. & 3. RECIPIENT'S CATALOG NUMBER \\
\hline \multirow{2}{*}{$\begin{array}{l}\text { A BITL (and Subutio) } \\
\text { Shelf Between Point Lobos and Point Sur, } \\
\text { California }\end{array}$} & $\begin{array}{l}\text { 5. TYPE OF REPORT A PERIOO COVERED } \\
\text { Master's Thesis } \\
\text { September } 1973\end{array}$ \\
\hline & 6. PERFORMING ORG. REPORT NUMBER \\
\hline $\begin{array}{l}\text { 7. AUTHOR(s) } \\
\text { Walter Browne Woodson, III }\end{array}$ & 8. CONTRACT OR GRANT NUMBER(•) \\
\hline $\begin{array}{l}\text { 9. PERFORMING ORGANIZATION NAME ANO ADORESS } \\
\text { Naval Postgraduate School } \\
\text { Monterey, California } 93940\end{array}$ & $\begin{array}{l}\text { 10. PROGRAM ELEMENT, PROJECT, TASK } \\
\text { AREA \& WORK UNIT NIMEERS }\end{array}$ \\
\hline \multirow{2}{*}{$\begin{array}{l}\text { 11. CONTROLLING OFFICE NAME AND ADDRESS } \\
\text { Naval Postgraduate SChool } \\
\text { Monterey, California } 93940\end{array}$} & $\begin{array}{l}\text { 12. REPORT DATE } \\
\text { September } 1973\end{array}$ \\
\hline & $\begin{array}{l}\text { 13. NUMBER OF PAGES } \\
112^{\text {NUE }}\end{array}$ \\
\hline \multirow[t]{2}{*}{ 14. MONITORING AGENCY NAME A ADORESS(It dillerent Irom Coritrolling Ofilco) } & $\begin{array}{l}\text { 15. SECURITY CLASS. (OI (hi roport) } \\
\text { Unclassified }\end{array}$ \\
\hline & $\begin{array}{l}\text { 15. DECLASSIFICATION/DOWNGRAOING } \\
\text { SCHEOULE }\end{array}$ \\
\hline
\end{tabular}

\section{DISTRIBUTION STATEMENT (of this Roport)}

Approved for public release; distribution unlimited

17. DISTRIBUTION STATEMENT (of the abelfact enloped In Block 20, 1 dillerent trom Report)

18. SUPPLEMENTARY NOTES

19. KEY WORDS (Contlnue on roverso ide If noceeseary and ldentlfy by block number)

20. ABSTRACT (Continue on reveree elde $\|$ nece.eery end identity by block numbor)

From an occupation of 68 ocean bottom and 38 land gravity stations between Pt. Lobos and Pt. Sur, California, a complete Bouguer anomaly map was produced and analyzed. The steps in data reduction leading to the complete Bougue $r$ anomaly field is presented, unique features of which are associated with bottom gravimetry. The geological interpretation of the gravity data shows excellent correlation with earlier seismic records of the proposed offshore extension of the Serra Hill fault, a structure long associated with

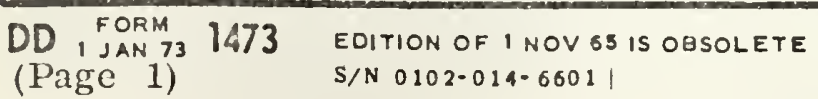

Unclassified SECURITY CLASSIFICATION OF THIS PAGE (When Dala Bntered) 

20.

the Sur-Nacimiento fault zone. Two dimensional models of gravity anomaly profiles were constructed across this fault and another fault located several kilometers to the northwest and extending into the western tributary of the Carmel Canyon. The results indicate a minimum vertical displacement of the basement of approximately $2 \mathrm{~km}$ on the southwest sides. It was concluded that these two faults a re one in the same. Evidence is presented which indicates that the Palo Colorado fault zone, located approximately $2 \mathrm{~km}$ to the east, parallels the Serra Hill fault and subsequently leads into the eastern tributary of the Carmel Canyon. 



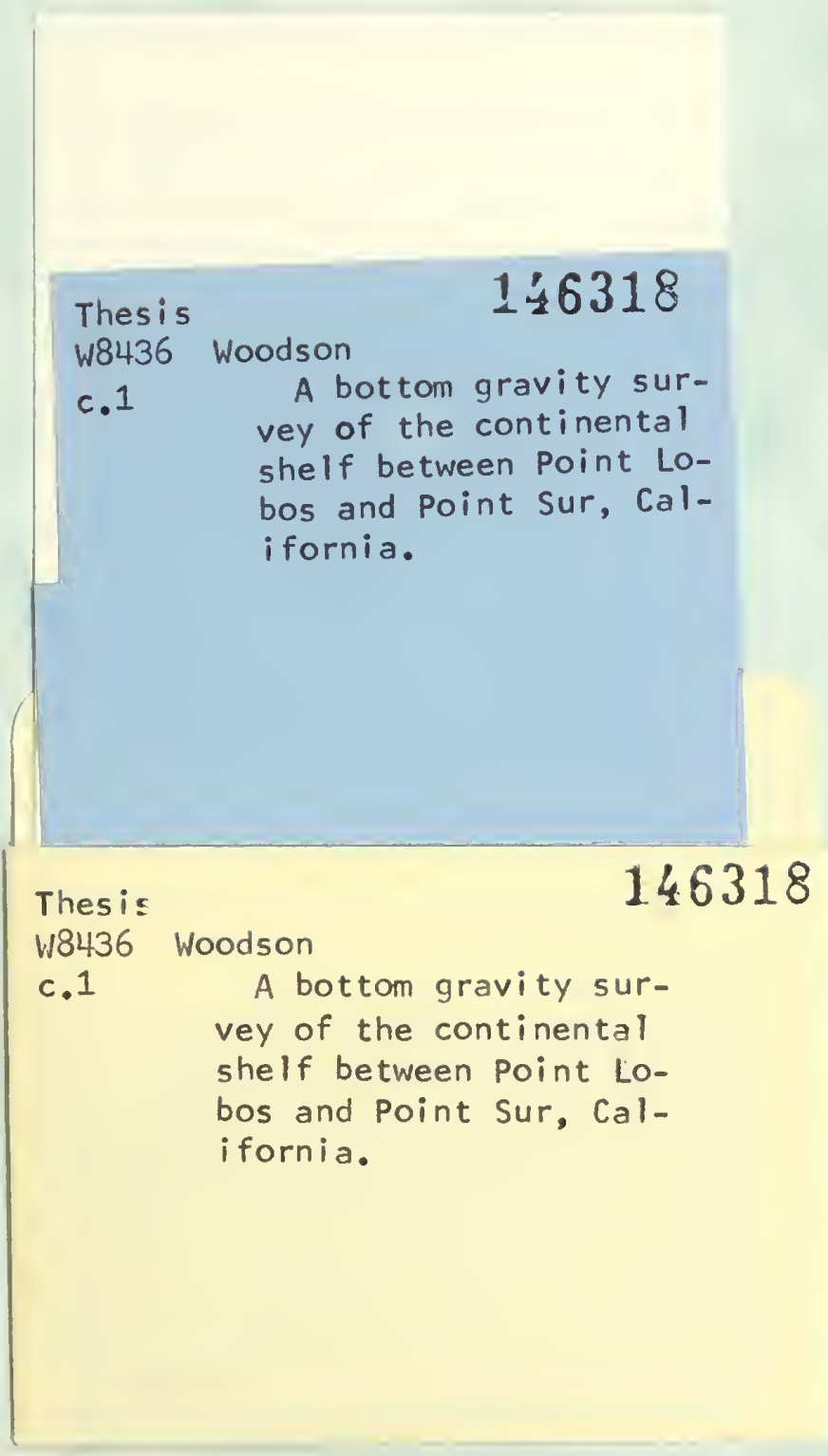


A bottom gravity survey of the continent

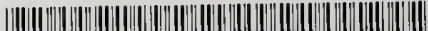

.|.

32768001906241

DUDLEY KNOX LIBRARY 